Wesley Fernando Usida

\title{
CONTROLE FUZZY PARA MELHORIA DO PERFIL DE TENSÃO EM SISTEMAS DE DISTRIBUIÇÃO DE ENERGIA ELÉTRICA
}

Dissertação apresentada à Escola de Engenharia de São Carlos, da Universidade de São Paulo, como parte dos requisitos para obtenção do Título de Mestre em Engenharia Elétrica.

Área de Concentração: Sistemas Elétricos de Potência Orientador: Prof. Tit. Denis Vinicius Coury.

São Carlos 

Dedico esse trabalho a minha família principalmente aos meus pais. 



\section{AGRADECIMENTOS}

Agradeço a Deus pelo trabalho realizado.

Ao Prof ${ }^{\mathrm{o}}$ Tit. Denis Vinicius Coury que me orientou nesse trabalho.

Gostaria de agradecer, em especial, ao Prof. Dr. Ivan Nunes da Silva pela co-orientação, amizade e incentivo durante a realização desse trabalho.

Aos Professores Dr. Mário Oleskovicz e MSc Rogério Andrade Flauzino pela amizade e incentivo.

Aos amigos do LSEE - Laboratório de Sistemas de Energia Elétrica e também ao LAIPS Laboratório de Automação Inteligente Processos e Sistemas em especial ao amigo e companheiro Eng ${ }^{\circ}$ Danilo Hernane Spatti que me ajuda desde a graduação.

Aos professores, funcionários, graduandos e pós-graduandos do Departamento de Engenharia Elétrica. Aos funcionários da empresa ELEKTRO em nome de Vinicius Marques Benichio, Valmir Ziolkowski e Ana Regina Martinelli.

A todas as pessoas que me ajudaram neste trabalho de alguma forma, principalmente à jornalista Vivian Chies pelas correções gramaticais.

À CAPES - Coordenação de Aperfeiçoamento de Nível Superior pela bolsa concedida. 

"Inspiração é fibra para o sucesso.

Transpiração e persistência é o próprio sucesso." Wesley F. Usida 



\section{RESUMO}

USIDA, W. F., Controle Fuzzy para Melhoria do Perfil de Tensão em Sistemas de Distribuição de Energia Elétrica. São Carlos, 2007, 121p. Dissertação de Mestrado - Escola de Engenharia de São Carlos, Universidade de São Paulo.

Os objetivos deste trabalho compõem apresentar o andamento das pesquisas relacionadas à regulação de tensão em sistemas de distribuição de energia elétrica e propor um controle baseado em sistemas inteligentes para melhoria do perfil de tensão, permitindo que sejam atendidas as regulamentações mais exigentes do setor elétrico brasileiro. São considerados os aspectos sazonal, diário e não previsto do comportamento das cargas referentes à subestação de distribuição. Para isso, o trabalho propõe um relé regulador de tensão baseado em sistemas Fuzzy que irá atuar diretamente no comutador de tap em transformadores de potência instalados em subestações de distribuição. Tal relé foi implementado por meio de um algoritmo computacional no Matlab.

Os resultados foram obtidos por meio de simulações do real comportamento de carga indicando a viabilidade do sistema proposto.

Palavras chaves: Qualidade de Energia Elétrica, Regulação de Tensão, Sistemas Fuzzy e Sistemas Elétricos de Potência. 



\begin{abstract}
USIDA, W. F. Fuzzy Control to Improve Voltage Profile in Distribution System. São Carlos, 2007, 121p. Dissertation (Master Degree) - Escola de Engenharia de São Carlos, Universidade de São Paulo.
\end{abstract}

The aim of this work is to present some research applied to voltage regulation in distribution systems and to propose a control system based on intelligent tools to improve the voltage profile of the system, considering the most demanding requirements of Brazilian utilities. Periodical, daily and not foreseen aspects of the electrical loads in distribution system were considered. Therefore, the work proposes an automatic voltage regulator relay based on Fuzzy Systems, acting directly on load tap changing of transformers installed in a substation of the distribution system. This relay was implemented by computational algorithm in Matlab. The results were obtained by simulation of the real load behavior indicating the applicability of the proposed system.

Keywords: Power Quality, Voltage Regulation, Fuzzy System and Power System. 



\section{LISTA DE FIGURAS}

Figura 1.1 -Esquema do relé regulador automático de tensão............................................ 12

Figura 2.1 - Queda de tensão ao longo do transporte.......................................................... 17

Figura 2.2 - Circuito de compensação de queda de linha. ....................................................23

Figura 2.3 - Esquema do LDC considerando centro de carga............................................. 23

Figura 2.4 - Perfis de tensão em circuitos com várias formas de regulagem. ........................25

Figura 2.5 - Capacitores instalados na barra da subestação e ao longo dos alimentadores......28

Figura 2.6 - Reguladores de tensão instalados ao longo dos alimentadores. ............................31

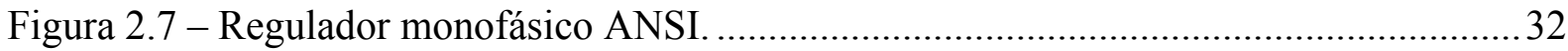

Figura 2.8 - Conexões trifásicas para o autotransformador. ............................................ 32

Figura 2.9- Esquema do relé regulador automático de tensão. ........................................... 34

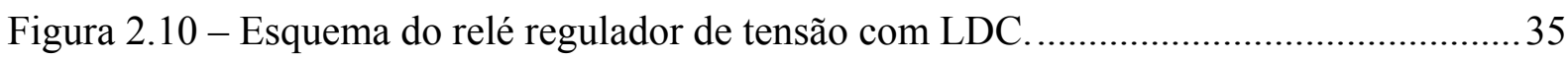

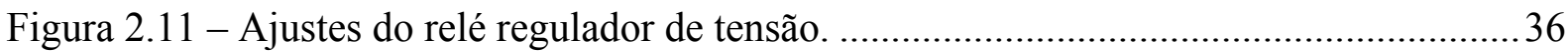

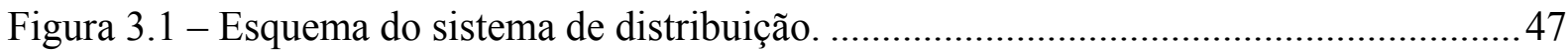

Figura 3.2 - Diagrama simplificado do controlador Fuzzy. ............................................ 48

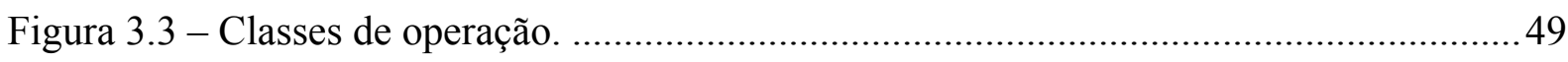

Figura 4.1 - Diagrama esquemático simplificado do relé inteligente referente à estratégia I. .56

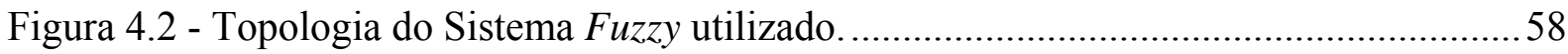

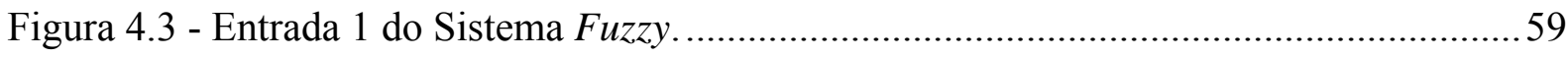

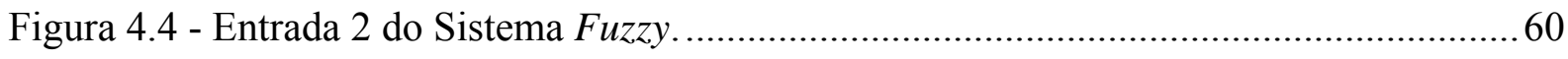

Figura 4.5 - Faixas de desvios de tensão do modelo Fuzzy ................................................ 61

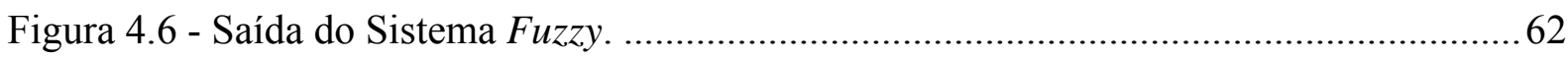

Figura 4.7 - Superfície de correlação entre as entradas e saídas do sistema modelado............. 64

Figura 5.1 - Modelo simplificado de simulação para o relé convencional............................... 68 
Figura 5.2 - Modelo simplificado de simulação para o relé fuzzy......

Figura 5.3 - Esquema de simulação convencional implementado no Simulink/Matlab.......... 70

Figura 5.4 - Esquema de simulação fuzzy implementado no Simulink/Matlab. ..................... 71

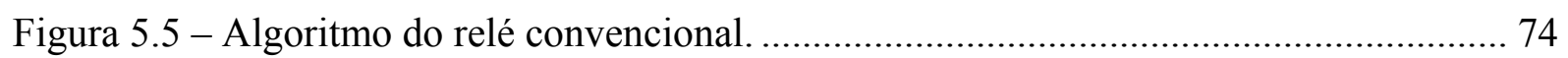

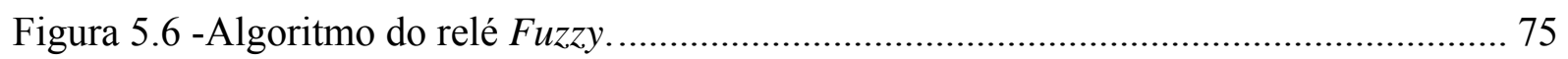

Figura 5.7 - Histórico de comutações para as simulações de Andradina Trafo 1................... 78

Figura 5.8 - Perfil de tensão na subestação para as simulações de Andradina Trafo 1. .......... 79

Figura 5.9 - Comparação de tensão para as simulações de Andradina Trafo 1 ....................... 80

Figura 5.10 - Curvas de potência ativa e tensão para as simulações de Andradina Trafo 1.... 81

Figura 5.11 - Tempo de permanência nas faixas para as simulações de Andradina Trafo 1... 82

Figura 5.12 - Tensão média em carga pesada para as simulações de Andradina Trafo 1........ 82

Figura 5.13 - Histórico de comutações para as simulações de Cordeirópolis Trafo 2............. 83

Figura 5.14 - Perfil de tensão na subestação para as simulações de Cordeirópolis Trafo 2.... 84

Figura 5.15 - Comparação de tensão para as simulações de Cordeirópolis Trafo 2 ................ 85

Figura 5.16 - Curvas de potência ativa e tensão para as simulações de Cordeirópolis

Trafo 2 . 86

Figura 5.17 - Tempo de permanência nas faixas para as simulações de Cordeirópolis Trafo 2 87

Figura 5.18 - Tensão média em carga pesada para as simulações de Cordeirópolis Trafo 2. . 87

Figura 5.19 - Histórico de comutações para as simulações de Mogi-Guaçu 2 Trafo 1. 88

Figura 5.20 - Perfil de tensão na subestação para as simulações de Mogi-Guaçu 2

Trafo 1 89

Figura 5.21 - Comparação de tensão para as simulações de Mogi-Guaçu 2 Trafo 1 90 
Figura 5.22 - Curvas de potência ativa e tensão para as simulações de Mogi-Guaçu 2

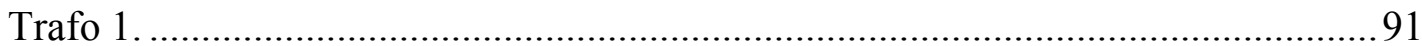

Figura 5.23 - Tempo de permanência nas faixas para as simulações de Mogi-Guaçu 2

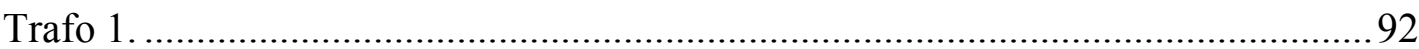

Figura 5.24 - Tensão média em carga pesada para as simulações de Mogi-Guaçu 2

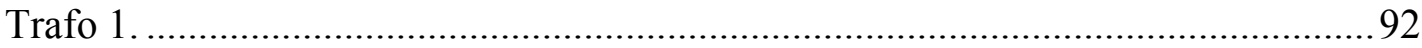





\section{LISTA DE TABELAS}

Tabela 1.1 - Pontos de entrega ou conexão em tensão nominal superior a $1 \mathrm{kV}$ e inferior a $69 \mathrm{kV}$. 10

Tabela 2.1 - Aproximações recomendadas para modelagem de cargas. 21

Tabela 4.1 - Interpretação da Saída Fuzzy 62

Tabela 4.2 - Regras Fuzzy. 63

Tabela 5.1 - Potência ativa média associada às subestações testadas. 76

Tabela 5.2 - Comparação dos resultados obtidos para as subestações de teste para $\mathrm{V}_{\text {referência }}=$ $14,1 \mathrm{kV}$ 93

Tabela 5.3 - Comparação dos resultados obtidos para as subestações de teste para $\mathrm{V}_{\text {referência }}=$ $14,15 \mathrm{kV}$ 93

Tabela 5.4 - Comparação dos resultados obtidos para as subestações de teste para $V_{\text {referência }}=$ $14,2 \mathrm{kV}$ 94

Tabela 5.5 - Comparação dos resultados obtidos para as subestações de teste para $\mathrm{V}_{\text {referência }}=$ $14,1 \mathrm{kV}$ e desvios de $1 \%$ e $1,3 \%$ 95

Tabela 5.6 - Comparação dos resultados obtidos para as subestações de teste. 96 



\section{LISTA DE ABREVIATURAS E SIGLAS}

ACL - Ambiente de Contratação Livre

ACR - Ambiente de Contratação Regulada

AG - Algoritmos Genéticos

ANEEL - Agência Nacional de Energia Elétrica

ANSI - American National Standards Institute

CCEE - Câmara de Comercialização de Energia Elétrica

DMS - Distribution Management System

DRC - Duração Relativa da Transgressão de Tensão Crítica

$\mathrm{DRC}_{\mathrm{M}}$ - Duração Relativa da Transgressão Máxima de Tensão Crítica

DRP - Duração Relativa da Transgressão de Tensão Precária

$\mathrm{DRP}_{\mathrm{M}}$ - Duração Relativa da Transgressão Máxima de Tensão Precária

FP - Funções de Pertinência

LDC - Line Drop Compensation

LTC - Load Tap Changer

MAE - Mercado Atacadista de Energia

RNA - Redes Neurais Artificiais

OLTC - On-Load Tap Changer

ONS - Operador Nacional do Sistema

PD - Programação Dinâmica

PU - Por Unidade

QEE - Qualidade de Energia Elétrica

SE - Subestação

SEP - Sistemas Elétricos de Potência 
TA - Tensão de Atendimento

TC - Tensão Contratada

TN - Tensão Nominal

TL - Tensão de Leitura

TP - Transformador de Potencial

TPC - Taiwan Power Company

TR - Trafo

ULTC - Under-Load Tap Changer 


\section{SUMÁRIO}

AGRADECIMENTOS .. $\mathrm{V}$

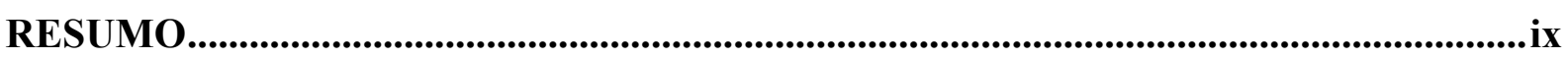

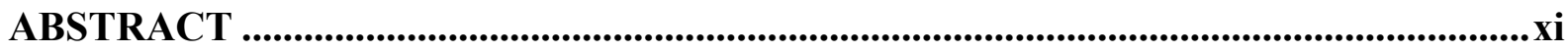

LISTA DE FIGURAS......................................................................................................................xiii

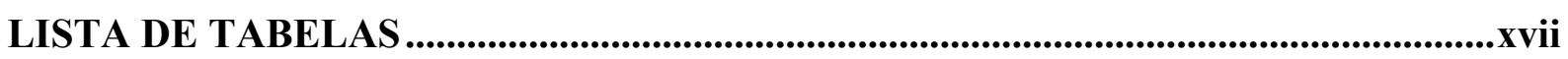

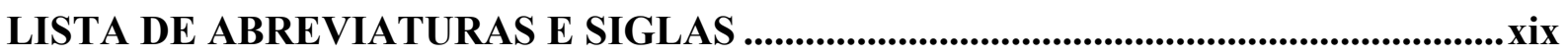

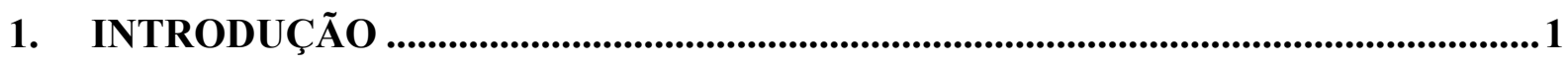

1.1 A Qualidade da Energia Elétrica e a sua Conjuntura Atual no Setor Elétrico

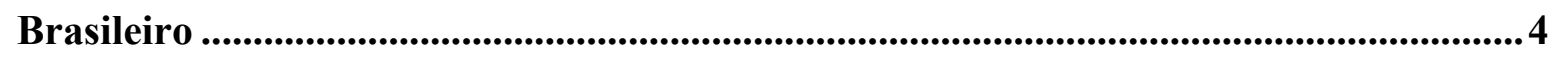

1.2 Aspectos Relacionados à Legislação e Regulação de Tensão..................................7

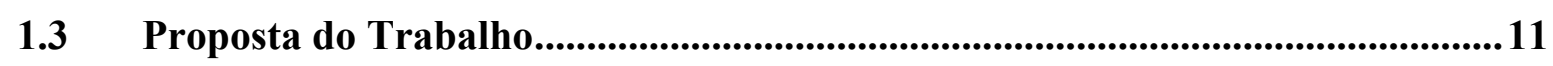

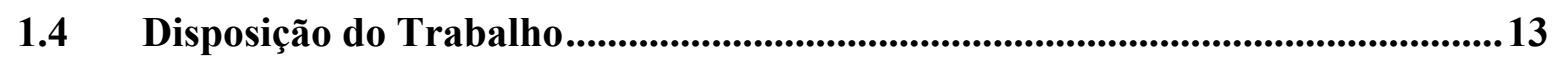

2. ESTRATÉgias EMPREgAdAS NO MELHORAMENTO DO PERFIL DE TENSÃO EM SISTEMAS DE DISTRIBUIÇÃO DE ENERGIA ELÉTRICA.................. 15

2.1 Principais Metodologias aplicadas na Regulação de Tensão em Sistemas de

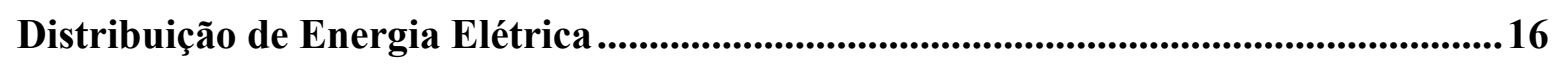

2.1.1 Modelagem por Fluxo de Carga ................................................................19

2.1.2 Compensação por Queda de Tensão na Linha .............................................22

2.2 Dispositivos Empregados na Regulação de Tensão ..........................................26

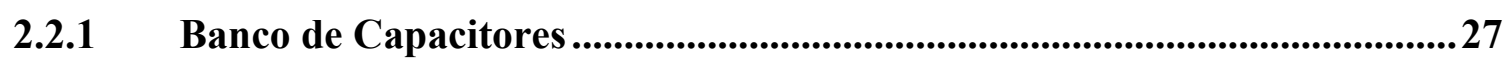

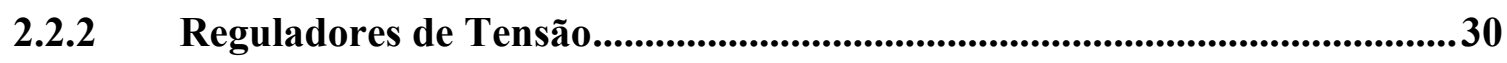

2.2.3 Transformadores com Comutação de Tap ......................................................33

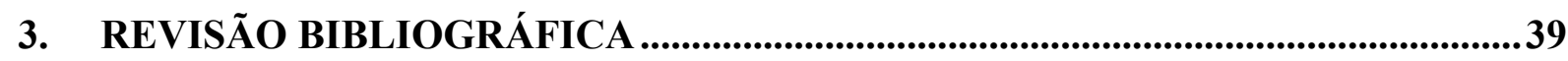


3.1 Organização e Estudo Bibliográfico …................................................................. 39

3.2 Estratégias de Controle de Tensão Off-Line ................................................... 41

3.3 Estratégias de Controle de Tensão On-Line ................................................... 46

4. ASPECTOS RELATIVos À MOdelagem dO CONTROLE DE TENSÃo

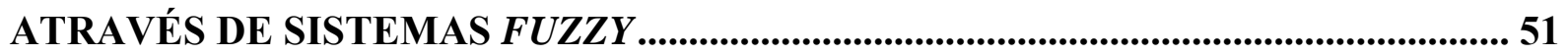

4.1 Diagrama Esquemático do Relé Inteligente....................................................... 53

5. UM SISTEMA FUZZY PARA CONTROLE DE TENSÃO .................................. 67

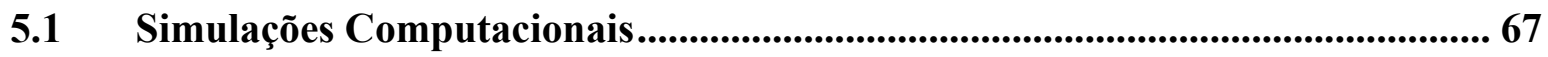

5.1.1 Sistema de Distribuição Estudado ................................................................. 72

5.1.2 Algoritmos dos Relés Reguladores de Tensão Implementados................... 74

5.1.3 Condições de Simulação ......................................................................... 76

5.2 Resultados computacionais referentes ao controle adaptativo do tap............... 77

5.2.1 Subestação Andradina (Transformador 1) ............................................... 77

5.2.2 Subestação Cordeirópolis (Transformador 2)......................................... 83

5.2.3 Subestação Mogi-Guaçu 2 (Transformador 1)................................................. 88

$5.3 \quad$ Análise comparativa para as subestações de teste .......................................... 93

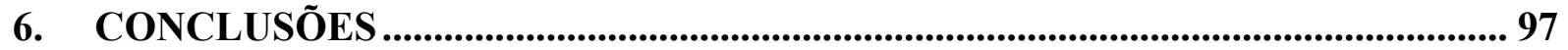

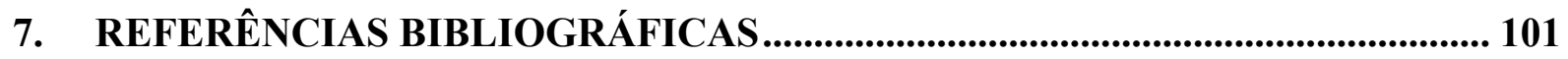

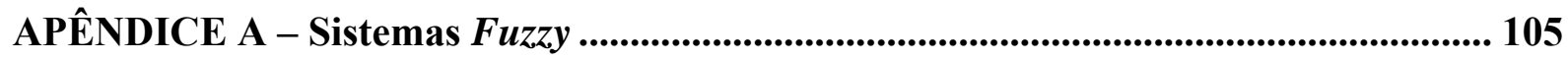

APÊNDICE B - Curvas históricas de Potência Ativa e Reativa ..................................... 117

APÊNDICE C - Dados dos transformadores............................................................. 119 


\section{INTRODUÇÃO}

Nos dias atuais, a qualidade do fornecimento de energia elétrica preocupa consumidores e agentes do setor. No Brasil, isso ganhou impulso com a aprovação das leis 8.987 e 9074, ambas de 1995. Essas normas dispõem sobre o regime de concessão e permissão da prestação de serviços públicos, destacando os relativos à energia elétrica. Iniciava-se então o processo de desverticalização, ou seja, a privatização de muitas empresas estatais e a separação das áreas de geração, transmissão, distribuição e comercialização de energia elétrica no Brasil. A partir daí, começa a entrada de investimentos privados nesse setor.

Em 26 de dezembro de 1996, a Lei 9.427 instituiu a Agência Nacional de Energia Elétrica (ANEEL) com o papel de disciplinar o regime econômico e financeiro das concessões de serviço públicos de energia elétrica. A ANEEL começou a funcionar em dezembro de 1997 como órgão regulador e fiscalizador do setor elétrico nacional e uma das suas principais competências foi regimentar as concessões referentes aos serviços de energia elétrica. Quando ela surgiu, encontravam-se em andamento outros aspectos relativos ao trabalho de reestruturação do setor elétrico brasileiro que culminaram na reestruturação da Eletrobrás (Lei 9.648/98) e no surgimento do Operador Nacional do Sistema (ONS) e do Mercado Atacadista 
de Energia Elétrica (MAE) ${ }^{1}$. O Decreto $n^{\circ} 2.655$, de julho de 1998, regulamentou o MAE e também definiu as regras de organização do ONS.

Essas mudanças objetivavam assegurar o suprimento de energia elétrica. Visavam também à liberdade de competição na geração e na comercialização e à melhoria dos serviços prestados aos consumidores, já que o aumento das exigências de qualidade dos produtos manufaturados e da competitividade das atividades industriais, certamente, em futuro próximo será fator dependente da continuidade e qualidade do fornecimento de energia elétrica [1]. As diversas áreas industriais e econômicas do país irão necessitar de energia elétrica de melhor qualidade do que é fornecido hoje pelas concessionárias como garantia para a sua expansão.

Hoje, o setor elétrico ainda está sendo regulamentado. Algumas mudanças importantes ocorreram nos anos de 2003 e 2004, quando o Governo Federal emitiu as bases de um novo modelo para o Setor Elétrico Brasileiro, por meio das Leis $\mathrm{n}^{\mathrm{o}} 10.847$ e 10.848 , ambas de 15 de março de 2004. Em termos institucionais, o novo modelo criou três entidades: a Empresa de Pesquisa Energética - EPE, responsável pelo planejamento do setor elétrico a longo prazo; o Comitê de Monitoramento do Setor Elétrico - CMSE, com a função de avaliar permanentemente a segurança do suprimento de energia elétrica; a Câmara de Comercialização de Energia Elétrica - CCEE, encarregada de dar continuidade às atividades do MAE relativas à comercialização de energia elétrica no Sistema Interligado. Outras alterações importantes incluem a definição do exercício do Poder Concedente ao Ministério de Minas e Energia (MME) e a ampliação da autonomia do ONS. Em relação à comercialização de energia, foram instituídos dois ambientes para celebração de contratos de

\footnotetext{
${ }^{1}$ No ano de 2004, a Lei $\mathrm{n}^{\mathrm{o}} 10.848$ e o Decreto $\mathrm{n}^{\mathrm{o}} 5.177$, respectivamente, instituiram e criaram o CCEE Câmara de Comercialização de Energia Elétrica que absorveu as funções do MAE e suas estruturas organizacionais e operacionais.
} 
compra e venda: o Ambiente de Contratação Regulada (ACR), do qual participam agentes de geração e de distribuição de energia, e o Ambiente de Contratação Livre (ACL), do qual participam agentes de geração, comercializadores, importadores e exportadores de energia, além de consumidores livres [2].

Basicamente, o novo modelo do setor elétrico criou um ambiente para a competição nas transações comerciais envolvendo energia elétrica, visando também a atingir três objetivos principais:

- Garantir a segurança do suprimento de energia elétrica

- Promover a modicidade tarifária

- Promover a inserção social no setor elétrico brasileiro, em particular pelos programas de universalização de atendimento.

O modelo prevê um conjunto de medidas a serem observadas pelos agentes do setor, como o monitoramento permanente da continuidade e da segurança de suprimento, visando detectar desequilíbrios conjunturais entre oferta e demanda. As particularidades desses desequilíbrios serão tratadas posteriormente [2].

A ANEEL tem papel fundamental nesse processo de implementação do novo modelo, além das competências já estabelecidas na sua criação. Para isso, tem-se a descentralização de parte das suas atividades, por meio de convênios de cooperação com as agências reguladoras estaduais credenciadas, em conformidade com a legislação pertinente. Essa descentralização é um mecanismo facultativo de delegação das competências da Agência Nacional aos estados e ao Distrito Federal, objetivando agilizar e aproximar as ações da ANEEL junto aos consumidores de energia elétrica, agentes setoriais e demais segmentos da sociedade, com respeito às peculiaridades locais e regionais. As atividades descentralizáveis 
abrangem preferencialmente a fiscalização, o apoio à regulação dos serviços e instalações de energia elétrica e a mediação de problemas e soluções entre os agentes e entre esses e os consumidores [3].

Todo o processo de reestruturação do setor elétrico ocorreu em busca do equilíbrio econômico e financeiro entre os agentes e consumidores. Com isso, os contratos de concessão de serviço público de energia elétrica entre o poder concedente e empresas concessionárias estabeleceram obrigações e encargos a serem cumpridos pela distribuidora, de forma a assegurar ao consumidor qualidade e continuidade na prestação do serviço. Esses contratos prescrevem que a concessionária de distribuição adote, na prestação de serviços, tecnologia adequada e equipamentos, instalações e métodos operativos que garantam níveis de regularidade, continuidade, eficiência, segurança e modicidade tarifária.

A qualidade da energia elétrica (QEE), principalmente no que tange à melhoria do perfil de tensão, será o assunto tratado neste trabalho. Os principais estudos sobre esse assunto serão abordados nas próximas seções.

\subsection{A Qualidade da Energia Elétrica e a sua Conjuntura Atual no Setor Elétrico Brasileiro}

Não se tem uma definição padrão para a qualidade da energia elétrica. Um conceito de qualidade de energia está relacionado a um conjunto de alterações que podem ocorrer no sistema elétrico. Uma outra definição para o problema de qualidade de energia é: "Qualquer problema de energia manifestada na tensão, corrente ou nas variações de freqüência que resulte em falha ou má operação de equipamentos de consumidores" [4]. Tais alterações 
podem ocorrer em várias partes do sistema de energia, seja nas instalações de consumidores, seja no sistema supridor da concessionária.

Além disso, atualmente, os fornecedores de energia elétrica concentram-se cada vez mais na eficácia e adequação da relação entre o preço e a qualidade da energia elétrica fornecida. Uma garantia de qualidade de fornecimento e de serviço adequado ao mercado é extremamente importante. Como explorador do sistema, as empresas de distribuição necessitam se adequar às exigências do mercado, ou seja, entrar em conformidade com as normas e recomendações.

Há diversos problemas relacionados à QEE como, por exemplo, instabilidades, oscilações, surtos, transientes, etc. Estes problemas vêm se agravando rapidamente em todo o mundo por diversas razões, entre as quais se destacam-se:

- Instalação cada vez maior de cargas não-lineares.

- Maior sensibilidade dos equipamentos instalados aos efeitos dos fenômenos (distúrbios) relacionados à qualidade de energia.

- Evolução e crescimento das cargas elétricas dos consumidores.

Analisar as grandezas tensão e freqüência é suficiente para avaliar se o sistema está operando dentro ou fora das condições adequadas. A freqüência em um sistema elétrico deve situar-se na faixa de $60 \pm 0,5 \mathrm{~Hz}$. Sobre a tensão, três aspectos principais devem ser verificados:

- Forma de onda, a qual deve ser o mais próximo possível de senóide;

- Simetria do sistema elétrico.

- Magnitudes das tensões dentro de limites aceitáveis. 
Os distúrbios relacionados à energia elétrica podem surgir tanto nos sistemas das empresas concessionárias como nos consumidores. Esses problemas são classificados em categorias segundo efeito, duração e intensidade. As categorias de distúrbios relacionados à QEE são transitórios, variações de curta duração, variações de longa duração, desequilíbrio de tensão, distorção da forma de onda e variação da freqüência do sistema.

O fornecimento de energia dentro dos níveis de QEE requerido possibilita uma devida operação do equipamento em determinado meio para o qual foi projetado. Usualmente, há padrão muito bem definido de medidas para a tensão, o que faz com que convencionalmente associe-se a QEE à qualidade da tensão pela flexibilidade de controle dessa grandeza e, concomitante, dificuldade de controle sobre a corrente que às cargas podem solicitar. Portanto, o padrão aceito no que tange à QEE é direcionado a manter o funcionamento de tensão dentro de limites apropriados [4].

Tendo esses conceitos no que concerne à QEE, a maioria das principais empresas distribuidoras anteriormente administradas pela União ou pelos Estados está agora sob a gestão de agentes privados. Dentre os objetivos esperados com esta mudança foi o investimento dessas empresas para garantir a universalização do atendimento e a qualidade tanto do produto quanto do serviço de fornecimento de energia elétrica.

No Brasil, diante do novo modelo do setor elétrico foi necessário criar medidas de controle e acompanhamento da qualidade de energia elétrica tanto pelos órgãos especializados como pelas próprias empresas concessionárias e permissionárias de serviços públicos de distribuição de energia elétrica. Com isso, a ANEEL estabelece resoluções referentes à qualidade do fornecimento da energia elétrica como a Resolução 024/2000 [5] e a Resolução 505/2001[6] . Os aspectos mais detalhados dessa resolução serão tratados em seção posterior. 
A ANEEL também elaborou os Procedimentos de Distribuição, isto é, documentos regulatórios na forma de regulamentações, normatizações e padronizações que têm como objetivo possibilitar a conexão elétrica aos sistemas de distribuição por usuários, garantindo que os indicadores de desempenho ou de qualidade de serviço sejam atingidos de forma clara e transparente, preservando, dentre outros aspectos, a segurança, a eficiência e a confiabilidade dos sistemas elétricos [7].

\subsection{Aspectos Relacionados à Legislação e Regulação de Tensão}

A qualidade no fornecimento está relacionada à qualidade do serviço e também a qualidade do produto [8]. A primeira pode ser entendida como a continuidade do fornecimento da energia elétrica. As interrupções no fornecimento da energia elétrica, geralmente, são provocadas por falhas no sistema, paradas programadas pela manutenção, faltas e outras perturbações transitórias.

Portanto, existem diversos indicadores que avaliam o desempenho dos serviços prestados pelas empresas concessionárias de energia conforme estabelece a Resolução $\mathrm{n}^{\circ}$ 024/2000 da ANEEL.

Já a qualidade do produto é determinada pela forma de onda fornecida. Como discutido na seção anterior, esse fator é crucial para o correto funcionamento dos equipamentos elétricos. A Resolução $n^{\circ}$ 505/2001 da ANEEL estabelece as disposições relativas à conformidade dos níveis de tensão de energia elétrica em regime permanente, portanto o fornecimento desses níveis tem que estar dentro de certos limites aceitáveis para não comprometer o funcionamento correto dos equipamentos pertencentes aos consumidores. 
Essa resolução considera que, para a conceituação do fornecimento adequado, é indispensável o estabelecimento de níveis de tensão bem como a definição dos limites de variação das tensões a serem observadas pelo ONS, concessionárias e permissionárias de serviços públicos de distribuição de energia elétrica [6].

Algumas definições estabelecidas na Resolução n 505/2001 da ANEEL e que serão relevantes para o desenvolvimento desse trabalho são apresentadas a seguir:

- Duração Relativa da Transgressão de Tensão Crítica (DRC): indicador individual referente à duração relativa das leituras de tensão, nas faixas críticas, no período de observação definido. Expresso em percentual (\%).

- Duração Relativa da Transgressão de Tensão Precária (DRP): indicador individual referente à duração das leituras relativas de tensão, nas faixas de tensão precária, no período de observação definido. Expresso em percentual (\%).

- Duração Relativa da Transgressão Máxima de Tensão Crítica $\left(\mathrm{DRC}_{\mathrm{M}}\right)$ : percentual máximo de tempo admissível para as leituras de tensão, nas faixas de tensão críticas, no período de observação definido.

- Duração Relativa da Transgressão Máxima de Tensão Precária $\left(\mathrm{DRP}_{\mathrm{M}}\right)$ : percentual máximo de tempo admissível para as leituras de tensão, nas faixas de tensão precárias, no período de observação definido.

- Tensão de Atendimento (TA): valor eficaz de tensão no ponto de entrega ou de conexão, obtido por meio de medição, podendo ser classificada em "Adequada", "Precária" ou "Crítica", de acordo com a leitura efetuada. Expresso em Volts (V) ou quilovolts $(\mathrm{kV})$. 
- Tensão Contratada (TC): valor eficaz de tensão que deverá ser informado ao consumidor por escrito ou estabelecido em contrato. Expresso em Volts (V) ou quilovolts $(\mathrm{kV})$.

- Tensão Nominal (TN): valor eficaz de tensão pelo qual o sistema é projetado. Expresso em Volts ou quilovolts $(\mathrm{kV})$.

- Tensão de Leitura (TL): valor eficaz de tensão, integralizado a cada 10 (dez) minutos, obtido de medição por meio de equipamentos apropriados. Expresso em Volts ou quilovolts $(\mathrm{kV})$.

Os pontos de conexão à Rede Básica, à Rede de Distribuição, aos pontos de conexão entre concessionárias e também nos pontos de entrega de energia às unidades consumidoras são avaliados em termos de conformidade com níveis de tensão como prescrito na Resolução no 505/2001 da ANEEL.

São estabelecidos também nessa resolução os limites "Adequados", "Precários" e "Críticos" para os níveis de tensão em regime permanente, os indicadores de qualidade, os critérios de medição e registro, prazos para regularização e de compensação ao consumidor, caso os limites para o atendimento adequado não sejam obedecidos. Esses limites, para pontos de entrega ou conexão em tensão nominal superior a $1 \mathrm{kV}$ e inferior a $69 \mathrm{kV}$, estão representados na Tabela 1.1. 
Tabela 1.1 - Pontos de entrega ou conexão em tensão nominal superior a $1 \mathrm{kV}$ e inferior a 69 $\mathrm{kV}$.

\begin{tabular}{|c|c|}
\hline Classificação da TA & Faixa de variação da TL em relação à TC \\
\hline Adequada & $0,93 \mathrm{TC} \leq \mathrm{TL} \leq 1,05 \mathrm{TC}$ \\
\hline Precária & $0,90 \mathrm{TC} \leq \mathrm{TL} \leq 0,93 \mathrm{TC}$ \\
\hline Crítica & $\mathrm{TL}<0,90 \mathrm{TC}$ ou $\mathrm{TL}>1,05$ \\
\hline
\end{tabular}

As concessionárias distribuidoras de energia elétrica apuram os indicadores DRP e DRC, que por sua vez não podem ser superiores à $\mathrm{DRP}_{\mathrm{M}}$ e $\mathrm{DRC}_{\mathrm{M}}$, pois estarão fornecendo serviço inadequado.

De acordo com o artigo 24 da Resolução no 505, o valor do $\mathrm{DRP}_{\mathrm{M}}$ até o ano de 2003 ficou estabelecido em 7\%, sendo o mesmo reduzido em um valor absoluto de $1 \%$ a cada ano durante o período de 2004 à 2007, quando passará a ter o valor fixo de 3\%.

Já o $\mathrm{DRC}_{\mathrm{M}}$ em 2004 ficou estabelecido em 1,1\%, sendo o mesmo reduzido de um valor absoluto de $0,2 \%$ a cada ano durante o período de 2005 a 2007, quando passará a ter o valor fixo de $0,5 \%[6]$.

Os índices relativos DRP e DRC são apurados pela coleta e pelo processamento dos dados informados periodicamente pelas empresas à ANEEL. Os dados são tratados e avaliados para a verificação do desempenho das empresas concessionárias. Com isso, é fundamental o monitoramento do serviço oferecido pelas concessionárias, pois elas têm que atender às exigências dessas resoluções para não sofrerem penalidades. Para atendê-las, é importante prover um adequado controle de tensão, como do ponto de vista de eliminação de harmônicos ou desequilíbrios. 


\subsection{Proposta do Trabalho}

Em um mercado cada vez mais exigente quanto à QEE e com regras mais restritas para a definição dos parâmetros e limites de fornecimento aceitáveis, existe a necessidade de ferramentas capazes de se adequar a esta realidade e permitir uma regulação de tensão apropriada.

Neste contexto, há diversas formas de se regular a tensão em um sistema de distribuição de energia elétrica. O principal delas é a regulação da tensão no barramento secundário da subestação pela comutação de tap em transformador, pois a utilização de outras estratégias depende do desempenho dessa regulação. Os detalhes envolvidos com as outras abordagens utilizadas na regulação de tensão serão apresentados no Capítulo 2.

A regulação de tensão ou o controle automático de tensão pela comutação de tap em transformadores de potência é comandado pelo relé regulador de tensão, atuando sobre o Comutador de Derivações (Taps) sob Carga, de forma a elevar ou abaixar a tensão, conforme necessário.

Este trabalho de mestrado tem por objetivo propor uma metodologia baseada em sistemas inteligentes que defina em tempo real o valor mais adequado possível de regulação da tensão na barra secundária da subestação, a qual possui vários alimentadores de distribuição de energia elétrica conectados. O valor definido deve estar dentro dos níveis préestabelecidos pela empresa distribuidora, visando sobretudo à qualidade no atendimento dos seus clientes, estando também em conformidade com a Resolução 505/2001 da ANEEL.

Além disso, o relé inteligente adaptar-se-á automaticamente às mudanças que venham a ocorrer na demanda de carga do sistema elétrico, quer sejam elas decorrentes das oscilações normais ao longo do tempo, quer advenham das alterações na configuração do 
sistema como, por exemplo, de manobras ou da expansão do sistema elétrico. Com isso, evitase que a ocorrência de eventos imprevistos na rede, como o isolamento de um trecho, tenha como conseqüência o fornecimento de tensão acima ou abaixo dos limites para as cargas consumidoras.

A figura abaixo ilustra o esquema simplificado do sistema proposto:

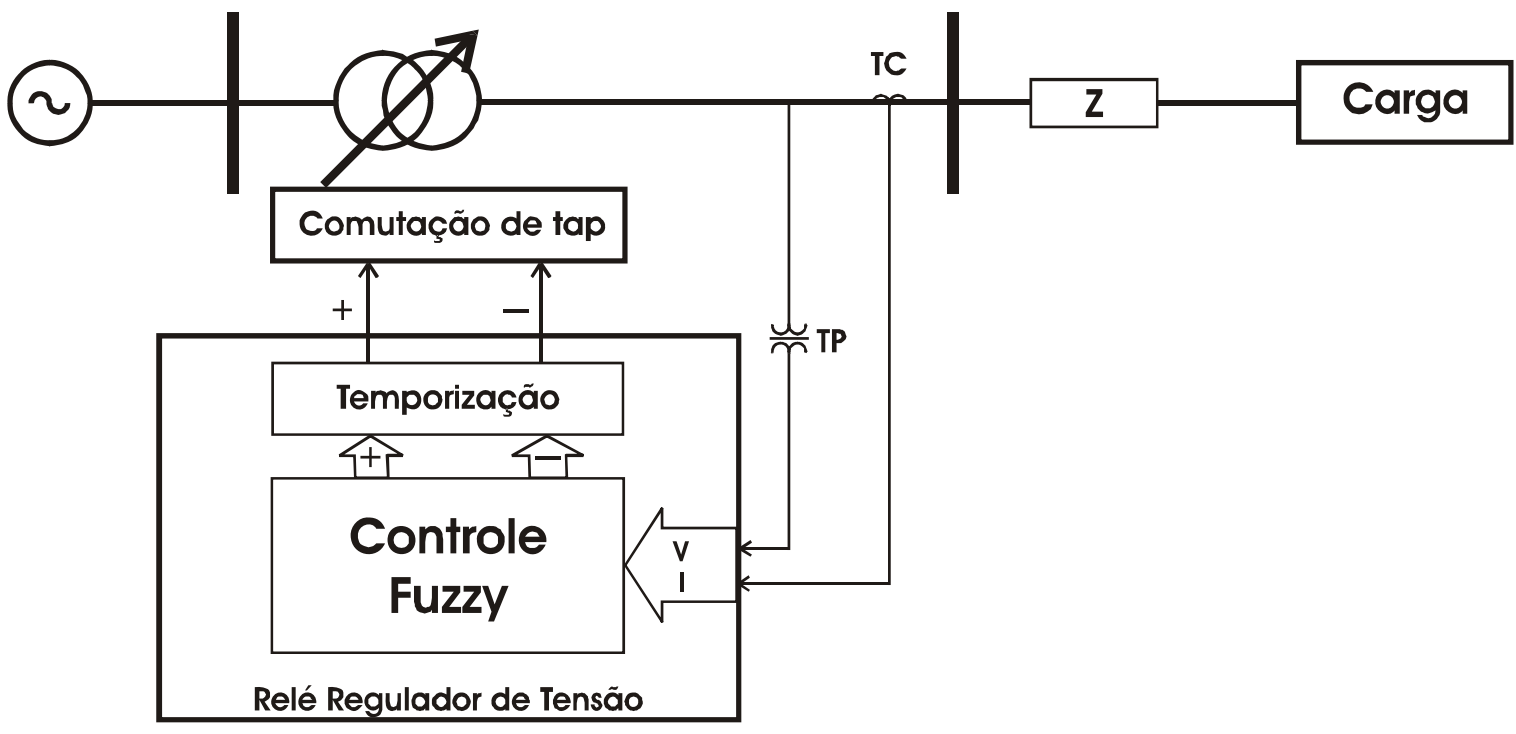

Figura 1.1 -Esquema do relé regulador automático de tensão.

Devido a características não-lineares e dinâmicas das cargas, pode-se dizer que esse problema é difícil de mapear usando técnicas convencionais, o que justifica o emprego de sistemas inteligentes.

O conhecimento de todas as variáveis e fatores envolvidos com o problema do controle do perfil de tensão deve ser delineado para se alcançar o objetivo proposto. Assim sendo, uma vez conhecidos todos os parâmetros e técnicas que têm sido usados no controle do perfil de tensão em sistemas de distribuição, pode-se proceder a implementação da lógica Fuzzy em relés reguladores de tensão. 


\subsection{Disposição do Trabalho}

O trabalho trata de um tema de pesquisa bastante interessante dentro do cenário brasileiro de energia elétrica. Ele está dividido em sete capítulos. O Capítulo 1, como citado, apresenta uma visão geral sobre o trabalho, bem como a focalização do seu tema na conjuntura do setor elétrico brasileiro e os principais conceitos relativos à QEE. Nesse capítulo faz-se também referência às resoluções de órgãos competentes no tocante ao assunto do trabalho proposto.

O Capítulo 2 fornece a sistematização dos principais aspectos envolvidos com a regulação de tensão em sistemas de distribuição de energia elétrica, abordando desde os métodos mais usuais até os equipamentos mais utilizados para tal propósito.

O Capítulo 3 aborda os aspectos fundamentais relativos às técnicas e metodologias que têm sido recentemente propostas na bibliografia científica. Também são descritas nesse capítulo algumas das principais metodologias inteligentes relatadas na literatura, as quais são aplicadas nos processos envolvidos com o controle da tensão em sistemas de distribuição.

O Capítulo 4 explicita de forma preliminar alguns aspectos metodológicos do relé inteligente, que auxiliará no controle mais otimizado do perfil de tensão ao longo dos alimentadores.

O Capítulo 5 mostra os resultados obtidos nas subestações testadas usando tanto o sistema de controle de tensão baseado em lógica Fuzzy como também o sistema convencional de controle de tensão.

As conclusões e a continuidade do trabalho são explicitadas no Capítulo 6. 
Finalmente, o Capítulo 7 mostra as referências bibliográficas estudadas e utilizadas na confecção desse projeto de mestrado até o presente momento. 


\section{ESTRATÉGIAS EMPREGADAS NO MELHORAMENTO DO PERFIL DE TENSÃO EM SISTEMAS DE DISTRIBUIÇÃO DE ENERGIA ELÉTRICA}

Essa seção apresenta os principais aspectos relacionados à regulação de tensão em sistemas de distribuição de energia elétrica. O melhoramento do perfil de tensão está relacionado ao adequado e eficiente controle de tensão nos Sistemas Elétricos de Potência (SEP). Tal controle de tensão tem sido identificado como uma operação fundamental para a qualidade no fornecimento de energia elétrica. Alguns pontos mostram a importância disso:

- Tanto os equipamentos da concessionária como os pertencentes aos consumidores são projetados para operar em determinado nível de tensão. A operação prolongada desses equipamentos em uma tensão fora de limites aceitáveis pode afetar o seu correto funcionamento reduzindo a sua vida útil ou até mesmo causando interrupções não programadas. Por isso, a tensão deve ser mantida dentro de limites aceitáveis.

- Outro ponto importante é a estabilidade dos SEP. O controle de tensão tem um impacto significante sobre a estabilidade do sistema.

- O controle adequado reduz as perdas de energia. 
Os problemas relativos ao perfil de tensão nas redes elétricas são um dos mais severos problemas relacionados à qualidade de energia elétrica. Diferentes modos e métodos de controle de tensão serão apresentados nas seções seguintes. Em particular, será fornecida uma abordagem detalhada sobre o controle de tensão através de comutação de tap em transformadores de potência situados na subestação.

\subsection{Principais Metodologias aplicadas na Regulação de Tensão em Sistemas de Distribuição de Energia Elétrica}

Uma das principais responsabilidades das distribuidoras de energia elétrica é fornecer aos consumidores tensões em faixas apropriadas, pois muitas atividades exigem níveis regulados de tensões. As quedas de tensão do primário e secundário podem ser ajustadas ao longo do circuito para que o consumidor final tenha níveis apropriados de tensões.

Os principais problemas relatados pelos consumidores são tensões abaixo do valor nominal, comprometendo a qualidade no fornecimento de energia elétrica. A principal dificuldade de fornecer aos consumidores tensões em faixas apropriadas é o problema da queda de tensão durante o transporte da energia, ou seja, o nível de tensão no barramento secundário da subestação não é o mesmo no ponto de entrega aos consumidores. Essa queda ao longo do alimentador pode ser aproximada como: 


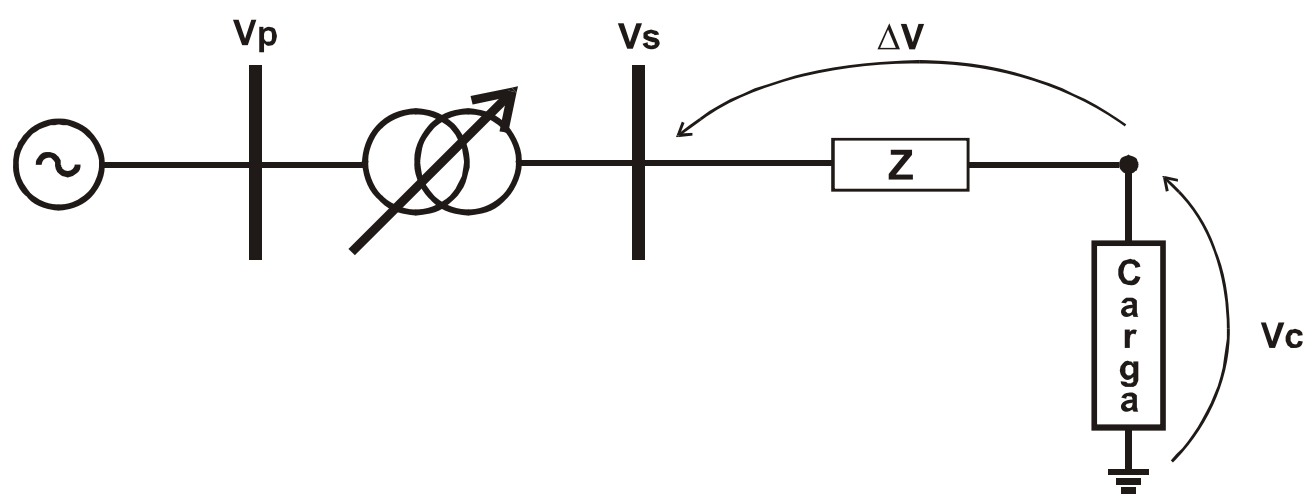

Figura 2.1 - Queda de tensão ao longo do transporte.

A queda de tensão equivalente ao longo dos alimentadores pode ser representada pela queda de tensão na impedância equivalente.

$V_{\text {queda }} \approx \Delta V=V_{S}-V_{C}$

onde:

$V_{\text {queda }}$ e $\Delta V \rightarrow$ Queda de tensão ao longo do alimentador (V).

$V_{P} \rightarrow$ Tensão no barramento primário $(\Omega)$.

$V_{S} \rightarrow$ Tensão no barramento secundário $(\Omega)$.

$V_{C} \rightarrow$ Tensão no ponto de entrega à carga equivalente $(\Omega)$.

Em termos do fator de potência $(f p)$, as correntes de linha são:

$$
\begin{aligned}
& I_{R}=I \cdot f p=I \cdot \cos \theta \\
& I_{X}=I \cdot \operatorname{sen}\left(\cos ^{-1}(f p)\right)=I \cdot \operatorname{sen} \theta
\end{aligned}
$$


onde:

$I_{R} \rightarrow$ Corrente de linha referente ao fluxo de potência real (em fase com a tensão)

(A).

$I_{X} \rightarrow$ Corrente de linha referente ao fluxo de potência reativa (A).

$I \rightarrow$ magnitude da corrente de linha (A).

$f p \rightarrow$ fator de potência

$\theta \rightarrow$ ângulo entre a tensão e a corrente.

A equação (2.1) é uma aproximação do valor de queda de tensão. Ela apresenta uma boa precisão para a maioria das situações nos sistemas de distribuição, proporcionando erros menores que $1 \%$ para defasagens de até $8^{\circ}$ entre a tensão secundária e a tensão de entrega na carga equivalente [9].

Para fatores de potência elevados, a queda de tensão depende fortemente da resistência do alimentador. Com um fator de potência de 0.95 , por exemplo, o fator de potência referente ao fluxo de potência reativo $\left(\operatorname{sen}\left(\cos ^{-1}(f p)\right)\right)$ é de 0.31 e, como para essas situações a resistência normalmente é menor que a reatância, sendo que a resistência do alimentador apresenta o papel principal na queda de tensão. Já para fatores de potência de médio a baixo, a queda de tensão depende principalmente da reatância do alimentador. Por exemplo, com um fator de potência de 0.8 , o fator de potência referente ao fluxo de potência reativo é de 0.6 e com predominância da reatância sobre a resistência, para essas situações, as cargas reativas tornam-se as principais causadoras das quedas de tensão na linha. Conseqüentemente, fatores de potência indesejáveis aumentam a queda de tensão ao longo do alimentador. A queda de tensão é maior nos sistemas de distribuição de baixa tensão com 
fator de potência baixo, circuitos monofásicos e circuitos desbalanceados [9]. Algumas das medidas mais utilizadas para se reduzir a queda de tensão ao longo dos alimentadores são:

- Reduzir o comprimento do alimentador.

- Elevar o fator de potência por meio de instalação de banco de capacitores

- Converter as seções de monofásicas para trifásicas.

- Redistribuir a carga.

- Balancear os circuitos.

- Redimensionar o condutor para um tamanho maior.

Essas medidas devem ser contempladas nos projetos de construção dos sistemas de distribuição, já que a maioria delas fica inviável de se implantar nos sistemas já em operação.

A magnitude da queda de tensão fornecida aos consumidores situados ao longo dos alimentadores é dependente da demanda atual da rede de distribuição, pois a queda de tensão pode ser maior em horários de maior consumo de energia. O uso de dispositivos de regulação de tensão pode prover um melhor perfil de tensão, elevação do fator de potência e, consequentemente, a redução dessas perdas.

Nos tópicos a seguir serão discutidas algumas das principais estratégias de regulação e compensação, fundamentados nos limites operativos estabelecidos na seção anterior.

\subsubsection{Modelagem por Fluxo de Carga}

O planejamento por meio de estudos de fluxo de carga permite melhorar o perfil de tensão quando se está projetando novos circuitos de distribuição. Esse estudo representa a 
rede para a qual dispõe da topologia com os parâmetros elétricos de seus elementos, das demandas de carga e da geração.

O estudo do fluxo de carga permite o cálculo das tensões em todos os pontos da rede, possibilitando verificar se o atendimento está dentro de níveis adequados. Outras finalidades do fluxo de carga são os cálculos das perdas e da queda de tensão ao longo da rede [8].

Como há diversas cargas ligadas na rede de distribuição, elas são agrupadas em conjuntos de unidades consumidoras. Cada conjunto de unidades consumidoras é representado como uma carga equivalente na modelagem do sistema para estudos de fluxo de potência. Tal estudo tem fundamental importância para se definir o nível de tensão a ser fornecido no barramento secundário da subestação de forma que a tensão tanto no consumidor mais próximo quanto no mais distante esteja dentro dos limites aceitáveis.

As quedas de tensão ao longo dos alimentadores também podem ocorrer devido ao transporte quanto ao tipo de carga. Por exemplo, as cargas desbalanceadas causam maiores quedas de tensão, pois a impedância vista por elas, incluindo a impedância de seqüência zero, é maior que a impedância de seqüência positiva vista pela carga balanceada. Assim, se a corrente fluir de forma desigual por fase, cargas pesadas irão proporcionar maiores quedas de tensão.

Há diversas abordagens para modelagem das cargas em um sistema de distribuição, que podem ser [9]:

- Potência da Carga Constante: As potências ativas e reativas se mantêm constantes mesmo que a tensão mude. Caso a tensão diminua, a carga irá solicitar uma maior corrente, elevando-se a queda de tensão. Essa abordagem é utilizada para motores de indução. 
- Corrente da Carga Constante: A corrente se mantém constante, mesmo que a tensão mude. A potência é elevada com a tensão. Se a tensão decai, a corrente drenada continua constante, diminuindo-se a potência e não alterando a queda de tensão.

- Impedância de Carga Constante: Para essa situação, a impedância é constante, mesmo que a tensão mude. A potência aumenta com o quadrado da tensão. Se a tensão decai, a corrente decai linearmente, diminuindo-se a queda de tensão. Essa abordagem é interessante para cargas puramente resistivas.

Normalmente pode-se modelar os circuitos de distribuição como sendo de $40 \%$ a $60 \%$ de potência constante e de $40 \%$ a $60 \%$ de impedância constante. Considerar a modelagem de todas as cargas como sendo de corrente constante é uma boa aproximação para a maioria dos circuitos. Agora, modelar todas as cargas como sendo de potência constante conserva a queda de tensão. Na Tabela 2.1 a seguir, encontra-se diversas configurações de cargas para aproximações na realização de fluxo de carga [9].

Tabela 2.1 - Aproximações recomendadas para modelagem de cargas.

\begin{tabular}{|c|c|c|}
\hline Tipo do Alimentador & $\begin{array}{c}\text { Potência Constante } \\
(\mathbf{\%})\end{array}$ & $\begin{array}{c}\text { Impedância Constante } \\
(\mathbf{\%})\end{array}$ \\
\hline $\begin{array}{c}\text { Residencial e comercial (Pico do } \\
\text { verão) }\end{array}$ & 67 & 33 \\
\hline $\begin{array}{c}\text { Residencial e comercial (Pico do } \\
\text { inverno) }\end{array}$ & 40 & 60 \\
\hline Urbano & 50 & 40 \\
\hline Industrial & 100 & 0 \\
\hline Países em Desenvolvimento & 25 & 75 \\
\hline
\end{tabular}

Fonte: Willis, H. L., “Characteristics of Distribution Loads,” Electrical Transmission and Distribution Reference Book. Raleigh, NC, ABB Power T\&D Company, 1997. 


\subsubsection{Compensação por Queda de Tensão na Linha}

O objetivo principal do compensador de queda de tensão na linha ou LDC (LineDrop Compensation) é manter a tensão constante, não no barramento secundário do transformador, mas no consumidor. Sem a utilização do LDC, ao final do alimentador haverá uma variação de tensão que dependerá da impedância do alimentador para uma condição de carga pesada, e da variação da corrente de carga para uma condição de carga leve.

Com a utilização da compensação por queda de linha, diminui-se a variação da tensão ao final do alimentador por meio da elevação da tensão na saída do equipamento de regulação.

Os transformadores com comutação de tap e os reguladores de tensão durante a carga pesada, elevam a tensão ao máximo; ao passo que na carga leve, diminuem a tensão ao mínimo. O LDC utiliza um modelo interno de impedância do alimentador de distribuição para encontrar a impedância da linha. O usuário pode ajustar os valores de $R$ e $X$ no compensador para melhorar a compensação.

O controlador ajusta o tap baseado na tensão do relé regulador de tensão, que é a tensão do transformador de potencial (TP) adicionado com a tensão do circuito compensador de queda de linha. Se não há compensação por queda de linha, o relé regulador ajusta o tap com base nas informações do TP. Informações mais detalhadas do relé regulador de tensão serão apresentadas na seção 2.2.3. Na Figura 2.2 extraída da ref. [9], pode-se visualizar o circuito básico de um LDC. 


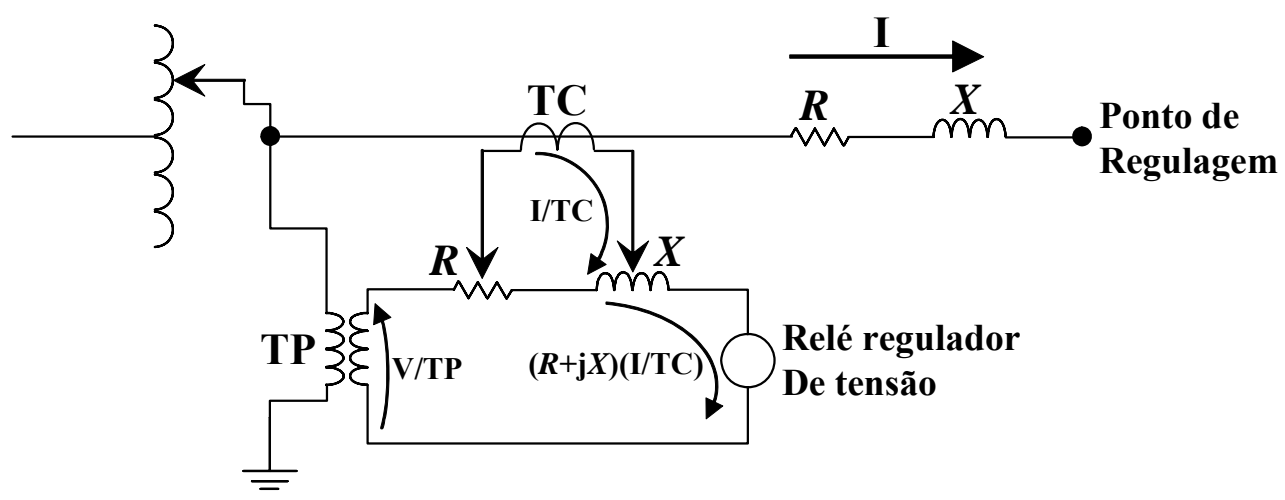

Figura 2.2 - Circuito de compensação de queda de linha.

Em uma linha de distribuição típica, os compensadores $R$ e $X$ são escolhidos para que a máxima elevação de tensão seja obtida sob carga pesada, enquanto que a tensão mínima seja obtida para a carga leve. Pode-se utilizar o centro de carga para se ajustar os parâmetros do regulador para cada ponto de regulagem de tensão dado.

A utilização do centro de carga como ponto de regulagem é o modo clássico para se ajustar a compensação por queda de tensão na linha. Considera-se que essa linha tenha impedâncias $R_{L}$ e $X_{L}$ e uma carga no fim, como mostra a Figura 2.3.

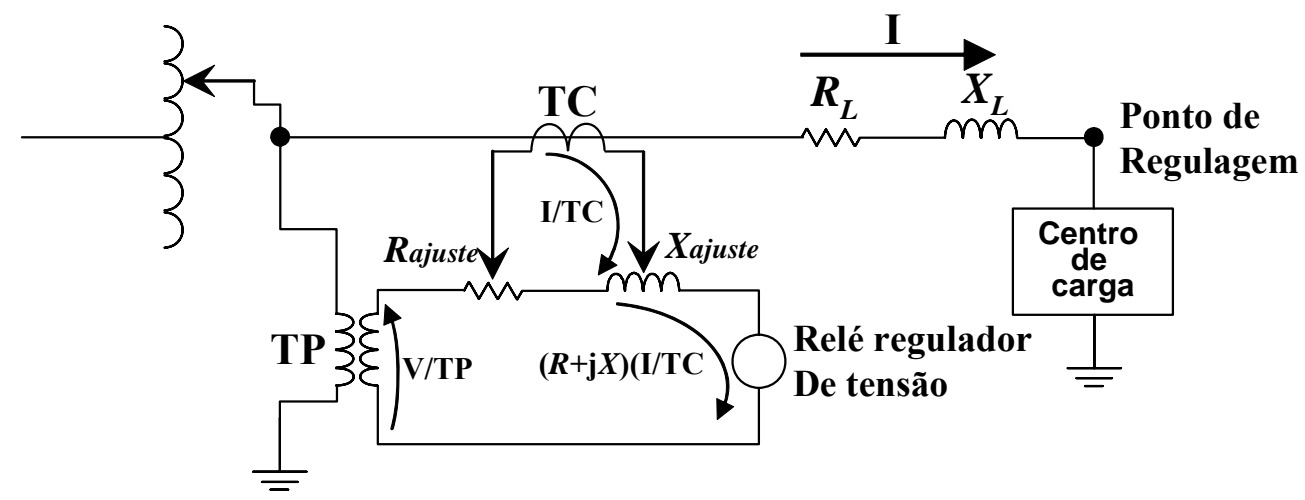

Figura 2.3 - Esquema do LDC considerando centro de carga.

Os parâmetros $R_{\text {ajuste }}$ e $X_{\text {ajuste }}$ do regulador podem então ser encontrados por meio das seguintes expressões: 


$$
\begin{aligned}
& R_{\text {ajuste }}=\frac{I_{T C}}{N_{T P}} \cdot R_{L} \\
& X_{\text {ajuste }}=\frac{I_{T C}}{N_{T P}} \cdot X_{L}
\end{aligned}
$$

Onde:

$R_{\text {ajuste }} \rightarrow$ Ajuste do regulador para compensação resistiva (V).

$X_{\text {ajuste }} \rightarrow$ Ajuste do regulador para compensação reativa (V).

$I_{T C} \rightarrow$ Valor do primário do transformador de corrente (A).

$N_{T P} \rightarrow$ Razão de transformação do transformador de potencial (tensão no primário / tensão no secundário).

$R_{L} \rightarrow$ Resistência da linha para o ponto de regulação $(\Omega)$.

$X_{L} \rightarrow$ Reatância da linha para o ponto de regulação $(\Omega)$.

Na Figura 2.4, retirada da referência [9], pode-se visualizar o perfil de tensão de um determinado circuito, com e sem a atuação do compensador por queda de linha. 


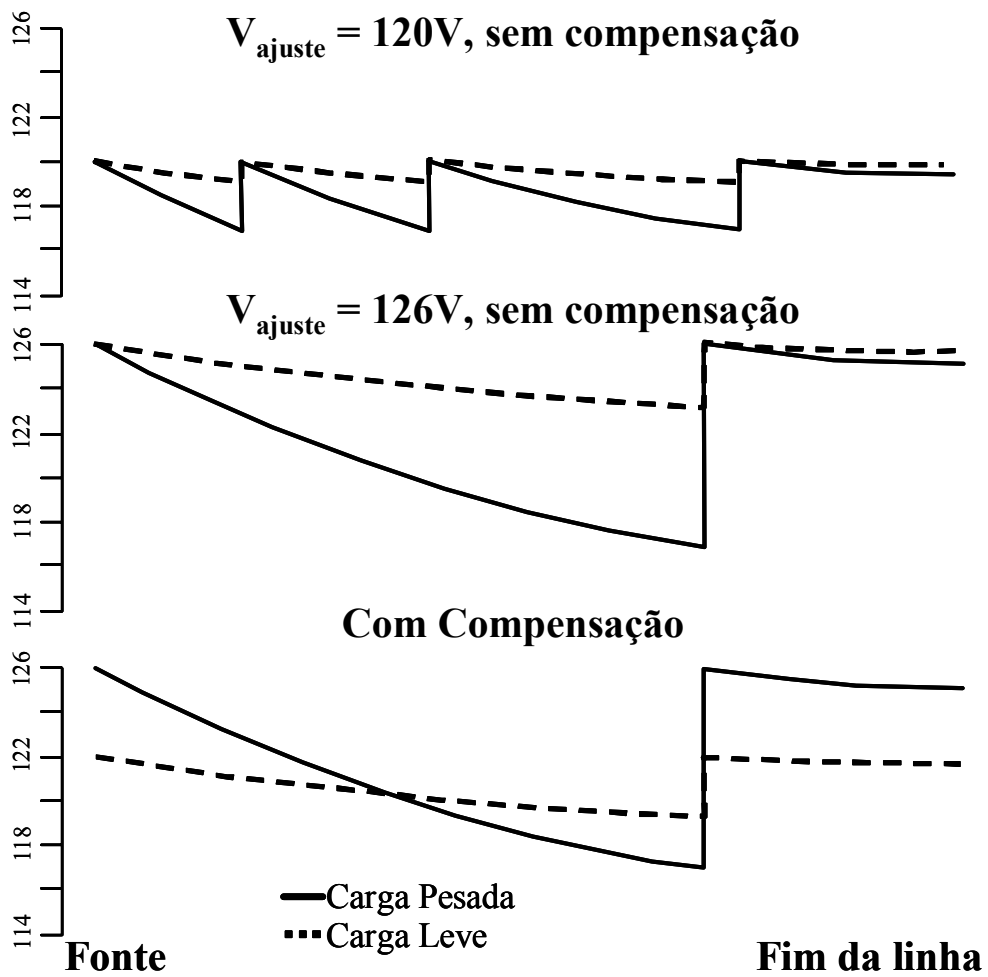

Figura 2.4 - Perfis de tensão em circuitos com várias formas de regulagem.

O método de compensação por queda de linha funciona perfeitamente para uma carga ao final da linha. Caso existam cargas distribuídas uniformemente ao longo do alimentador, com uma impedância também uniforme, pode-se manter a tensão constante no ponto médio do alimentador.

Um circuito com uma carga uniformemente distribuída tem uma queda de tensão na extremidade do alimentador igual à metade da que ocorreria caso todas as cargas fossem modeladas como uma só carga ao final da linha.

A compensação segura apenas é possível para certa quantidade de unidades consumidoras. Sobretensões nos consumidores mais próximos da subestação ocorrerão caso uma compensação excessiva seja realizada pelo regulador. 
A tensão do relé regulador não pode ficar acima dos limites. A tensão máxima pode ser calculada segundo a expressão abaixo:

$$
V_{\text {max }}=V_{\text {ajuste }}+\left(f p \cdot R_{\text {ajuste }}+\operatorname{sen}\left(\cos ^{-1}(f p)\right) \cdot X_{\text {ajuste }}\right) \cdot I_{\text {max }}
$$

Onde:

$V_{\text {ajuste }} \rightarrow$ Tensão ajustada do regulador $(\mathrm{V})$

$R_{\text {ajuste }} \rightarrow$ Ajuste do regulador para compensação resistiva (V).

$X_{\text {ajuste }} \rightarrow$ Ajuste do regulador para compensação reativa (V).

$f p \rightarrow$ Fator de potência ativa.

$I_{\max } \rightarrow$ Máxima corrente de carga em p.u. relativa ao TC do regulador.

Nos tópicos a seguir serão discutidos os detalhes dos principais dispositivos de regulação de tensão.

\subsection{Dispositivos Empregados na Regulação de Tensão}

As cargas ligadas à rede de distribuição de energia elétrica variam no decorrer do dia devido principalmente às manobras e oscilações na demanda de consumo. Juntamente com a carga, a tensão fornecida pela empresa distribuidora também varia. Para resolver esse problema são instalados alguns dispositivos para o controle da tensão. Os principais são:

- Bancos de Capacitores 
- Reguladores de Tensão

- Regulador de Tensão utilizando transformadores de potência com comutação de tap.

Os dispositivos são utilizados em sistemas de distribuição de energia elétrica visando à redução das perdas de potência e minimização dos efeitos provocados pela queda de tensão ao longo dos alimentadores. Além disso, o funcionamento correto desses dispositivos ocasiona no atendimento às faixas de tensão previstos pela legislação. Outro fator relevante é a interação entre esses dispositivos, pois esta pode ser controlada em tempo real ou por meio de pré-programação. As seções a seguir apresentam detalhadamente os dispositivos usados no controle de tensão dentro da rede de distribuição de energia elétrica.

\subsubsection{Banco de Capacitores}

Em sistemas de distribuição, os bancos de capacitores promovem inúmeras vantagens como, por exemplo, o cancelamento do excedente de potência reativa gerada pelas cargas indutivas ou outras cargas com baixo fator de potência.

Os bancos de capacitores diminuem a corrente no alimentador, fazendo o mesmo suprir mais cargas. As perdas na linha também são significativamente reduzidas já que dependem do quadrado da corrente $\left(I^{2} \mathrm{R}\right)$. Esse dispositivo eleva a tensão no alimentador, reduzindo uma parte das perdas produzidas pelas cargas do sistema.

A aplicação correta dos bancos de capacitores pode ampliar a eficiência do sistema e reduzir a queda de tensão. No entanto, seu uso incorreto pode significar uma maior perda e sobretensões. Geralmente, utiliza-se a compensação reativa por meio de capacitores tanto por 
fatores econômicos, para evitar penalidades, como por fatores de performance e qualidade de energia fornecida pelo sistema, uma vez que se diminuem as perdas.

Nos sistemas de distribuição, o emprego dos bancos de capacitores ocorre tanto na barra da subestação $\left(\mathrm{C}_{\text {shunt }}\right)$ quanto ao longo dos alimentadores $(\mathrm{C} 1)$, como pode ser visto na Figura 2.5.

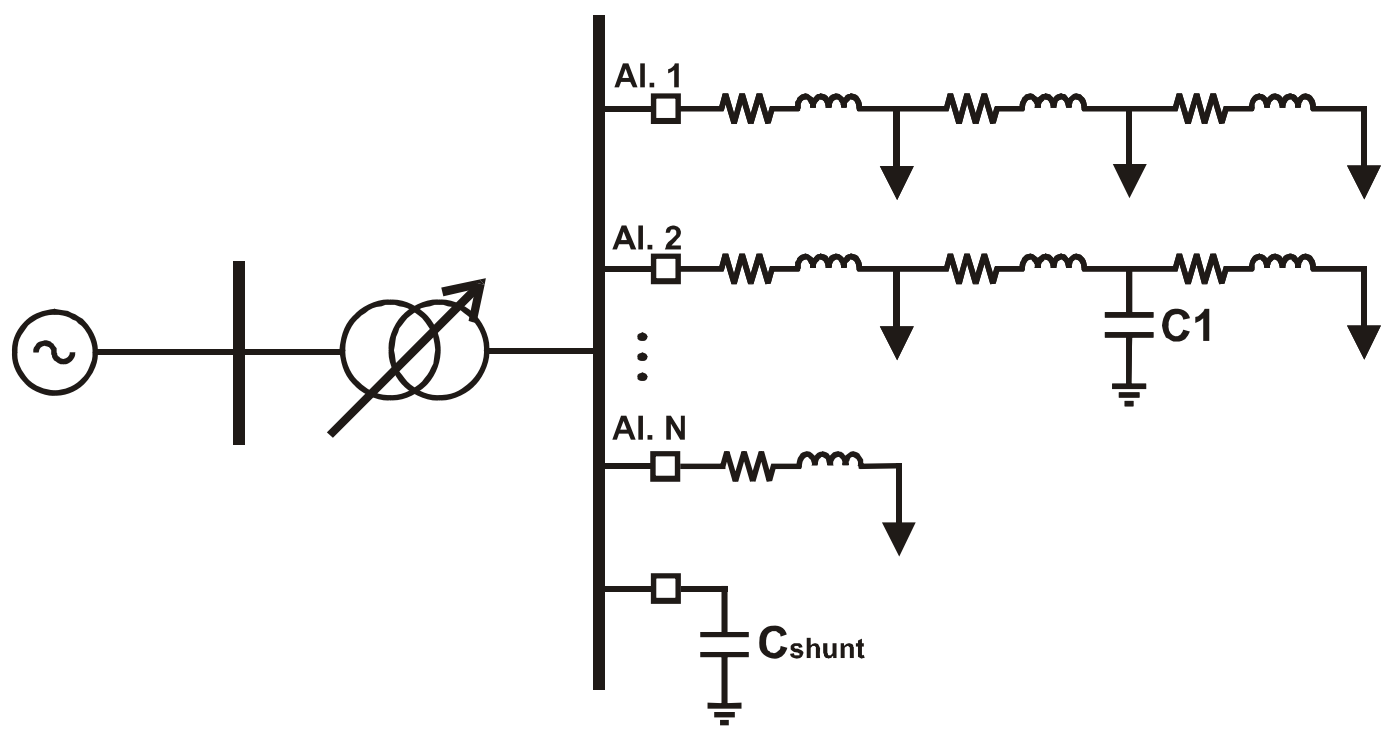

Figura 2.5 - Capacitores instalados na barra da subestação e ao longo dos alimentadores.

De acordo com a Figura 2.5, o $\mathrm{C}_{\text {shunt }}$ é o banco de capacitores conectado à barra secundária da subestação, aplicado no controle de reativos no sistema com o intuito de manter a tensão dentro dos limites estabelecidos. São utilizados para melhorar o fator de potência.

Os capacitores são postos em operação de acordo com a necessidade do sistema, sendo que todos os bancos são raramente chaveados em uma única operação.

As operações de chaveamento de bancos de capacitores em subestação são acompanhadas diariamente por sistemas supervisórios remotos ou por controladores locais. 
Os capacitores podem ser instalados ao longo dos circuitos de distribuição em paralelo ou série. Em paralelo, o local onde foi instalado o capacitor passa a compensar reativos, elevando a tensão naquele ponto. Já na configuração série, o capacitor passa a funcionar como um regulador de tensão automático comandado pela corrente, pois compensa a reatância da linha.

Os capacitores instalados em paralelo permitem uma elevação constante da tensão no alimentador, bem como uma diminuição na variação da mesma, uma vez que essa elevação independe da corrente de carga. O chaveamento de capacitores permite reduzir perdas, pois assim como o fluxo reativo muda, o estado do capacitor pode mudar de ligado para desligado e acompanhar o fluxo. Em carga leve, a presença de capacitores fixos pode elevar a tensão acima dos limites, portanto faz-se necessário a presença de bancos de capacitores chaveados.

Capacitores fixos são mais fáceis de serem instalados e dimensionados quando comparados com os chaveados, além de serem mais baratos. Devido às pesquisas recentes, já existem no mercado diversos softwares para dimensionamento, colocação e chaveamento adequado de bancos de capacitores.

O controle local dos capacitores pode ter como apoio à tomada de decisão diversas estratégias, tais como:

- Hora do dia: Os capacitores são chaveados em horários previamente programados.

- Temperatura: Altera-se o estado dos capacitores de acordo com a temperatura.

- Tensão: O controlador estabelece larguras de faixas, limites e tempos para reduzir operações de chaveamento, baseado na medição da tensão. 
- Potência Reativa: O capacitor se utiliza de medidas de reativos para tomar a decisão de chaveamento.

- Fator de potência: O controle do capacitor faz medições do fator de potência e as utiliza para decidir por alterar seu estado. Essa metodologia é dificilmente empregada.

- Corrente: O capacitor faz medições da corrente na linha para tomar decisão.

- Muitos controles oferecem algumas ou até mesmo todas essas estratégias, utilizando-as até mesmo combinadas.

Devido à diminuição dos custos das tecnologias, muitos sistemas utilizam bancos de capacitores com controle automatizado. As principais estratégias para controle remoto de capacitores são: despacho realizado pelo operador; despacho diário programado; despacho mediante medições de reativos na subestação e despacho utilizando combinação entre medições de variáveis na subestação e ao longo do alimentador [9].

\subsubsection{Reguladores de Tensão}

Os reguladores de tensão são autotransformadores com ajuste automático de tap, que permitem elevar ou abaixar a tensão. Normalmente os reguladores possuem uma faixa de regulação de $-10 \%$ à $+10 \%$. Esses também são conhecidos como autotransformadores, que são equivalentes a transformadores com um enrolamento em série com outro. 
Os reguladores possuem várias entradas, permitindo a configuração do número de enrolamentos de acordo com a variação da tensão de entrada. Esse ajuste é feito por meio de uma chave rotatória. O enrolamento é escalonado e equipado com comutadores de tap que permitem a mudança na relação de transformação. A utilização desses equipamentos em sistemas de distribuição tem por objetivo manter constante a tensão no secundário, compensando as variações de tensões do primário e do secundário. Geralmente, estes dispositivos são aplicados em pontos ao longo do alimentador em que a tensão não consegue ser regulada pela subestação. A Figura 2.6 ilustra reguladores instalados ao longo dos alimentadores.

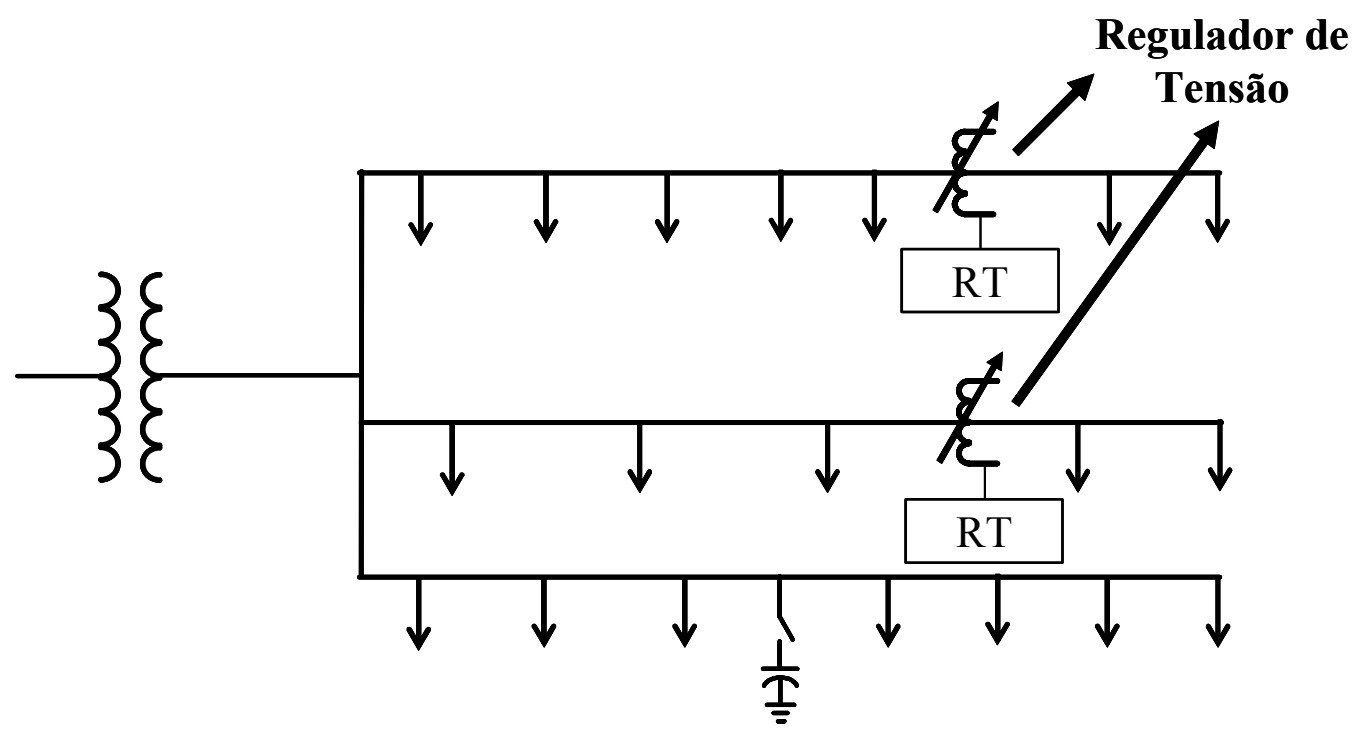

Figura 2.6 - Reguladores de tensão instalados ao longo dos alimentadores.

Um regulador monofásico ANSI (American National Standards Institute) possui 3 buchas: Fonte, Carga e Fonte-Carga, conforme pode ser visto na Figura 2.7. 
Elevação de tensão

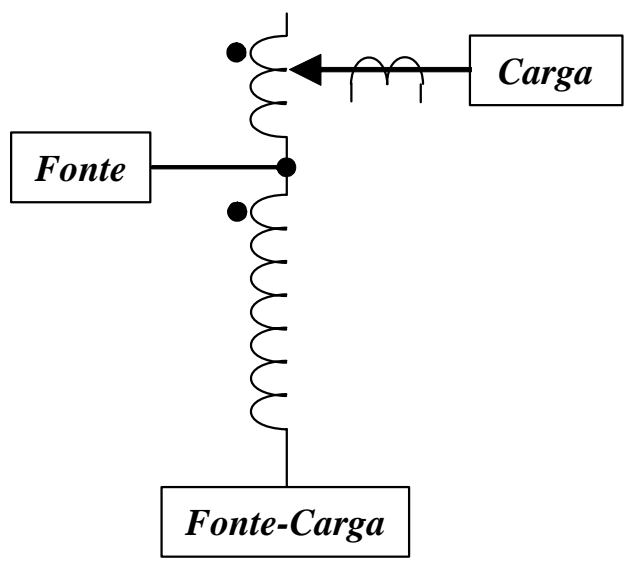

Diminuição de tensão

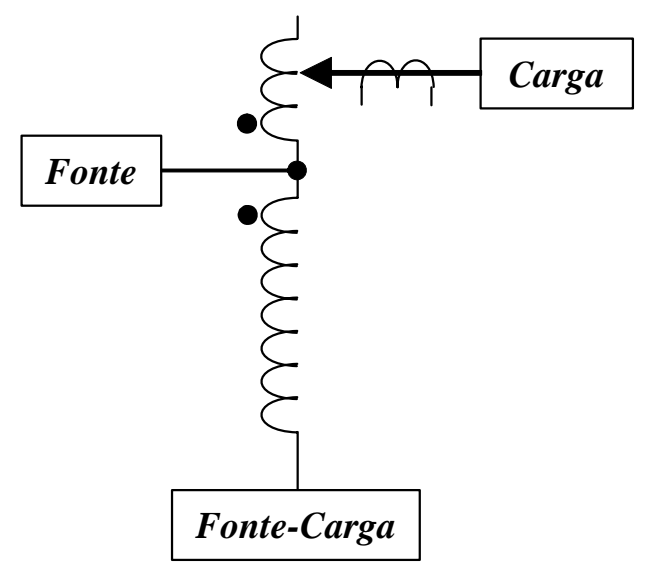

Figura 2.7 - Regulador monofásico ANSI.

O enrolamento série encontra-se entre a Fonte e a Carga, com o tap do lado da carga.

Os reguladores trifásicos, geralmente utilizados em subestações, controlam as três fases simultaneamente. Eles podem ter conexões Estrela com Terra, Triângulo Aberto e Triângulo Fechado, conforme pode ser visto na Figura 2.8.

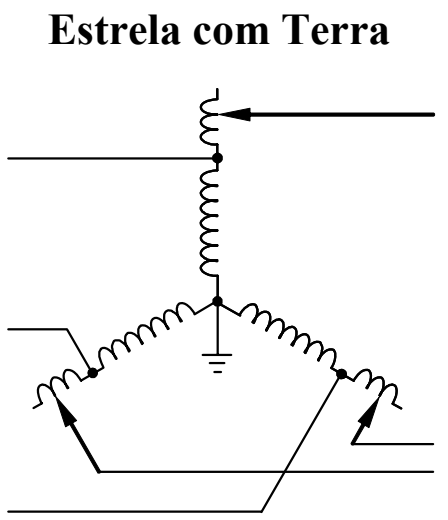

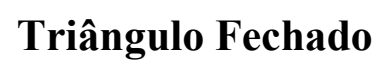

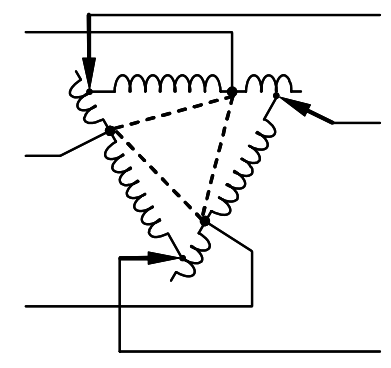

Triângulo Aberto

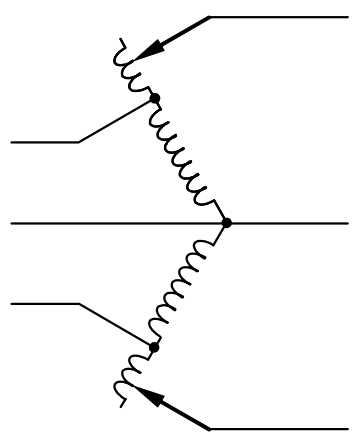

Figura 2.8 - Conexões trifásicas para o autotransformador. 
Na configuração Estrela com Terra à quatro condutores, geralmente utilizam-se três reguladores monofásicos, que conectam a linha ao neutro. Cada regulador controla independentemente a tensão, melhorando o controle do sistema desbalanceado.

Na configuração Triângulo Fechado, três reguladores estão conectados fase a fase. Esse arranjo permite um acréscimo na faixa de regulação passando de $\pm 10 \%$ para $\pm 15 \%$. Já na configuração Triângulo Aberto, apenas dois reguladores monofásicos são necessários, conectando uma fase a outra [9].

\subsubsection{Transformadores com Comutação de Tap}

As cargas ligadas à rede de distribuição variam ao longo do dia, o que causa variações na tensão. Se for incontrolada, é inaceitável essa variação para os consumidores como para os órgãos regulamentadores. Para prevenir tal fato, os transformadores em subestações primárias possuem comutador de tap sob carga (OLTC - On-Load Tap Changer).

Os transformadores que provêm um pequeno ajuste de magnitude de tensão, usualmente numa faixa de $\pm 10 \%$, e/ou que mudam o ângulo de fase da tensão de linha, são importantes componentes do sistema de potência. Alguns transformadores regulam tanto a magnitude como o ângulo de fase.

Os transformadores provêm de tap para variar a relação entre o número de enrolamentos do primário e secundário através de uma chave. O controle é feito pela análise da tensão de entrada visando manter a saída em um nível constante e mais próximo da referência.

Uma comutação de tap pode ser realizada enquanto o transformador está energizado. Essa operação é denominada “Load Tap Changer” (LTC). 
Cada comutador de tap tem associado um relé regulador automático de tensão (conhecido como "relé 90"), que monitora a tensão do secundário do transformador e comanda as operações de comutação de tap como desejado. Essa comutação é automática e operada por motores que respondem ao comando desse relé para ajustar a tensão dentro de um nível especificado. Circuitos especiais mostram a comutação a ser feita sem a interrupção da corrente. O tempo morto de atuação (temporização) é incluso e deve ser ajustado para ser levemente maior que o tamanho do passo do transformador para prevenir oscilações abruptas. Na prática, a temporização é inclusa para evitar o uso desnecessário devido à alta freqüência de comutações de tap.

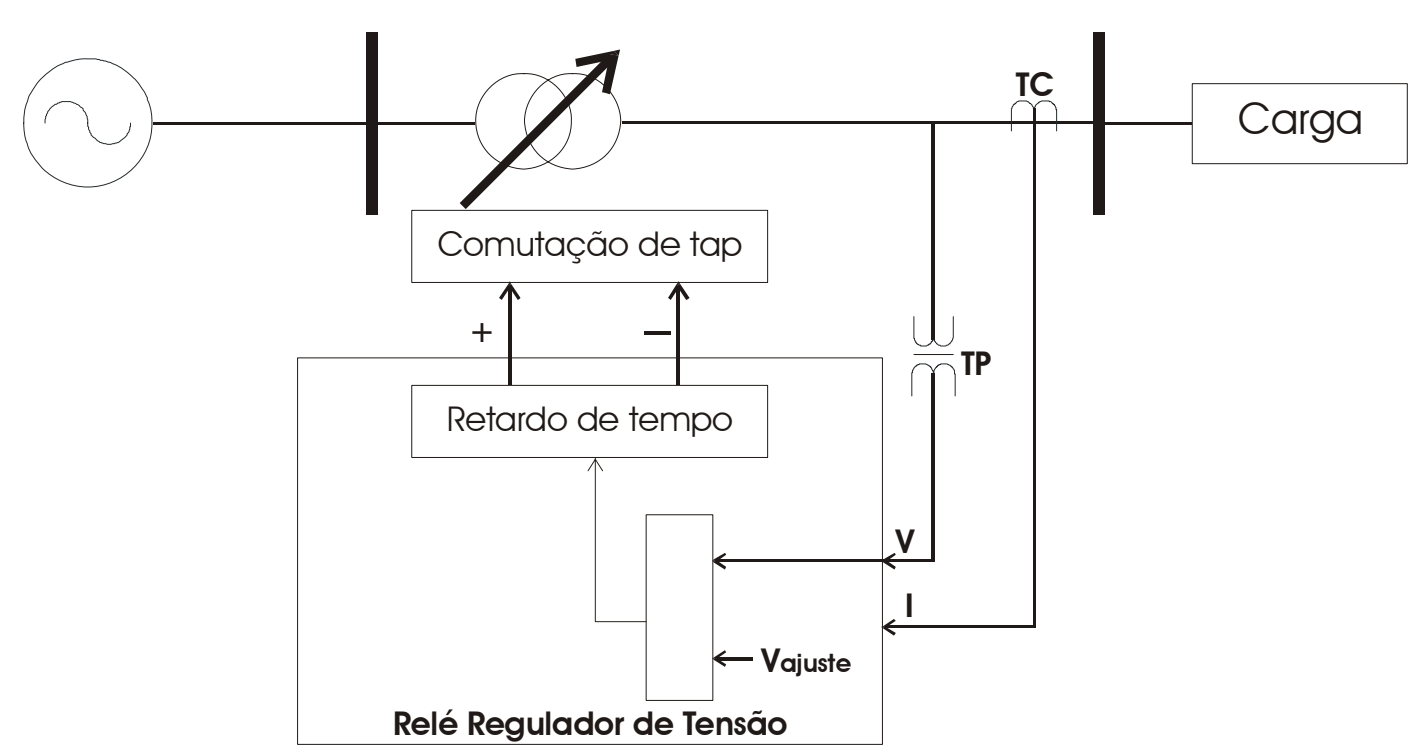

Figura 2.9- Esquema do relé regulador automático de tensão.

O mais simples arranjo de controle de tensão introduzido na Figura 2.9 é muito robusto. Não existe motivo para ele ser afetado por mudanças em fator de potência ou mesmo uma reversão de potência reativa. O fator limitante é que o esquema da Figura 2.9 não 
considera a queda de tensão ao longo do alimentador e também a operação em paralelo de transformadores.

Os controles de tensão empregados na prática são mais complexos do que o esquema da Figura 2.9. Uma dessas considerações práticas é levar em conta a queda de tensão ao longo do alimentador, como descrito acima, através da estratégia de LDC considerando centro de carga. Como visto anteriormente, o objetivo da compensação de queda de linha é manter a tensão nos consumidores dentro de uma faixa aceitável.

A Figura 2.10 indica uma corrente proporcional para a corrente de carga que flui através de uma impedância equivalente $\left(Z_{\mathrm{eq}}=\mathrm{R}+j . \mathrm{X}\right)$. A tensão dos componentes $\mathrm{R}$ e $\mathrm{X}$ são deduzidas da tensão do barramento secundário da subestação primária para dar um sinal de resposta de tensão à carga remota.

Os valores de $\mathrm{R}$ e $\mathrm{X}$ dentro do relé são ajustados de forma a corresponder diretamente às impedâncias $R_{L}$ e $X_{L}$ da linha real.

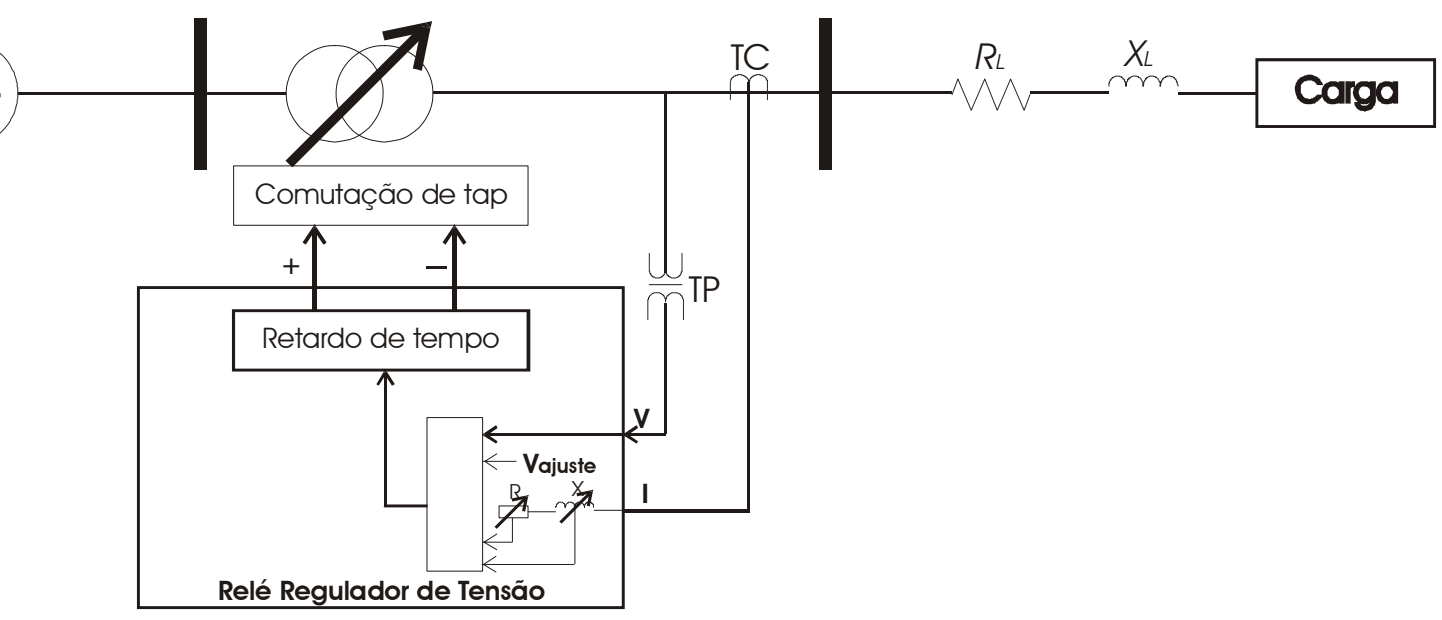

Figura 2.10 - Esquema do relé regulador de tensão com LDC.

O relé regulador de tensão possui basicamente 3 ajustes: 
- Tensão de Referência: Também chamada de ponto de ajuste ou centro de banda. É a tensão desejada na saída do regulador.

- Largura de Faixa: São os limites inferior e superior, os quais a tensão do regulador deve obedecer.

- Temporização ou Tempo Morto: Tempo de espera para se iniciar uma comutação de tap a partir do momento em que a tensão do regulador extrapola os limites estabelecidos. Esse ajuste permite evitar que o regulador atue em variações curtas de tensões.

Esses ajustes estão graficamente representados na Figura 2.11.

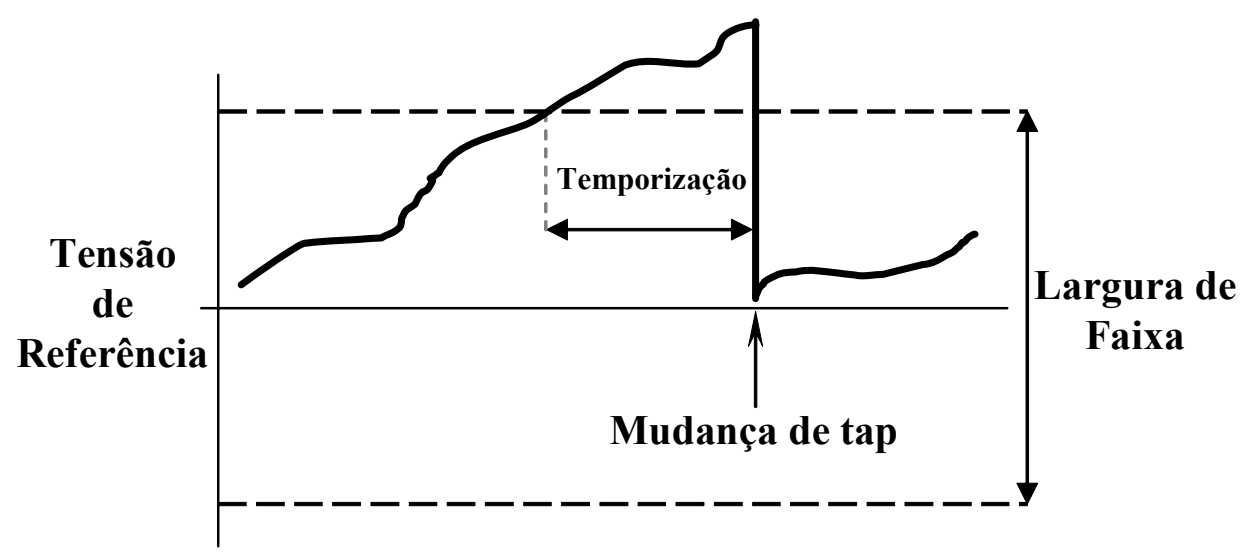

Figura 2.11 - Ajustes do relé regulador de tensão.

Uma temporização elevada ou uma grande largura de faixa diminuem o número de comutações, mas a regulação de tensão fica comprometida. Uma largura de faixa estreita ou uma baixa temporização melhoram o perfil de tensão, mas acarretam maiores comutações de tap e seu conseqüente desgaste. 
Os relés reguladores de tensão possuem contadores de operações que auxiliam a equipe de manutenção a identificar a melhor hora para se realizar a manutenção do dispositivo ou sua troca. Os comutadores de tap são concebidos para aproximadamente 1 milhão de operações em sua vida útil. Em condições normais, são realizadas 70 comutações por dia, um total de 25 mil por ano. Caso o número de comutações por dia seja excessivo, o contador de operações também pode ser útil, indicando que algum parâmetro está regulado de forma errada ou estão ocorrendo flutuações de tensões no primário [9].

Esse capítulo apresentou os principais aspectos no que tange à regulação de tensão de tensão em sistemas de distribuição de energia elétrica. O objetivo principal dessas estratégias é alcançar a melhoria no controle de tensão, ocasionando no atendimento às faixas de tensão estabelecidas pela legislação. Para isso, novas técnicas de controle dessa grandeza são pesquisadas de forma a responder às mais diversas situações que podem ocorrer num sistema elétrico de potência. Tendo isso em vista, o próximo capítulo mostra as principais contribuições que vêm ocorrendo nos últimos anos em termos de pesquisa do assunto. 



\section{REVISÃO BIBLIOGRÁFICA}

\subsection{Organização e Estudo Bibliográfico}

Esse capítulo apresenta os aspectos relativos ao estudo bibliográfico utilizado no desenvolvimento desse trabalho. As investigações realizadas forneceram as diretrizes fundamentais para a escolha das metodologias, abordagens e técnicas que deverão ser adotadas para o desenvolvimento desse trabalho de pesquisa visando a alinhar e aprimorar as mesmas com os objetivos propostos.

Como conseqüência, as compilações dos resultados obtidos a partir desta investigação concluíram em estudar as diferentes estratégias que têm sido relatadas na literatura técnicocientífica, as quais visam a melhorar a regulação de tensão em alimentadores do sistema de distribuição. Assim sendo, alguns dos assuntos estudados foram:

- Pesquisa de estratégias que permitam o desenvolvimento de relés inteligentes para regulação de tensão.

- Estudo de métodos e de técnicas utilizadas para o controle de tensão em sistemas de distribuição de energia elétrica.

- Análise de potenciais arquiteturas de sistemas inteligentes a serem utilizadas na pesquisa, levando-se em consideração as variáveis medidas na subestação. 
Os assuntos de pesquisa pautados acima proporcionaram uma investigação ampla e detalhada no que se refere ao tema deste trabalho.

O controle de tensão em sistemas de distribuição de energia elétrica é usado para manter o perfil de tensão dentro de limites especificados. Desta maneira, tem-se a redução de perdas, minimização do problema de instabilidade de tensão e eliminação da violação de tensão para a concessionária distribuidora de energia elétrica.

Para manutenção da tensão dentro de determinados limites operacionais são necessárias medidas de controle e de acompanhamento dos agentes de fiscalização como das concessionárias de energia. Isto porque os sistemas elétricos de distribuição estão sujeitos a variações de tensão. Esse problema relacionado ao fornecimento de energia pode comprometer o funcionamento correto dos equipamentos elétricos pertencentes aos consumidores.

Para manter o perfil de tensão dentro de limites especificados utiliza-se de diversas estratégias para regular a tensão. Segundo os pesquisadores EKWUE e McQUEEN [10], as principais são:

- Comutação de tap em transformadores de potência na subestação.

- Utilização de bancos de capacitores no barramento da subestação e/ou nos alimentadores.

- Utilização de reguladores de tensão ao longo dos alimentadores.

As estratégias de controle de tensão se fundamentam na injeção ou retirada de potência reativa no sistema e também pela mudança no nível da tensão do secundário por meio de comutação de tap em transformadores ou autotransformadores. 
A mudança de tap em transformadores da subestação de distribuição é realizada por um relé denominado Regulador Automático de Tensão que também tem a função de comando, controle e monitoração da tensão.

As estratégias de controle podem aparecer nos sistemas de distribuição de forma combinada ou atuando individualmente na regulação da tensão. Tal controle para sistemas de distribuição é dividido em duas categorias:

- Controle off-line.

- Controle on-line.

A primeira categoria de controle é feita através da previsão de carga para o próximo dia. A partir disso, obtém-se o despacho otimizado para a operação dos dispositivos ao longo do sistema. Na segunda categoria, as decisões de controle de tensão são tomadas em tempo real. As seções a seguir mostram os principais trabalhos científicos para essas duas categorias de controle.

\subsection{Estratégias de Controle de Tensão Off-Line}

No controle off-line utilizam-se freqüentemente métodos de programação dinâmica (PD), pois devido à natureza não linear dos problemas, fica extremamente complexa a utilização de alguns métodos on-line. Porém, essa técnica exige grande esforço computacional. Uma forma de minimizar esse problema é dividi-lo em subproblemas. De uma maneira geral, o controle off-line faz uma programação futura da operação dos dispositivos 
reguladores de tensão. Essa coordenação ótima, também designada como despacho ótimo, proporciona redução nas operações de comutação de tap bem como a melhor utilização dos bancos de capacitores no sistema.

HU et. al.[11] mostraram uma estratégia para controle off-line de tensão e potência reativa em sistemas de distribuição com o objetivo de determinar o despacho programado nas operações de chaveamento de capacitores e comutação de tap conforme a previsão de carga para o próximo dia. $\mathrm{Na}$ estratégia de controle $\mathrm{V} / \mathrm{VAr}$, estudado por esses pesquisadores, busca-se a coordenação ótima dos comutadores de tap e banco de capacitores conectados ao barramento do secundário da subestação e também instalados ao longo do alimentador. Essa coordenação ótima também conhecida como despacho ótimo proporciona a redução nas operações de comutação de tap, melhoria na utilização dos bancos de capacitores no sistema e a minimização das perdas de potência. Para se obter o despacho ótimo dos dispositivos de controle existentes no sistema de distribuição, os autores utilizaram dois passos. O primeiro consiste em obter a previsão de carga para o próximo dia em vários níveis de carga. No segundo passo determina-se a operação ótima dos dispositivos de controle V/VAr baseado na previsão de carga do primeiro passo. A técnica de Algoritmos Genéticos (AG) [21] foi empregada em ambos passos. A posição do tap permanece constante em cada nível de carga. Como saída tem-se o despacho programado para o próximo dia relativo às operações de chaveamento dos dispositivos de controle. As simulações indicam que o método produz uma melhoria da qualidade do nível de tensão, reduzindo as perdas de potência e as operações de chaveamento dos dispositivos [11].

Já o trabalho de LIU et. al. [12] propõe uma nova abordagem para controle ótimo de potência reativa e tensão em sistemas de distribuição radiais. O controle ótimo consiste em encontrar um escalonador apropriado para bancos de capacitores shunt e comutação de tap em 
subestações e bancos de capacitores nos alimentadores, de modo que a perda de potência seja minimizada e o perfil de tensão, melhorado. Para reduzir o esforço computacional, o controle total foi decomposto em dois subproblemas: um diz respeito a alimentadores e outro à de subestação. Para solucionar os dois subproblemas, foram utilizados, respectivamente, um controlador Fuzzy e um sistema de programação dinâmica simplificado. A correta coordenação entre esses dois métodos proporciona uma solução ótima para o problema completo. Os resultados numéricos demonstraram que a metodologia proposta foi eficaz e pode ser empregada na prática.

O único inconveniente desses dois primeiros trabalhos é o surgimento de alterações no sistema não previstas para o horizonte na qual se busca uma solução ótima. Se isso ocorrer, as abordagens propostas podem não responder de forma adequada, causando instabilidades de tensão no sistema. Porém vale ressaltar que, para cargas bem comportadas, essas estratégias se mostram muito interessantes, principalmente porque utilizam técnicas computacionais inteligentes.

O trabalho de HSU e LU [13] determina o apropriado status de on/off dos capacitores e também a posição do tap do transformador para as 24 horas do próximo dia. Para atingir esse objetivo, uma Rede Neural Artificial (RNA) [22] é designada para encontrar um despacho programado preliminar para o capacitor e o comutador de tap. As entradas da RNA são as potências ativas e reativas do transformador principal e as tensões do barramento primário e secundário. As saídas são as posições desejadas do tap e status de on/off dos capacitores. O despacho preliminar é refinado pela Programação Dinâmica Fuzzy para se encontrar o despacho programado final. Para demonstrar a eficiência do método proposto, o controle de tensão e potência reativa é executado para o caso de uma subestação de distribuição na cidade Taipei, situada em Taiwan. Os resultados advindos do exemplo 
mostram que o despacho programado apropriado do capacitor e LTC podem ser alcançados pelo método proposto em um período muito curto. A maior dificuldade desse trabalho situa-se na obtenção de padrões de treinamento para a RNA suficiente para representar o comportamento de qualquer sistema elétrico e com o objetivo de prover um adequado controle de tensão, ou seja, uma RNA treinada para um sistema de distribuição genérico. Portanto é questionável a generalização do sistema proposto, pois os autores utilizam apenas padrões extraídos da SE Taipei. O estudo que os autores fizeram contempla apenas um caso isolado. Isso mostra que o sistema proposto pode não responder de forma correta frente ao comportamento de alguns sistemas [13].

ROYTELMAN e GANESAN [14] prescrevem sobre controladores automáticos locais que são parte integrante de um moderno sistema de distribuição. Eles controlam a posição do comutador de tap em transformadores e o estado das chaves dos bancos de capacitores para garantir que a tensão e as restrições de carga sejam satisfeitas em condições de operação. Os aplicativos em Redes de Distribuição, que tradicionalmente tem sido usado para planejamento, descrevem a presença de controladores locais numa maneira simplificada. O Sistema de Gerenciamento da Distribuição (DMS) traz aplicações de rede para a prática operacional a qual requer muito mais detalhes da modelagem dos controladores locais para o propósito de monitoramento do fluxo de potência em tempo real e também para controle. Em último caso, o controlador local cria oportunidades e restrições para a otimização das funções do DMS tal como o controle V/Var e a reconfiguração do alimentador. Esse artigo descreve como os controladores locais de LTC e capacitores são modelados como uma parte da solução do fluxo de potência e como eles influenciam e afetam a otimização das funções do DMS. O impacto da modelagem do controlador local sobre o fluxo de potência, controle V/VAr e reconfiguração do alimentador é ilustrado por exemplos numéricos. O trabalho tem como 
destaque a utilização dos dados do sistema de gerenciamento. Com isso, as ações de controle podem ser determinadas com mais confiabilidade além do fato de considerar a reconfiguração dos alimentadores.

LIANG e WANG [15] apresentou um controle de tensão e potência reativa baseado em Fuzzy para um sistema de distribuição. A proposta principal é encontrar uma combinação entre as comutações do tap do transformador e a operação de chaveamento on/off dos capacitores em um dia, tal que o desvio da tensão no barramento secundário seja tão pequeno quanto possível, enquanto que o fluxo de potência reativa através do transformador principal e as perdas ativas nos alimentadores sejam os menores possíveis. Para minimizar o custo de manutenção do sistema, o número de operações de comutação de tap e chaveamento de capacitores deve ser o mínimo possível. Sobre as descrições dadas, expressões lingüísticas como "tão pequeno quanto possível”, “tão pouco quanto possível” e "o menor possível” não são claras. Assim nesse artigo o problema do controle de tensão e potência reativa é primeiramente formulado em sistemas Fuzzy e também pela técnica de busca Annealing, que é usada para encontrar a combinação apropriada entre comutações de tap e operações de chaveamento de capacitores em um dia. Para demonstrar a eficiência do método proposto, o controle de tensão e potência reativa será analisado em um sistema de distribuição dentro da área de serviço do escritório do distrito de Yunlin da Companhia de Potência de Taiwan (TPC). Um despacho programado apropriado para posições do tap e operação de chaveamento de capacitores pode ser alcançado pelo método proposto.

Os trabalhos referentes às estratégias de controle off-line têm como ponto vulnerável a desconsideração de um comportamento atípico e não prevista para o horizonte de decisão. As previsões ou as ações que serão tomadas podem ser surpreendidas com o aparecimento de 
situações incomuns como, por exemplo, manobras no sistema e cargas desbalanceadas. Mas cabe lembrar que essas estratégias são eficazes em sistemas elétricos bem comportados.

\subsection{Estratégias de Controle de Tensão On-Line}

Por outro lado, o controle on-line exige um elevado nível de automação nas subestações, cenário inexistente no Brasil dentro das concessionárias de distribuição de energia. Além disso, é muito complexo para o controle on-line considerar o carregamento diário e sua respectiva medida de controle de tensão através dos dispositivos especialistas.

Existem poucos trabalhos científicos na área de controle on-line de tensão em nível de distribuição de energia. Dentre eles pode-se citar os trabalhos de DIXON [16],[17] que propõem um sistema adaptativo de coordenação e controle de tensão no que tange aos dispositivos reguladores de tensão encontrados no sistema de distribuição de energia elétrica. O principal destaque desse trabalho é o fato de que a tomada de decisão dos dispositivos controladores de tensão se baseiam na monitoração da potência reativa. A justificativa de se usar essa grandeza é devida ao seu acoplamento com a tensão. Porém isso é válido nos sistemas de transmissão de energia elétrica já que nos sistema de distribuição isso pode não ocorrer.

CHOI e KIM [18] mostraram uma abordagem de controle de tensão somente pela atuação nos comutadores de tap através da técnica de otimização "Branch-and-Bound". Os autores utilizaram um avançado método online para controle de ULTC (Under-Load Tap Changer), de transformadores de potência para a regulação de tensão em sistemas de distribuição, considerando a diversidade de cargas desbalanceadas em múltiplos 
alimentadores e a mudança de tap do ULTC do transformador. Esse método determina a melhor posição de tap para o transformador, mantendo a tensão dos consumidores dentro dos limites permitidos. Os resultados apresentados nessa abordagem mostraram uma melhoria no perfil de tensão, porém um aumento no número de comutações de tap comparado com o sistema de controle de tensão convencional.

Outro trabalho de destaque dentro desse contexto é o de LIU et. al. [19], pois é proposto um controlador microprocessado baseado em lógica Fuzzy para prover a estabilidade da tensão. O controle atua no comutador de tap em transformador e banco de capacitores conectados ao barramento secundário da subestação de distribuição conforme ilustra a Figura 3.1. O controlador Fuzzy age sobre esses dispositivos, definindo a melhor operação a ser realizada no intuito de melhorar o perfil de tensão no barramento secundário de uma subestação.

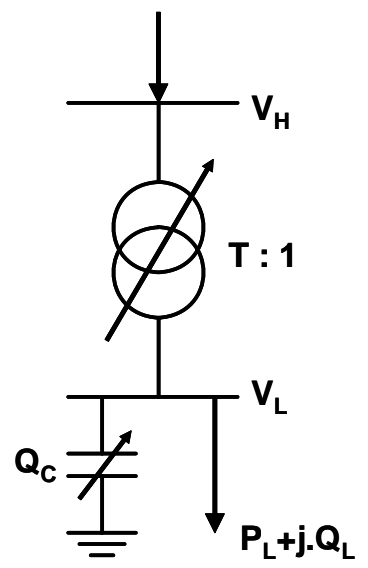

Figura 3.1 - Esquema do sistema de distribuição.

O sistema de controle baseado em Fuzzy foi implementado num microprocessador Intel 8098. O diagrama de blocos deste controlador é apresentado na Figura 3.2. 


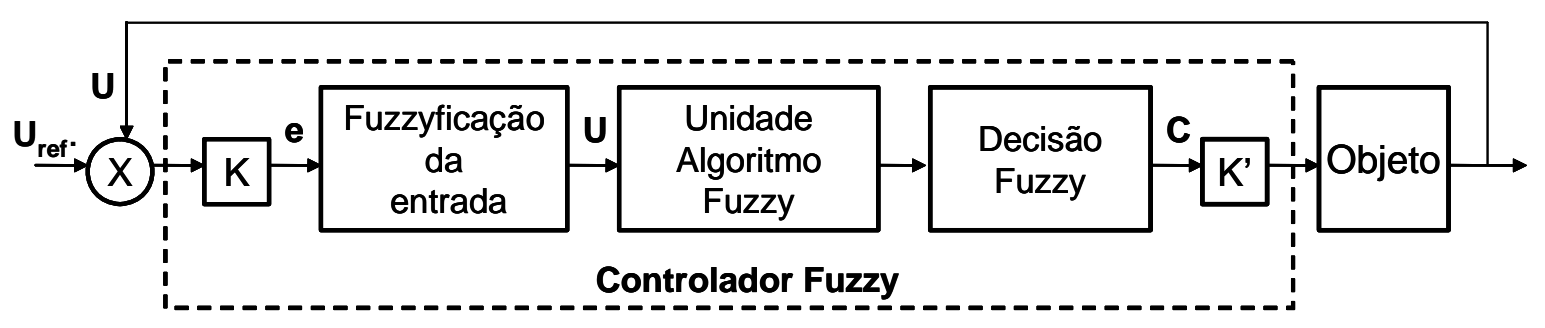

Figura 3.2 - Diagrama simplificado do controlador Fuzzy.

O sinal de entrada do controlador é a tensão secundária da subestação. De acordo com o erro entre a tensão atual e a normal, pode ser decidida qual operação deve ser executada para estabilizar a tensão dentro de níveis especificados. A saída do controlador é um comando para a operação de comutação de tap ou entrada em operação de bancos de capacitores conectados ao barramento secundário.

A base de regras Fuzzy é definida através do conhecimento das medidas de controle a serem tomadas de acordo com a situação. O grupo de regras lingüísticas acima segue três operações básicas:

- Se a tensão é baixa, então, os capacitores conectados à barra são ativados ou realiza-se a comutação do tap do transformador, de modo que aumente a tensão.

- Entretanto, se a tensão é alta, então, os capacitores conectados à barra são desativados ou realiza-se a comutação do tap do transformador de modo que diminua a tensão.

- Se a tensão está dentro do limite normal, então, os dispositivos se mantêm inalterados.

O controlador possui quatro estratégias de operação como mostra a figura a seguir: 


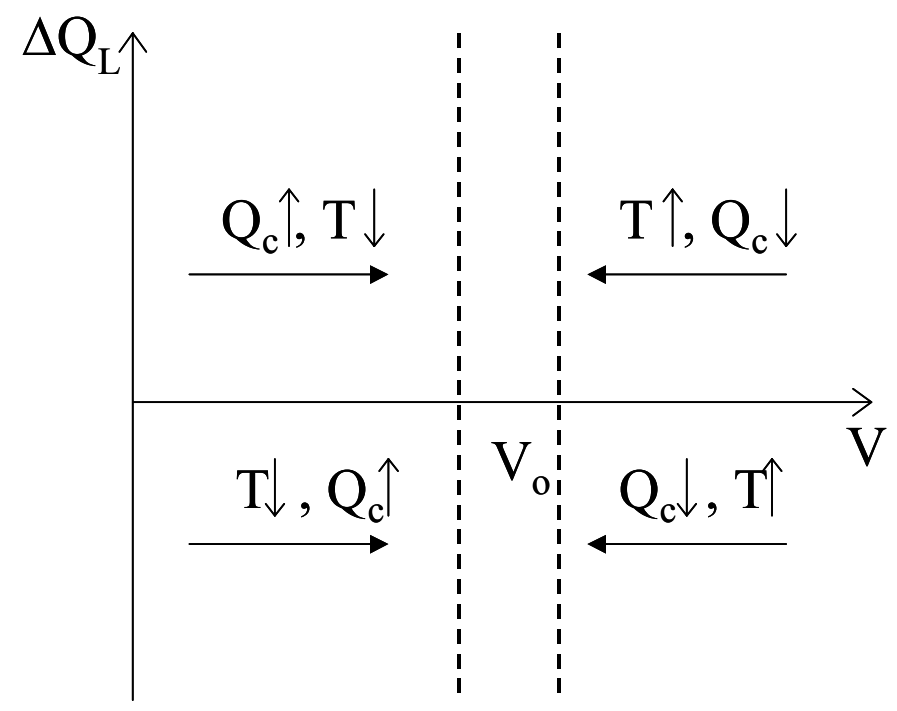

Figura 3.3 - Classes de operação.

As estratégias de operação comandam a comutação de tap em transformadores e o banco de capacitores em diferentes condições. Um exemplo disso é o nível de tensão estar mais baixo que o normal. Para a tensão voltar ao limite normal, injeta-se potência reativa no barramento secundário através de banco de capacitores shunt $\left(\mathrm{Q}_{\mathrm{c}}\right)$. Se ainda assim a tensão continuar fora dos limites faz-se também a comutação do tap $(\mathrm{T})$ de transformadores.

Através do controlador Fuzzy tem-se o controle automático da tensão no barramento secundário da subestação de distribuição de energia elétrica. Além disso, os resultados obtidos mostraram que a presença do controlador Fuzzy na subestação forneceu boa estabilidade de tensão até mesmo para casos de carga pesada.

Essa estratégia é bastante interessante, pois utiliza a técnica de sistemas inteligentes denominada de Sistemas Fuzzy. Por outro lado, essa estratégia não considera os aspectos de temporização na atuação do controle, já que uma elevação de carga momentânea causaria uma operação desnecessária do controlador Fuzzy. 
Neste capítulo, foram apresentadas algumas das principais estratégias para melhoria do perfil de tensão secundária de subestações de distribuição de energia elétrica fundamentadas em técnicas recentes. Dentre estas técnicas, destacam-se os Sistemas Fuzzy devido aos resultados promissores apresentados por essa abordagem e relatados junto à bibliografia correlata. Os resultados provenientes deste capítulo forneceram os diversos subsídios que auxiliarão no desenvolvimento do trabalho de pesquisa.

É importante frisar a escassez de trabalhos relativos ao tema desse trabalho, em especial, às estratégias para o melhoramento do perfil de tensão com tomada de decisão online usando técnicas de sistemas inteligentes. 


\section{ASPECTOS RELATIVOS À MODELAGEM DO CONTROLE DE TENSÃO ATRAVÉS DE SISTEMAS FUZZY}

Como mencionado anteriormente, o objetivo do controle de tensão nos sistemas elétricos de potência é manter o perfil de tensão dentro de certos limites, visando à minimização das perdas e prevendo casos de instabilidade de tensão. Os requerimentos desses controles são determinados principalmente pela utilização e configuração do sistema.

O despacho e controle de potência reativa, bem como o melhoramento do perfil de tensão, são considerados problemas de otimização que podem ser resolvidos por métodos de algoritmos numéricos. As vantagens principais dos métodos de algoritmos incluem [10]:

- A otimização é matematicamente rigorosa em alguns algoritmos.

- Os problemas são formulados levando-se em consideração a vantagem da existência de técnicas esparsas aplicáveis em grande escala nos sistemas elétricos de potência.

- Existência de uma larga faixa de tecnologias de programação matemática já solidificadas.

Apesar do sucesso das técnicas tradicionais de otimização, existe ainda uma grande classe de problemas que as mesmas são inapropriadas. Tais problemas têm as seguintes características [10]: 
- Requerimento do uso de bases de conhecimento.

- Requerimento da decisão do operador, particularmente sobre as situações práticas.

- Exigência da experiência adquirida sobre um período de tempo.

- Incertezas da rede

- Variação de cargas

Considerando os estudos apresentados no capítulo anterior é possível verificar que existem diversas técnicas que podem ser utilizadas para melhoria do perfil de tensão.

De acordo com as análises realizadas acima, uma das tendências mais promissoras consiste da utilização de sistemas inteligentes visando a fornecer soluções eficientes para o controle de tensão nos alimentadores derivados dos sistemas de distribuição de energia elétrica, permitindo assim a exploração das potencialidades advindas de tais técnicas.

Desta forma, tendo como objetivo considerar as diversas variáveis e grandezas que estão envolvidas com os processos que visam ao controle do perfil de tensão ao longo dos alimentadores derivados das subestações de distribuição, torna-se relevante a proposição de um sistema inteligente que possa ser eficientemente implementado neste tipo de aplicação. Por isso o uso de ferramentas inteligentes tem sido cada vez mais considerado para o controle de tensão, podendo-se destacar as principais como [20]:

- Sistemas Fuzzy.

- Redes Neurais Artificiais.

- Algoritmos Genéticos.

- Sistemas Inteligentes Híbridos. 
Um dos aspectos diferenciais do sistema proposto, estando o mesmo em uniformidade com os objetivos e propósitos do presente trabalho, está pautado na arquitetura de um relé inteligente. Tal relé deve levar em consideração somente as informações existentes na barra secundária da subestação, nas quais estarão disponibilizadas as grandezas elétricas mensuradas pelos instrumentos de medição (TC's e TP's - Transformador de Corrente e Transformador de Potencial).

Portanto, a solução a ser utilizada consiste em usar de forma integrada as diversas variáveis disponíveis na subestação e que possam contribuir para que o controle do perfil de tensão possa ser efetivado de forma confiável e segura [10].

\subsection{Diagrama Esquemático do Relé Inteligente}

O controle de tensão em um sistema elétrico é uma tarefa das mais importantes e deve ser executada em consonância com as instruções de operação, visando sempre à melhoria contínua para proporcionar serviços de qualidade aos consumidores. Na maioria das situações de operação do sistema, o comportamento de carga de um dia nunca se repete. Isso se deve pelo fato de que as cargas dos consumidores têm comportamentos diferentes.

As cargas dos consumidores possuem várias características como:

- Localização geográfica

- Dependência da energia elétrica

- Perturbações causadas pela carga ao sistema

- Finalidade a que se destina a energia elétrica [8]. 
Tais características devem ser consideradas nos ajustes dos relés reguladores de tensão. Sendo assim, o relé tem que ser capaz de tomar decisões frente a essas variações no sistema elétrico. Muitas vezes, esses relés convencionais não respondem corretamente a certas situações que ocorrem no sistema. Evolução da carga, chaveamento momentâneo de carga e perturbações no sistema são exemplos de situações em que esses dispositivos de controle de tensão não atuam de forma eficaz. Isso ocorre devido à complexidade e à dinâmica do sistema, que acabam dificultando os ajustes dos relés ou mesmo resultando na incapacidade de atuar corretamente frente a essas situações.

Considerando a ineficiência da técnica de controle utilizada nos relés convencionais, é necessária a utilização de uma técnica que se adapte às condições adversas do sistema elétrico. Os sistemas Fuzzy são os melhores candidatos, pois são considerados estruturas computacionais responsáveis pela solução de problemas de domínio limitado, cujas soluções requerem geralmente uma tomada de decisão que implica em ações ótimas que melhoram o desempenho do sistema. Assim sendo, um sistema provido de inteligência computacional é capaz de emitir uma decisão apoiada em conhecimentos pré-existentes, a partir de uma base de informações de entradas, tal como um especialista de determinada área do conhecimento.

Para solucionar problemas, os sistemas considerados inteligentes precisam realizar inferências das variáveis de saídas baseados nos valores reais das variáveis de entrada as quais estão representando o estado atual do processo. Portanto, o sucesso de um sistema Fuzzy depende da representatividade de suas variáveis de entrada, assim como dos mecanismos envolvidos com a exploração do inter-relacionamento delas com as variáveis de saída.

As características dos sistemas inteligentes enquadram-se na resolução do problema de regulação de tensão em redes de distribuição, além do fato de que o uso dessas novas 
técnicas no controle de tensão se destaca principalmente pela capacidade de se resolver esses problemas com grande eficiência, como mostrado na literatura correlata da seção anterior.

Considerando esses aspectos relacionados ao controle de tensão, é apresentada uma nova metodologia para relés reguladores de tensão baseados na técnica de sistemas inteligentes denominado Sistemas Fuzzy. Maiores detalhes sobre a teoria de Sistemas Fuzzy são apresentados no Apêndice A.

A escolha dessa técnica foi decisiva pela identificação de características qualitativas nas grandezas disponíveis (tensão, corrente, posição de tap, potência, etc.) na subestação, além do fato de o problema apresentar outras peculiaridades como a sua não-linearidade, dificuldade de mapeamento dessas grandezas e variação dinâmica.

Diante das análises dos dados históricos de regulação de tensão e curvas de carga reais, observou-se características como: "carga pesada", "carga média", “carga leve”, "carga mínima", "desvio de tensão positiva grande”, “desvio de tensão negativa grande” entre outras. Tendo isso em vista, propõe-se um relé regulador de tensão adaptativo que irá atuar diretamente no tap utilizando o critério de correlação entre a tensão e a curva de carga para tomada de decisão quanto à regulação de tensão. Tal relé deve avaliar também condições de manobra, evolução de cargas, sazonalidade e topologia da rede.

As decisões de operação de comutação de tap para essa estratégia dependem do monitoramento das variáveis de entrada, Potência Ativa e Desvio da Tensão. Um sistema Fuzzy foi confeccionado para representar a base de conhecimento do relé regulador de tensão, levando-se em consideração o monitoramento dessas duas variáveis citadas. Para uma melhor compreensão da estratégia, na Figura 4.1 encontra-se representado de forma simplificada o relé regulador de tensão baseado em sistemas Fuzzy: 


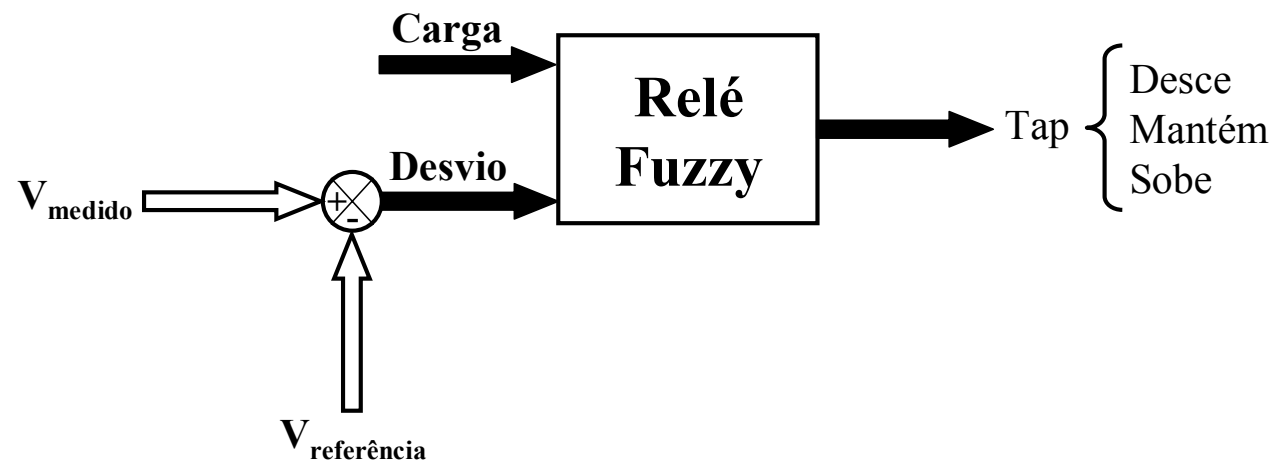

Figura 4.1 - Diagrama esquemático simplificado do relé inteligente referente à estratégia I.

O sistema inteligente da Figura 4.1 atua diretamente sobre o derivador de tap, enviando sinais para elevar ou abaixar a tensão. A tomada de decisão deve manter a tensão no ponto de entrega dos consumidores em conformidade com a Resolução $n^{\circ}$ 505/2001 da ANEEL.

O monitoramento da Potência Ativa, juntamente com a tensão, permite atender aos objetivos previamente estabelecidos neste projeto, ou seja, propiciar perfis de tensão mais elevados no barramento secundário da subestação em situações de carga média e pesada.

Já em condições de carga mínima e leve, o principal objetivo é otimizar o número de comutações de tap, mantendo também os níveis de tensão em conformidade com a Resolução $n^{\circ} 505 / 2001$ da ANEEL.

Desta forma, busca-se uma racionalização do uso do comutador de tap. Em condições de carga Média/Pesada, para manter a tensão em níveis mais elevados, um maior número de comutações será necessário, ao passo que em condições de carga Mínima/Leve, o número de comutações de tap será otimizado.

Este tipo de flexibilidade é possível devido à capacidade dos Sistemas Fuzzy se adaptarem automaticamente às mudanças que venham a ocorrer na demanda de carga do sistema elétrico, quer sejam elas decorrentes das oscilações normais ao longo do tempo, quer 
advenham das alterações na configuração do sistema como, por exemplo, de manobras ou da expansão do sistema elétrico.

Com isso, evita-se que a ocorrência de eventos imprevistos na rede, como o isolamento de um trecho, tenha como conseqüência o fornecimento de tensão acima ou abaixo dos limites para cargas consumidoras e o uso desordenado do comutador de tap. Essa característica adaptativa do relé inteligente se mostra capaz de atuar em qualquer subestação de distribuição de energia, além de otimizar o tempo de estudos elétricos para definição de ajustes, se comparado ao relé convencional.

A escolha da técnica de sistemas Fuzzy se deve aos inúmeros benefícios fundamentados na velocidade de cálculo de respostas para o problema, na capacidade de inter-relacionar as diversas entradas do processo com as saídas desejadas, na fundamentação da decisão a partir de bases de conhecimento, na segurança, na estabilidade, na flexibilidade, na tolerância à falhas e na facilidade de integração com outras ferramentas numéricas e computacionais.

As variáveis de entrada (Figura 4.1) são processadas pelo relé inteligente de forma que os resultados das saídas possam ser inferidos pelo mesmo. As entradas foram definidas como a potência ativa normalizada para valores entre 0.5 e 1.5 e o desvio da tensão dado em p.u.

A normalização da potência ativa foi feita em relação a um valor médio, por meio de estudos baseados em dados históricos. Desta forma, para o funcionamento desta estratégia é necessário o ajuste deste valor de potência média, objetivando que o Sistema Fuzzy possa se adaptar a qualquer subestação. Este valor de ajuste pode ser parametrizado diretamente pelo usuário ou obtido através de um módulo que seja capaz de calcular a potência média com base em dados históricos. 
A outra entrada é o desvio da tensão em relação a uma tensão de referência, calculada como se segue:

Desvio $=\frac{V_{\text {medido }}-V_{\text {referência }}}{V_{\text {referência }}}$

$V_{\text {medido }}$ é a magnitude da tensão de fase medida pelo TP.

$V_{\text {referência }}$ é a tensão de referência do sistema.

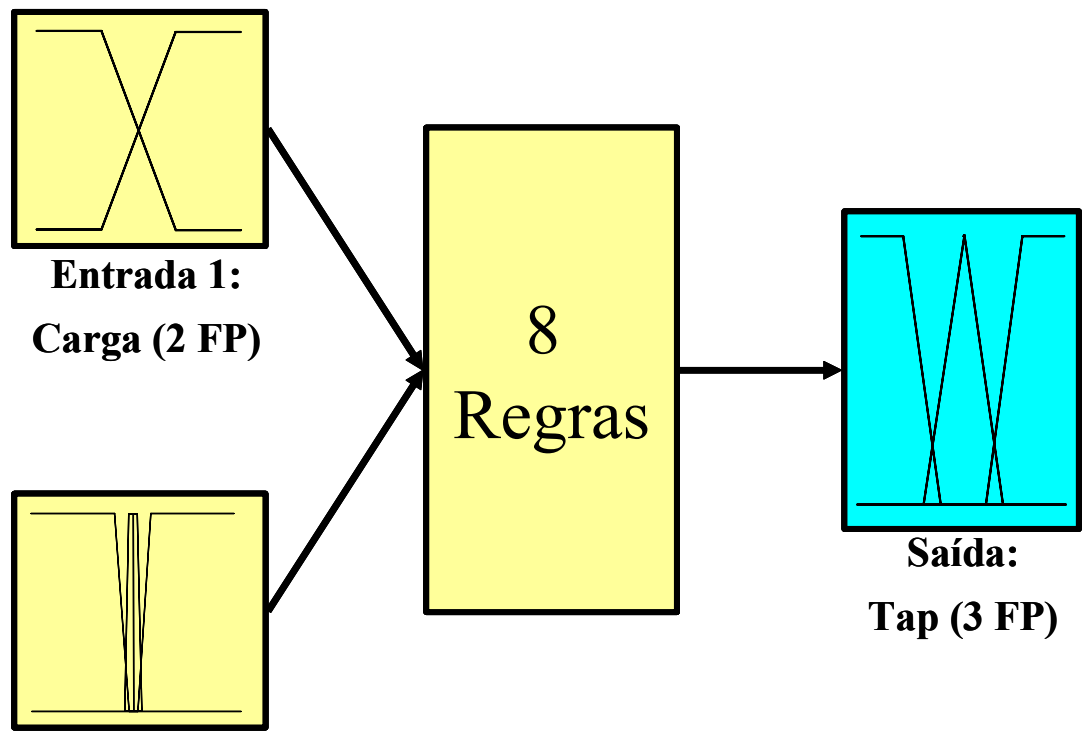

Entrada 2:

Desvio (4 FP)

Figura 4.2 - Topologia do Sistema Fuzzy utilizado.

Como pode ser observado na Figura 4.1 e na Figura 4.2, as variáveis Carga (Potência Ativa) e Desvio entre a tensão medida e a referência foram utilizadas como entrada do sistema de controle Fuzzy. A variável de entrada Carga foi representada em seu universo de discurso através de duas funções de pertinência (FP), como mostra a Figura 4.3. 
A entrada da potência ativa foi modelada com apenas duas funções de pertinência, pois se deseja que o comportamento do sistema Fuzzy consiga distinguir duas situações básicas: em carga Mínima/Leve, deve-se preservar a comutação de tap; em carga Média/Pesada, deve-se manter a tensão mais elevada, sempre levando em consideração os limites impostos pela Resolução nº 505/2001 da ANEEL.

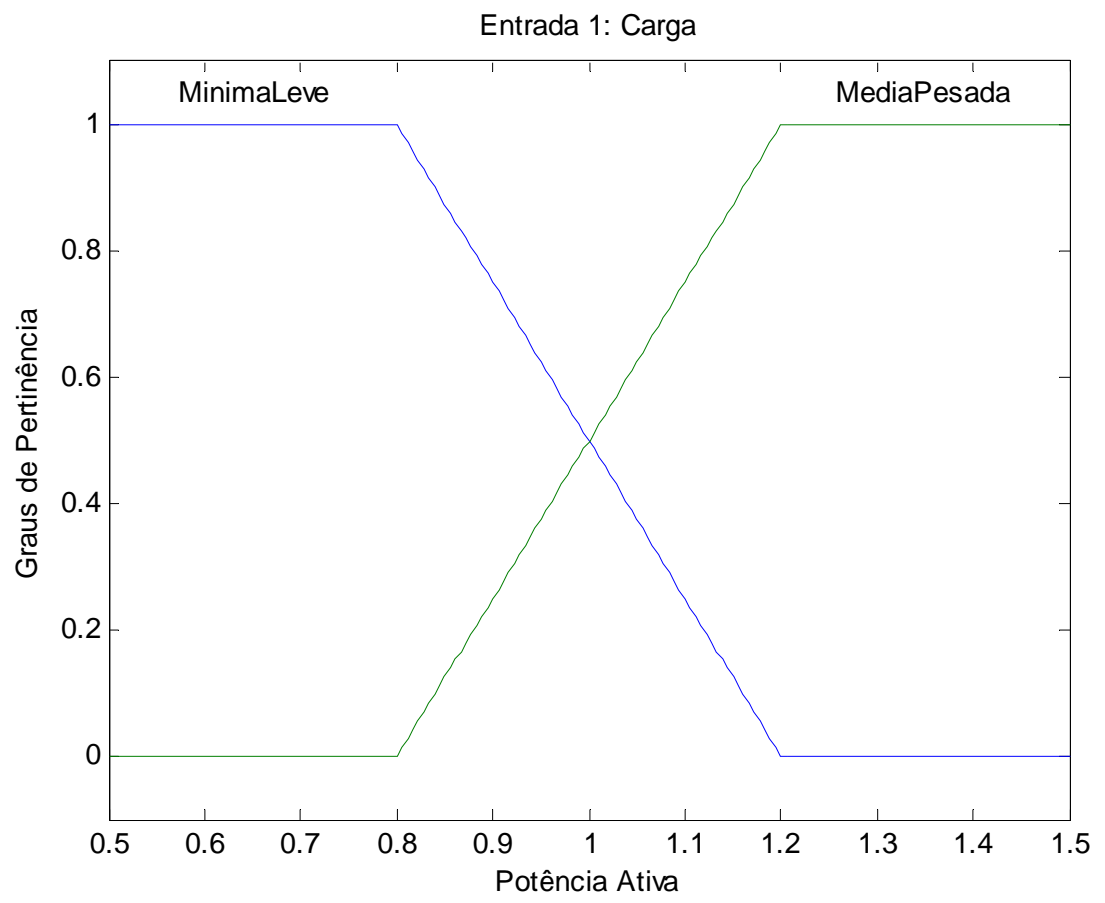

Figura 4.3 - Entrada 1 do Sistema Fuzzy.

Pode-se observar também na Figura 4.3 que todos os valores de potência vindos da medição são normalizados em torno de um valor médio. Assim, quanto mais próximo da média histórica de carga da subestação estiver um valor de medição, mais próximo de 1 estará o valor normalizado.

Devido à excelente capacidade de interpretar regiões de fronteiras que os Sistemas Fuzzy possuem, uma grande região de indecisão entre as situações de carga Mínima/Leve e 
Média/Pesada foi implementada, Figura 4.3, pois dessa forma haverá maiores contribuições das regras ativas para a composição da saída.

A outra variável de entrada foi representada em todo o seu universo de discurso através de quatro funções de pertinência (FP), como mostra a Figura 4.4. Os termos utilizados para essa variável lingüística foram: "Negativo Grande", "DI (Desvio Inferior)”, "DS (Desvio Superior)" e "Positivo Grande".

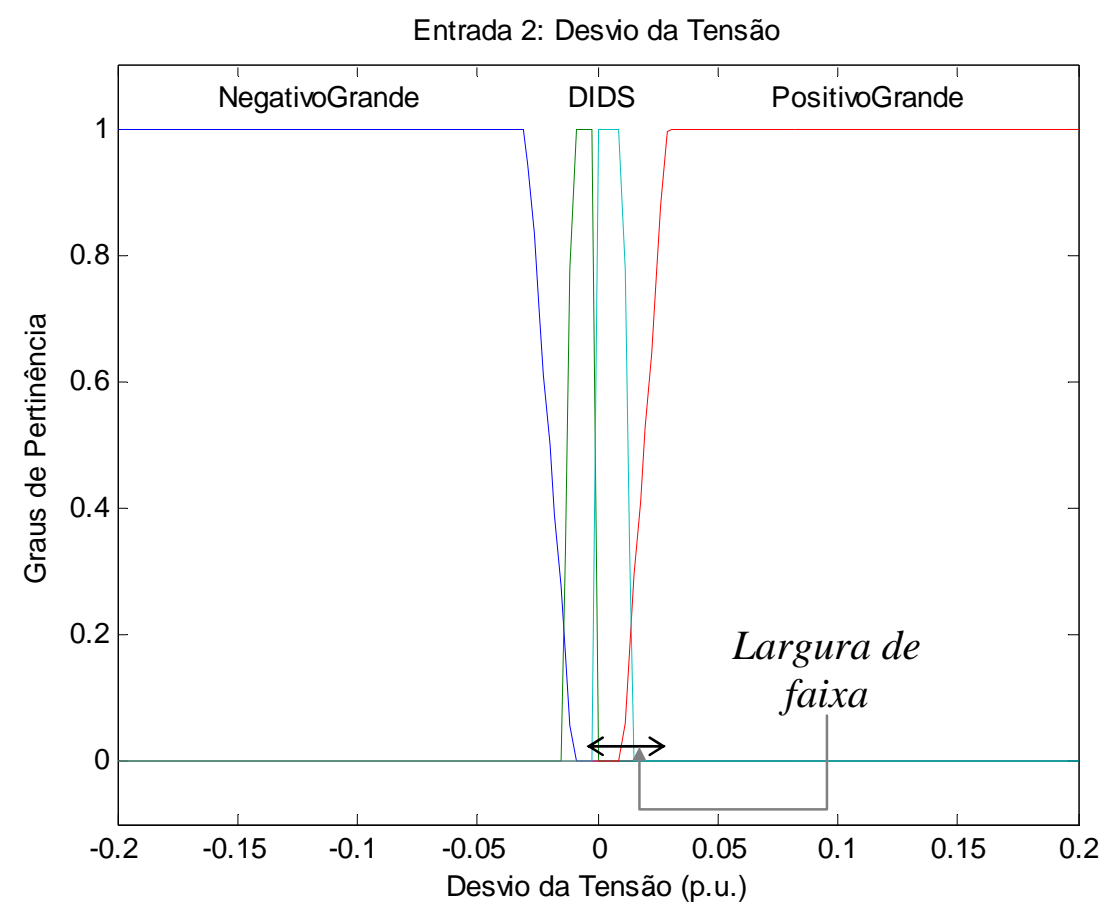

Figura 4.4 - Entrada 2 do Sistema Fuzzy.

As faixas de desvios compreendidas por "DI" e "DS" foram criadas como faixas adicionais do desvio da tensão, porém abrange a largura de faixa operativa como mostra a Figura 4.5. Essa medida foi tomada para poder implementar maiores níveis de tensão em carga Média/Pesada e menores comutações de tap em carga Mínima/Leve. 


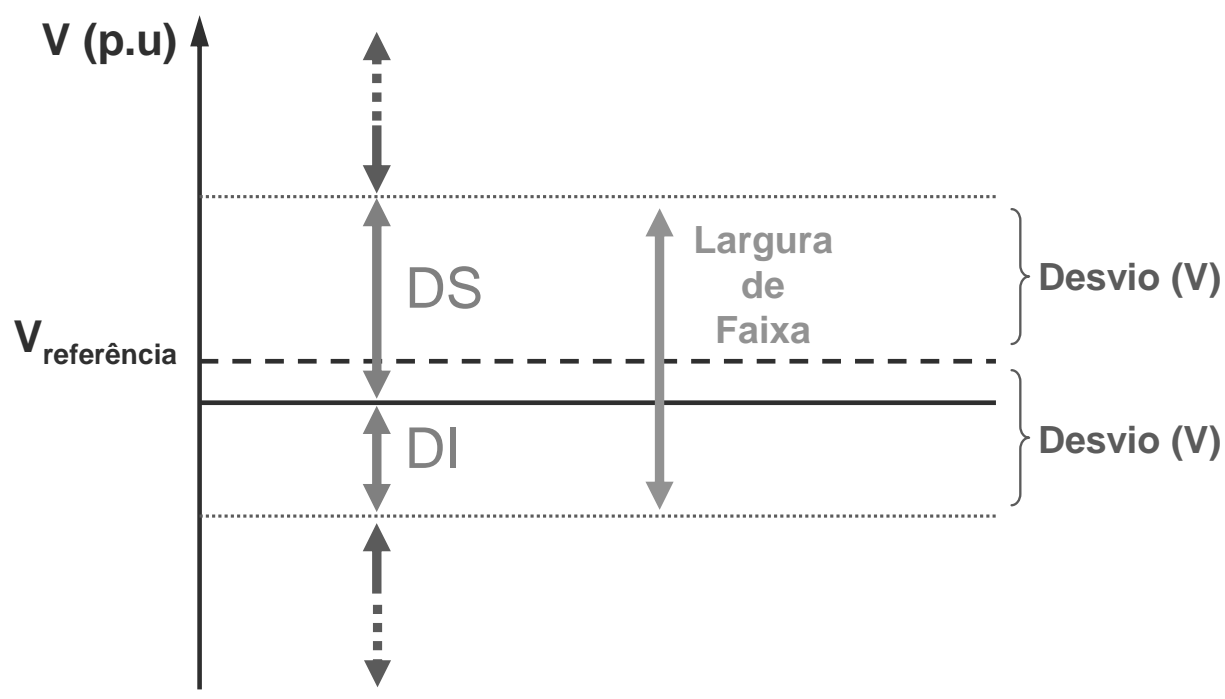

Figura 4.5 - Faixas de desvios de tensão do modelo Fuzzy.

A Largura de faixa de atuação do relé Fuzzy é definida por meio dos pontos de cruzamento das funções de pertinência "DI" e "DS" com "NegativoGrande" e "PositivoGrande", respectivamente. O ponto comum entre "DS" e "PositivoGrande" indica o limite superior da faixa, enquanto que o ponto comum entre "NegativoGrande" e "DI" indica o limite inferior da faixa. Os desvios "DS" e "DI" estão em conformidade com a Resolução no 505/2001 da ANEEL.

A variável lingüística de saída, ou seja, a variável Tap, foi mapeada por meio de três funções de pertinência: "sobe", "desce" e "mantém". O termo "sobe" representa comutar o tap de forma a elevar a tensão. O termo "desce" indica uma operação de comutação de tap para abaixar a tensão. E o termo "mantém" aponta que a posição do tap não deve ser alterada. A Figura 4.6 mostra as funções de pertinência da variável de saída do sistema Fuzzy modelado. 


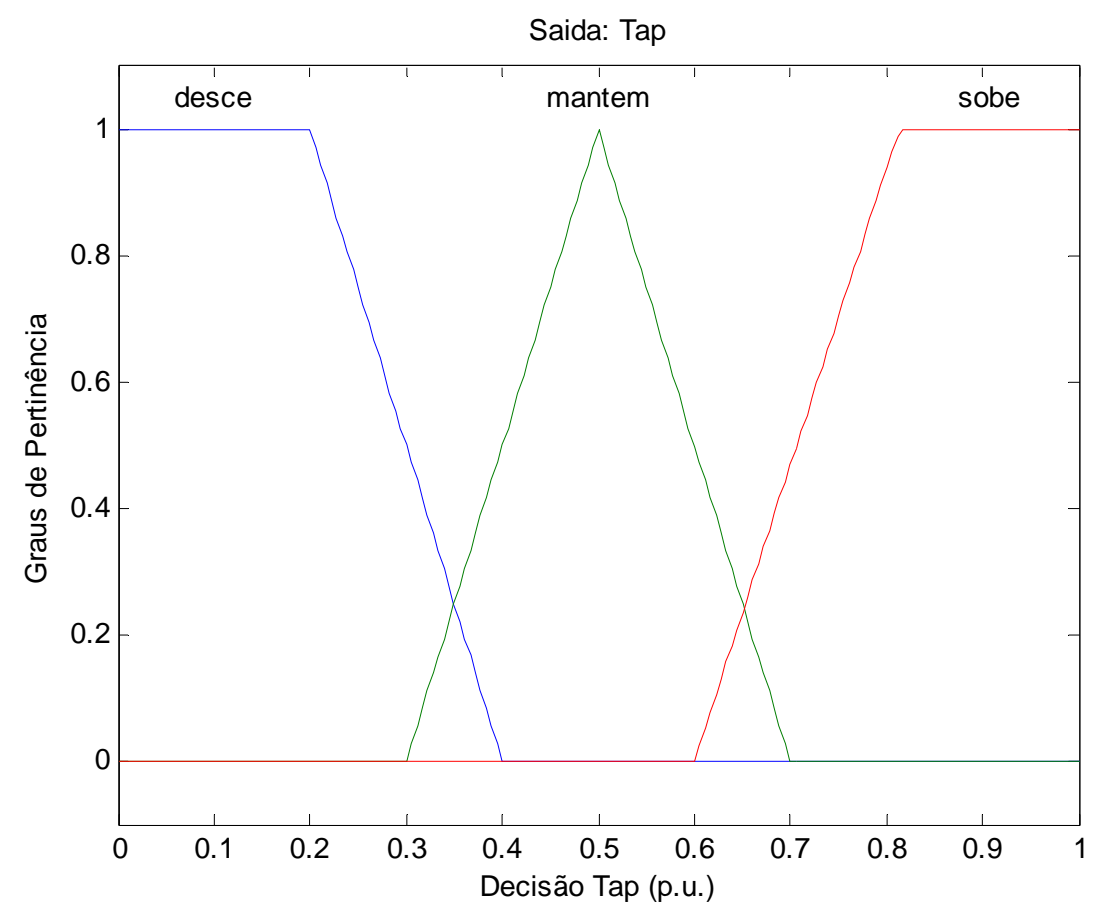

Figura 4.6 - Saída do Sistema Fuzzy.

Para esta estratégia, o sistema Fuzzy atua como um classificador de padrões, assim deve-se interpretar a saída para inferir uma ação de comutação de tap, como é mostrado na Tabela 4.1.

Tabela 4.1 - Interpretação da Saída Fuzzy.

\begin{tabular}{|c|c|}
\hline Tap & Saída do Sistema Fuzzy (S) \\
\hline desce & $\mathbf{0} \leq \mathbf{S}<\mathbf{0 . 3 5}$ \\
\hline mantém & $\mathbf{0 . 3 5} \leq \mathbf{S} \leq \mathbf{0 . 6 5}$ \\
\hline sobe & $\mathbf{0 . 6 5}<\mathbf{S} \leq \mathbf{1 . 0}$ \\
\hline
\end{tabular}

A base de conhecimento do sistema proposto encontra-se armazenada nas regras Fuzzy do tipo “Se-Então”. A seguir encontram-se representadas estas regras Fuzzy.

1 - “Se Desvio é Negativo Grande e Carga é Mínima/Leve, então o Tap sobe” 2 - “Se Desvio é Negativo Grande e Carga é Média/Pesada, então o Tap sobe’ 
3 - "Se Desvio é DS e Carga é Mínima/Leve, então o Tap mantém"

4 - "Se Desvio é DS e Carga é Média/Pesada, então o Tap mantém"

5 - "Se Desvio é DI e Carga é Mínima/Leve, então o Tap mantém"

6 - "Se Desvio é DI e Carga é Média/Pesada, então o Tap sobe"

7 - "Se Desvio é Positivo Grande e Carga é Mínima/Leve, então o Tap desce”

8 - "Se Desvio é Positivo Grande e Carga é Média/Pesada, então o Tap desce"

As regras 3 e 5 são responsáveis por diminuir o número de comutações de tap em situações de carga Mínima e Leve. A regra 6 é a responsável por manter a tensão em carga Média e Pesada em níveis mais elevados. A regra 4 é responsável por não se realizar comutações prematuras em carga Média/Pesada. As demais regras são responsáveis por manter a tensão dentro dos limites estabelecidos pela Resolução n ${ }^{0}$ 505/2001 da ANEEL.

Uma maneira mais simplificada de se estudar as regras Fuzzy é através da representação por tabela, que permite a visualização do fluxo de ação do sistema, como representado na Tabela 4.2.

Tabela 4.2 - Regras Fuzzy.

\begin{tabular}{|c|c|c|c|c|}
\hline \multirow{2}{*}{$\begin{array}{c}\text { Carga } \\
\text { (Potência Ativa) }\end{array}$} & \multicolumn{3}{|c|}{ Desvio da Tensão } \\
\cline { 2 - 5 } & $\begin{array}{c}\text { Negativo } \\
\text { Grande }\end{array}$ & DI & DS & $\begin{array}{c}\text { Positivo } \\
\text { Grande }\end{array}$ \\
\hline Mínima/Leve & Sobe & Mantém & Mantém & Desce \\
\hline Média/Pesada & Sobe & Sobe & Mantém & Desce \\
\hline
\end{tabular}

As regras representam o inter-relacionamento entre as entradas e a saída do sistema modelado. São por meio delas que são inferidas respostas do sistema de controle de tensão. 
Tais regras contêm todo o conhecimento especialista da operação do relé regulador de tensão e são definidas pela utilização do critério de correlação entre a tensão (tap) e a curva de carga (potência ativa) para determinação da posição de tap apropriado baseado no histórico e na avaliação das condições específicas de manobra, evolução de cargas e topologia da rede. Essa correlação entre as entradas e a saída do sistema pode ser melhor compreendida através da superfície de relacionamento entrada/saída Fuzzy pela Figura 4.7:

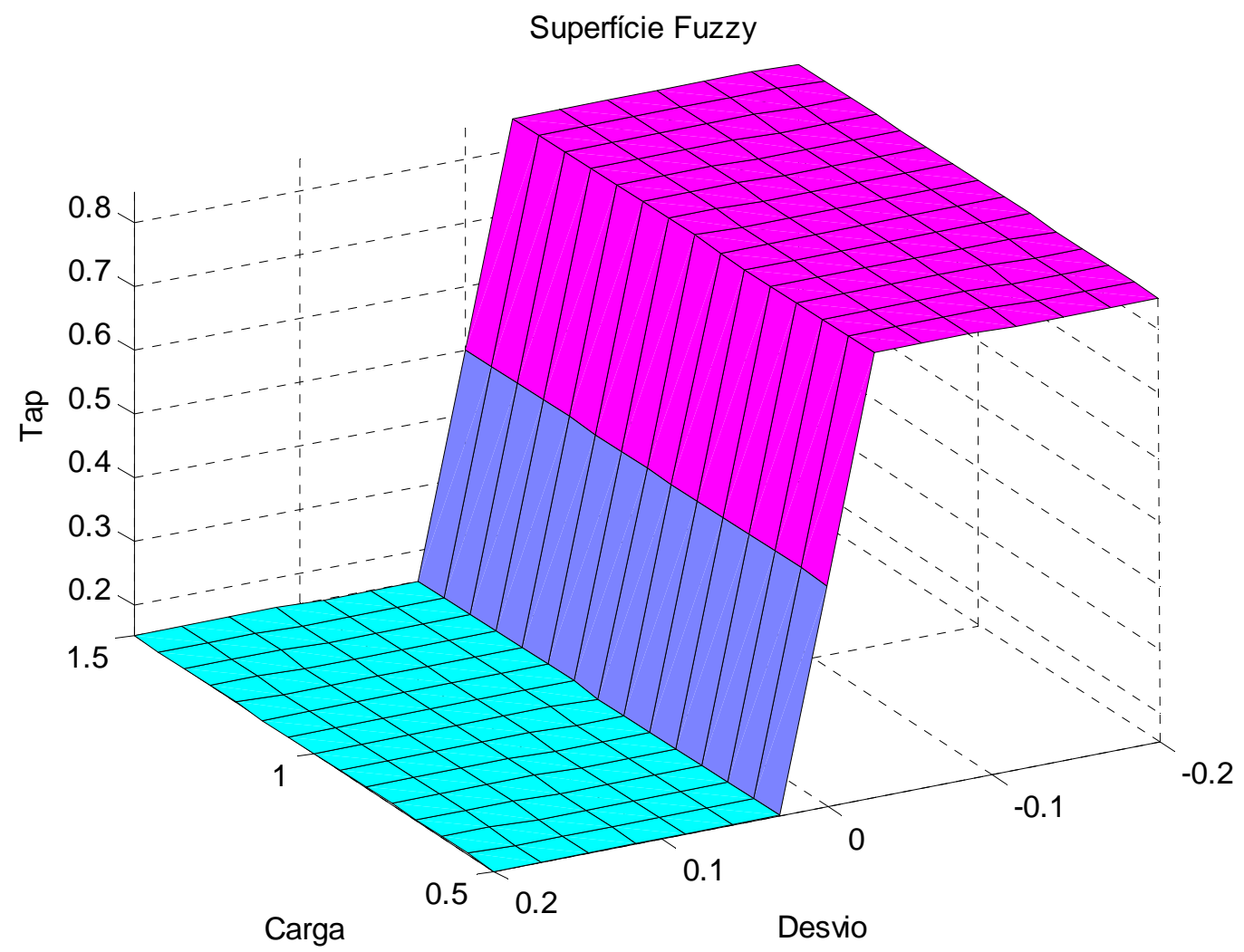

Figura 4.7 - Superfície de correlação entre as entradas e saídas do sistema modelado.

Maiores detalhes sobre a teoria de Sistemas Fuzzy utilizada nesse trabalho podem ser vistos no apêndice A.

Com a aplicação de sistemas Fuzzy, espera-se a redução das perdas de potência, o melhoramento do perfil de tensão, o aumento nas vendas de energia e a racionalização do número de comutações de tap. Esses objetivos devem ser alcançados para se comprovar a 
eficiência da metodologia proposta nessa estratégia. Na seção posterior, serão apresentados resultados de teste. 



\section{UM SISTEMA FUZZY PARA CONTROLE DE TENSÃO}

Esse capítulo apresenta os principais aspectos sobre as simulações computacionais, os algoritmos utilizados, os resultados e as análises pertinentes ao sistema proposto.

\subsection{Simulações Computacionais}

A fase de simulação computacional foi realizada em duas etapas. A primeira etapa consistiu em simular a atuação do relé regulador de tensão no Simulink/Matlab, realizando-se aprimoramentos no sistema inteligente proposto com o monitoramento de todo o processo de simulação, por meio da interface gráfica do Simulink. O custo computacional do uso do Simulink é elevado, levando a um tempo de processamento grande.

Na segunda etapa, o processo de simulação foi implementado por meio de rotinas do Matlab, reduzindo-se o esforço computacional, pois estas não utilizam à interface gráfica do Simulink. Essa mudança foi necessária devido ao elevado tempo de simulação do ambiente Simulink. Maiores detalhes serão apresentados posteriormente.

Para as duas etapas, o processo de simulação foi realizado por meio de três blocos:

- Bloco 1: Dados Históricos de Potência Ativa e Reativa - representa dados históricos reais de medição realizados em subestações de distribuição durante uma semana. 
- Bloco 2: Fluxo de Carga Simplificado - esse fluxo utiliza método simplificado de cálculo para se determinar a tensão no barramento secundário da subestação por meio de valores de potência ativa e reativa.

- Bloco 3: Relé Regulador de Tensão - simula a operação do relé regulador de tensão de transformadores de subestações de distribuição de energia elétrica.

As simulações computacionais foram realizadas para dois modelos de relés reguladores de tensão, sendo um Fuzzy e o outro, convencional. Os algoritmos dos relés são apresentados no subitem 5.1.2.

Na Figura 5.1 e Figura 5.2 encontram-se os modelos simplificados de simulação para o relé convencional e fuzzy, respectivamente.

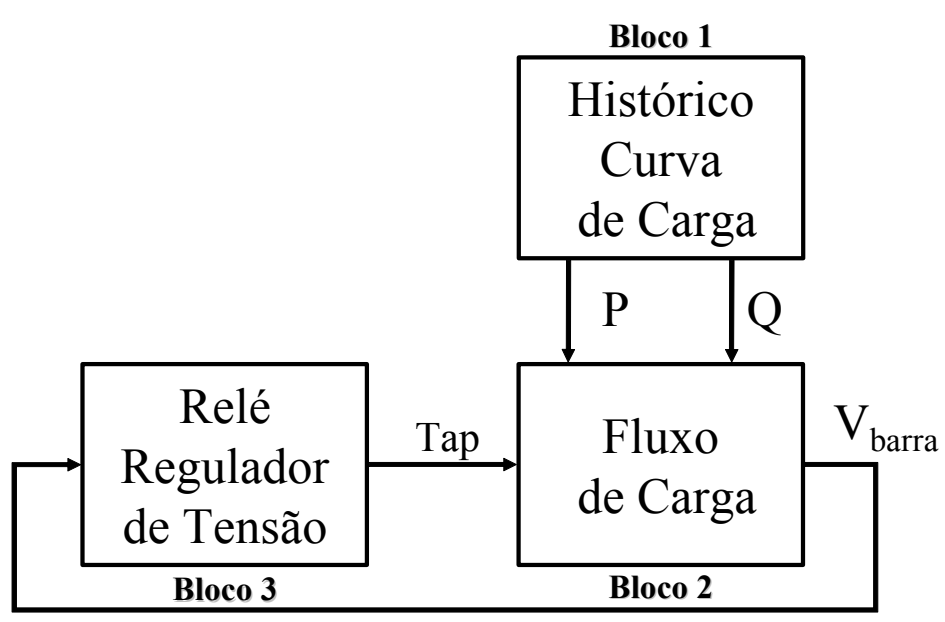

Figura 5.1 - Modelo simplificado de simulação para o relé convencional. 


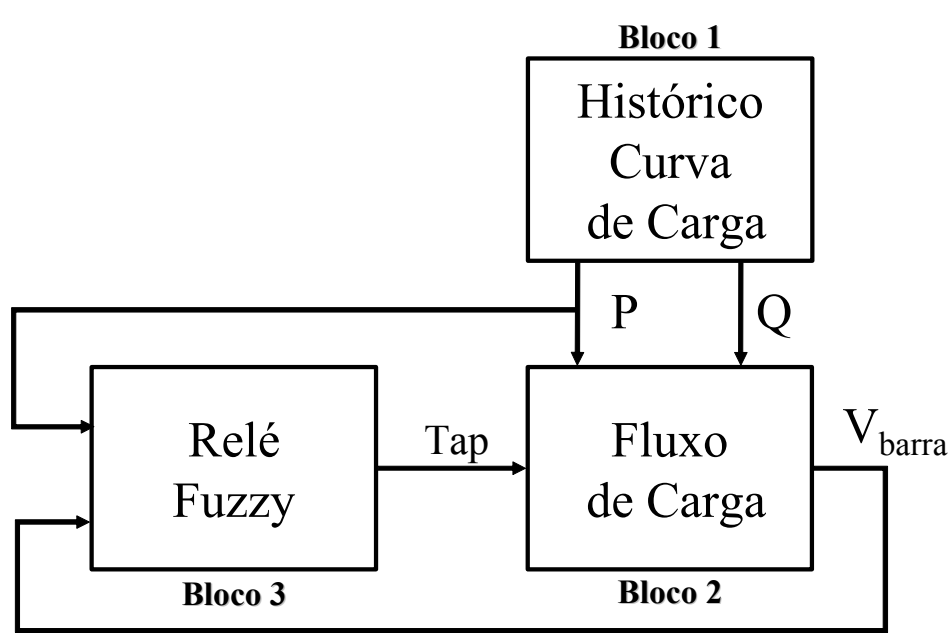

Figura 5.2 - Modelo simplificado de simulação para o relé fuzzy.

A partir de curvas de carga, realizou-se um fluxo de carga simplificado para determinar-se a tensão na subestação referente a cada valor de potência ativa e reativa fornecidos. Este valor de tensão na subestação é apresentado ao relé regulador que, por sua vez, realiza suas operações matemáticas para comutar ou não o tap do transformador. Os novos valores de tensão obtidos das comutações de tap realimentam o fluxo de carga simplificado, que passa a conter dados dinâmicos de tensão.

A utilização do fluxo de carga simplificado foi necessária para se estimar a tensão na subestação e realizar uma simulação dinâmica eficiente, pois o objetivo é apenas atuar na regulação de tensão pela subestação. A modelagem completa das subestações, incluindo-se todos os dados dos alimentadores, deixaria o modelo de simulação muito complexo. Utilizando-se dados reais de potência ativa e reativa em função do tempo medido na subestação, foi possível realizar simulações eficientes e rápidas.

Os modelos de simulação foram aplicados nas duas etapas de simulação. Na Figura 5.3 é apresentada o modelo referente à primeira etapa para o relé convencional: 


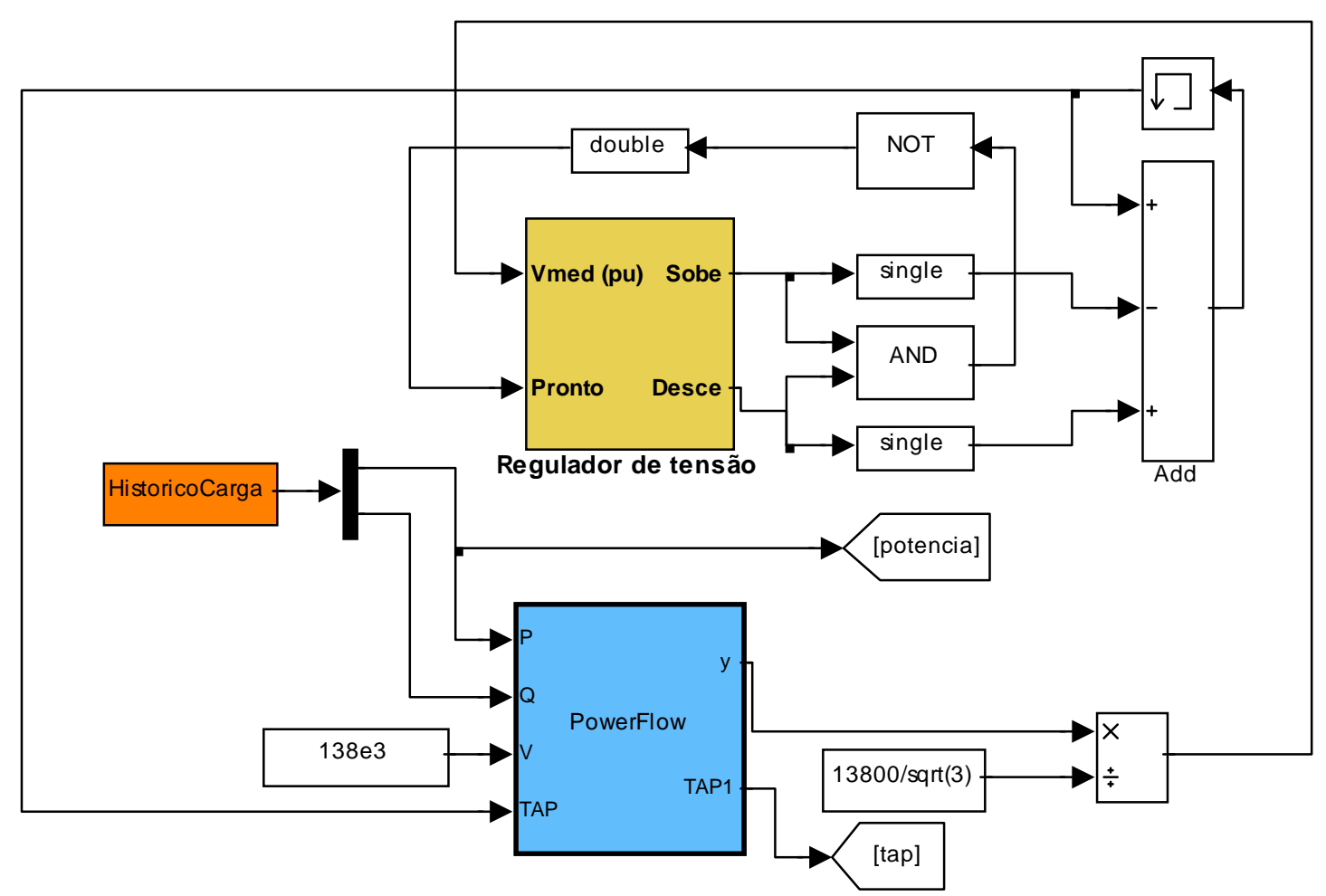

Figura 5.3 - Esquema de simulação convencional implementado no Simulink/Matlab.

A Figura 5.3 mostra o esquema de simulação para o relé convencional implementado no Simulink/Matlab. O bloco destacado na cor amarela (bloco 3) simula a atuação do relé regulador de tensão, o laranja (bloco 1) representa o histórico de carga e o azul (bloco 2), o fluxo de carga simplificado. Os outros blocos são da biblioteca do Simulink e representam monitoração das variáveis envolvidas, blocos lógicos e valores constantes de ajuste para a simulação.

A simulação para o relé convencional pode ser entendida por meio de três etapas:

1. O bloco histórico de carga representa valores de Potência Ativa e Reativa referentes a uma semana de medição. Uma medição de Potência Ativa e Reativa é apresentada para o bloco de fluxo de carga simplificado. 
2. O bloco de fluxo de carga estima o valor de tensão na barra secundária da subestação.

3. Esse valor de tensão é apresentado ao relé regulador de tensão que atuará no comutador de tap do transformador da subestação de distribuição.

A Figura 5.4 mostra o esquema de simulação para o relé Fuzzy implementado no

\section{Simulink/Matlab.}

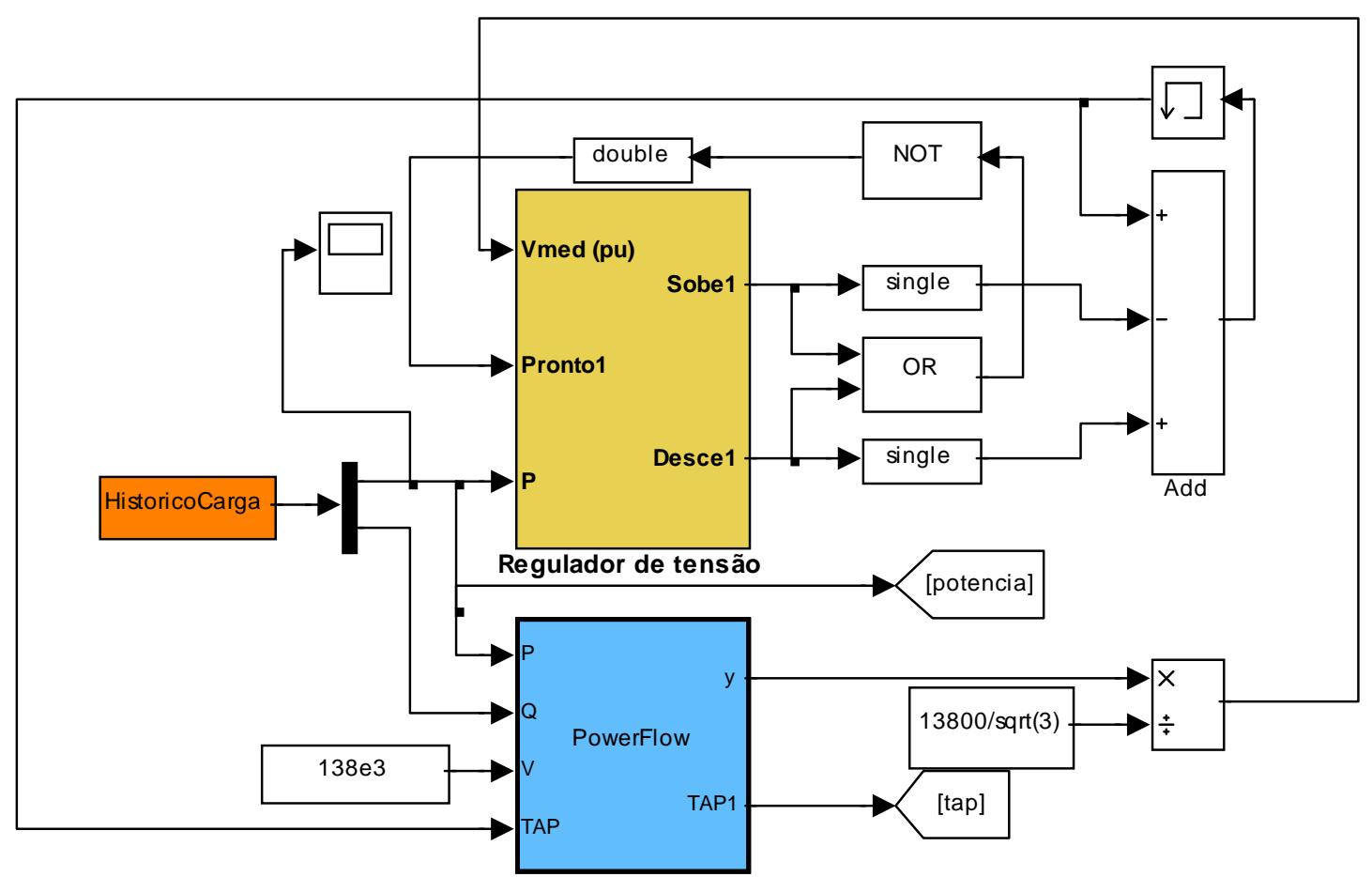

Figura 5.4 - Esquema de simulação fuzzy implementado no Simulink/Matlab.

O bloco destacado na cor amarela (bloco 3) simula a atuação do relé fuzzy,o laranja (bloco 1) representa o histórico de carga e o azul (bloco 2), o fluxo de carga simplificado.

A simulação para o relé convencional pode ser entendida por meio de três etapas: 
1. O bloco histórico de carga representa valores de Potência Ativa e Reativa referentes a uma semana de medição. Uma medição de Potência Ativa e Reativa é apresentada para o bloco de fluxo de carga simplificado.

2. O bloco de fluxo de carga estima o valor de tensão na barra secundária da subestação.

3. Esse valor de tensão juntamente com a medição de Potência Ativa é apresentado ao relé inteligente que irá definir a melhor regulação de tensão por meio de atuação no comutador de tap do transformador da subestação de distribuição.

Para a segunda etapa, as simulações foram realizadas por rotinas implementadas no Matlab. O processo de simulação é o mesmo do Simulink diferindo apenas na ausência da interface gráfica. Os resultados que serão apresentados no subitem 5.2 foram gerados pelo processo de simulação da segunda etapa já que a primeira serviu apenas de subsídio para a confecção do modelo de simulação implementado na segunda.

\subsubsection{Sistema de Distribuição Estudado}

Os dados históricos de potência ativa e reativa utilizados na simulação são valores reais de operação e foram fornecidos pela empresa ELEKTRO, que é uma concessionária de distribuição de energia elétrica com sede em Campinas. Os dados referem-se a históricos de curva de carga, das subestações (SE's) de Andradina (Transformador 1), de Cordeirópolis (Transformador 2) e de Mogi Guaçu 2 (Transformador 1). As medições e os dados dos transformadores relativos a essas subestações foram fornecidos pela empresa 
ELEKTRO/Campinas-SP. Esses dados de históricos de carga e dos transformadores utilizados no fluxo de carga são apresentados nos Apêndices B e C, respectivamente.

Essas três subestações foram escolhidas pelo critério de característica de carga. A SE Andradina TR 1 possui consumidores rurais em sua maioria. A SE Cordeirópolis TR 2 alimenta cargas com predominância industrial e a SE Mogi-Guaçu 2 TR 1 distribui energia elétrica a cargas em sua maior parte residenciais e industriais. Essa última SE tem uma característica de carga diferente, pois supre apenas uma parte dos consumidores do município. A outra parte fica responsável pela Usina Hidrelétrica de Mogi-Guaçu.

Com relação ao histórico das curvas de carga, esses dados medidos compreendem um período total de uma semana, entre os dias 19/06/2006 a 26/06/2006. Tal histórico contém medições de potência ativa e reativa tomadas em intervalos de 10 minutos.

Para uma melhor caracterização das simulações, foi necessário um intervalo de tempo de 1 segundo entre as medições, isso porque os registradores de tempo de atuação do relé trabalham com valores em segundos. Desta forma, utilizou-se um método numérico de interpolação linear para transformar as medições originais, com intervalo de medição de 10 minutos em dados discretizados segundo a segundo. A cada um ponto original de medição real foram acrescentados 600 pontos (10 minutos, de 1 em 1 segundo) com comportamento linear. Após este processo, as informações de potência ativa e reativa foram aplicadas nas simulações.

Como conseqüência deste procedimento, espera-se um número de comutações menor que os registrados pelos dispositivos da concessionária, tanto para as simulações convencionais quanto para a fuzzy, uma vez que a reamostragem irá substituir o comportamento desconhecido para os 10 minutos entre cada ponto original por pontos espaçados linearmente e com intervalo de um segundo. 


\subsubsection{Algoritmos dos Relés Reguladores de Tensão Implementados}

Como descrito no item 5.1, dois algoritmos foram implementados: um simulando a atuação do relé fuzzy e outro do relé convencional. O fluxograma do algoritmo do relé convencional implementado o qual simula o controle de tensão através de comutação de tap em um sistema de distribuição é apresentado a seguir:

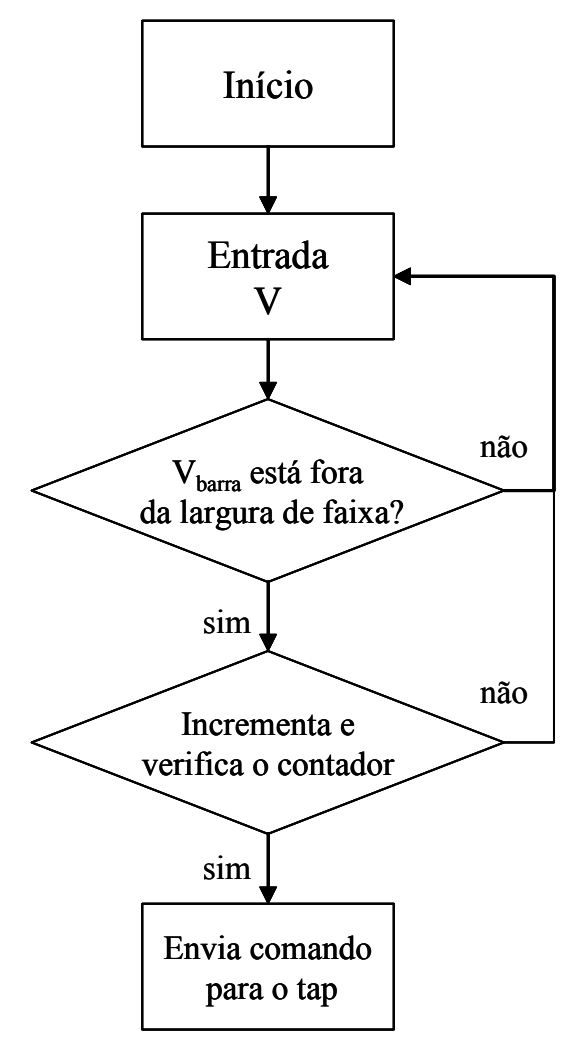

Figura 5.5 - Algoritmo do relé convencional.

Como mostra o fluxograma da Figura 5.5, um valor de tensão proveniente de uma medição na barra secundária da subestação de distribuição é apresentado para o relé convencional, que verifica se esse valor de tensão está dentro da largura de faixa operativa. Caso não esteja, o algoritmo retorna ao seu início e o contador é reiniciado. Caso contrário, o 
relé requisita uma outra medição de tensão e incrementa o contador, que é o responsável por verificar a persistência da tensão fora dos limites operativos. Se ele atingir um determinado valor, um sinal é enviado ao comutador de tap para abaixá-lo ou elevá-lo de acordo com a situação analisada. Esse valor limite do contador representa a temporização do relé para a atuação no comutador de tap.

O fluxo de execução do algoritmo referente ao relé adaptativo é apresentado no que segue:

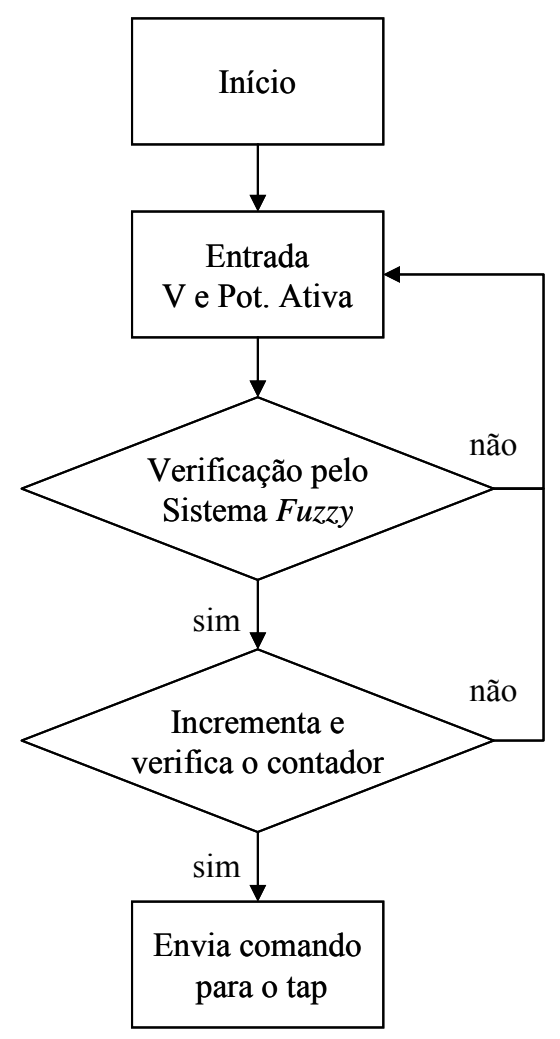

Figura 5.6 -Algoritmo do relé Fuzzy.

O fluxo de execução apresentado na Figura 5.6 se assemelha com o algoritmo do relé convencional tendo como principal diferença a Carga como variável de entrada. Um valor de potência ativa e um de tensão, provenientes de medições na subestação de distribuição, são 
apresentados ao relé Fuzzy. O sistema Fuzzy verifica quais regras estão ativas e infere um valor de saída indicando se há a necessidade de manter ou comutar o tap.

O contador é incrementado da mesma forma que no relé convencional, ou seja, o sistema Fuzzy tem que indicar consecutivamente um determinado número de vezes a mesma resposta de saída. Quando esse determinado valor (temporização ou tempo morto) é atingido, um sinal é enviado ao comutador de tap. É importante lembrar que o contador é incrementado apenas para situações em que haja necessidade de se atuar no tap, portanto toda vez que o sistema Fuzzy apontar para a manutenção do tap, o contador é reiniciado.

\subsubsection{Condições de Simulação}

Como a estratégia proposta utiliza Sistemas Fuzzy, o Universo de Discurso das funções de pertinência devem se ajustar de maneira adequada a todas as subestações simuladas, necessitando-se de uma normalização dos dados, como já foi descrito anteriormente. A entrada de potência ativa é normalizada em relação à potência ativa média associada à subestação, sendo que a entrada de desvio de tensão é normalizada em relação à tensão de referência utilizada para simulação. Na Tabela 5.1, encontram-se representadas as potências médias associadas a cada uma das subestações simuladas.

Tabela 5.1 - Potência ativa média associada às subestações testadas.

\begin{tabular}{|c|c|}
\hline Subestação & $\begin{array}{c}\text { Potência Ativa Média } \\
\text { (MW) }\end{array}$ \\
\hline $\begin{array}{c}\text { Andradina } \\
\text { (Transformador 1) }\end{array}$ & 9,893 \\
\hline $\begin{array}{c}\text { Cordeirópolis } \\
\text { (Transformador 2) }\end{array}$ & 12,956 \\
\hline $\begin{array}{c}\text { Mogi-Guaçu 2 } \\
\text { (Transformador 1) }\end{array}$ & 2,660 \\
\hline
\end{tabular}


As simulações envolvidas com a estratégia fuzzy e a convencional foram realizadas para um período de sete dias, com todas as subestações mostradas na Tabela 5.1. A tensão de referência adotada para as simulações foi de $14,1 \mathrm{kV}$, com desvio de tensão de $\pm 1 \%$ em relação ao mesmo valor de tensão de referência e temporização para comutação de 90 segundos. O valor da tensão primária do transformador foi $138 \mathrm{kV}$.

Para esses parâmetros de ajuste (tensão de referência, largura de faixa e temporização) foram considerados valores práticos de operação. Tais valores também foram fornecidos pela empresa ELEKTRO.

Os parâmetros variam segundo o comportamento da carga, portanto outras considerações foram estudadas e serão apresentadas posteriormente.

\subsection{Resultados computacionais referentes ao controle adaptativo do tap}

Nesta seção são apresentados os resultados computacionais obtidos das simulações, realizando-se o controle de tensão nas subestações mencionadas.

\subsubsection{Subestação Andradina (Transformador 1)}

$\mathrm{Na}$ Figura 5.7, encontra-se registrado o histórico de comutações associado à simulação do relé fuzzy (adaptativo) para a subestação Andradina Trafo 1. Nesta mesma figura também é possível se comparar o histórico de comutações para a mesma simulação, utilizando-se o relé convencional. 

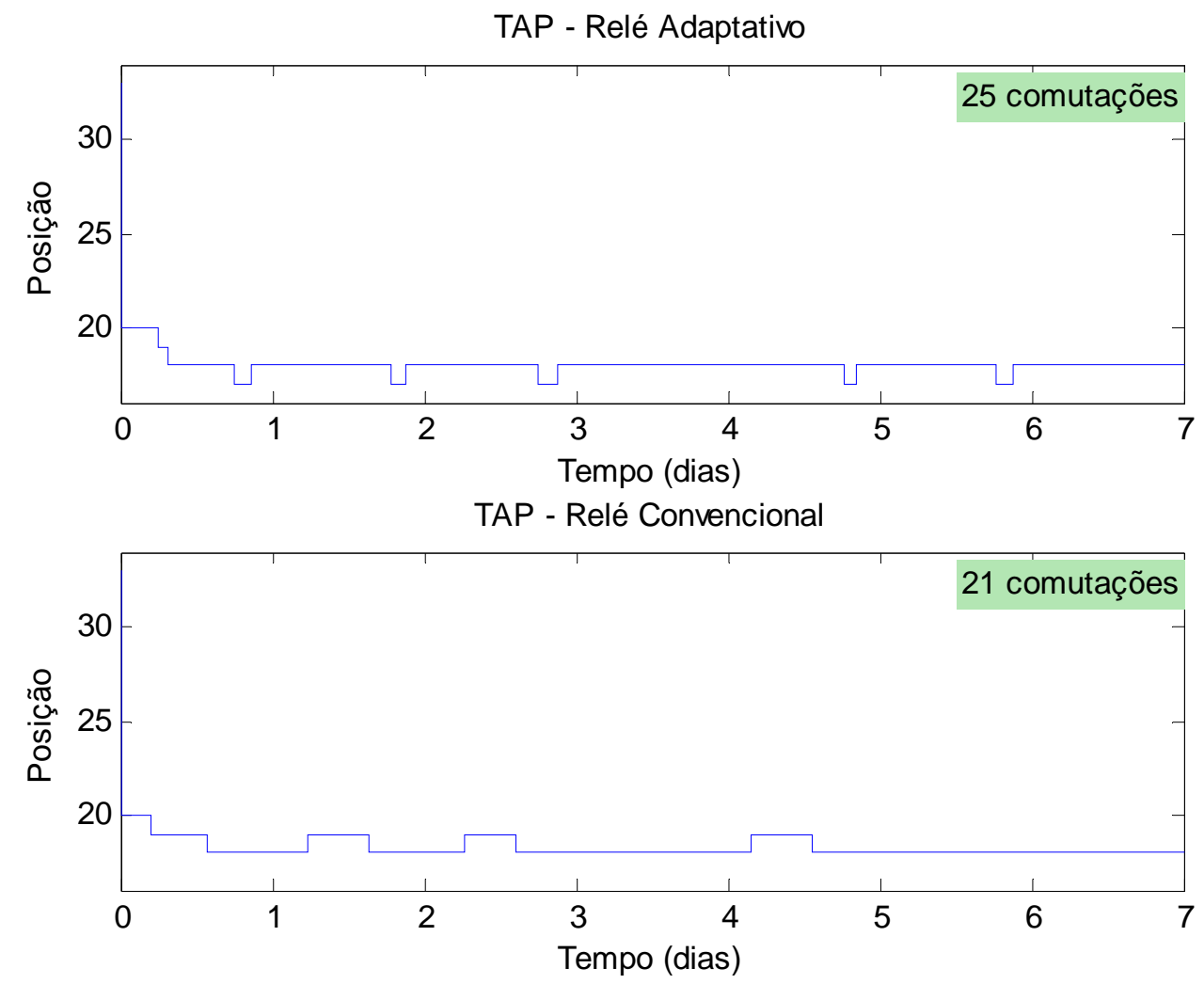

Figura 5.7 - Histórico de comutações para as simulações de Andradina Trafo 1.

Pode-se observar a partir da Figura 5.7 que a estratégia adaptativa realizou 4 comutações a mais que a estratégia convencional para o mesmo período de simulação. Já em relação às posições do tap, nota-se claramente a diferença entre as estratégias, uma vez que a adaptativa tem por finalidade reduzir as comutações de tap em carga Mínima/Leve e aumentar a tensão em carga Média/Pesada. Estes objetivos podem ser evidenciados na Figura 5.8, comparando-se a tensão na subestação para a estratégia adaptativa e convencional. 

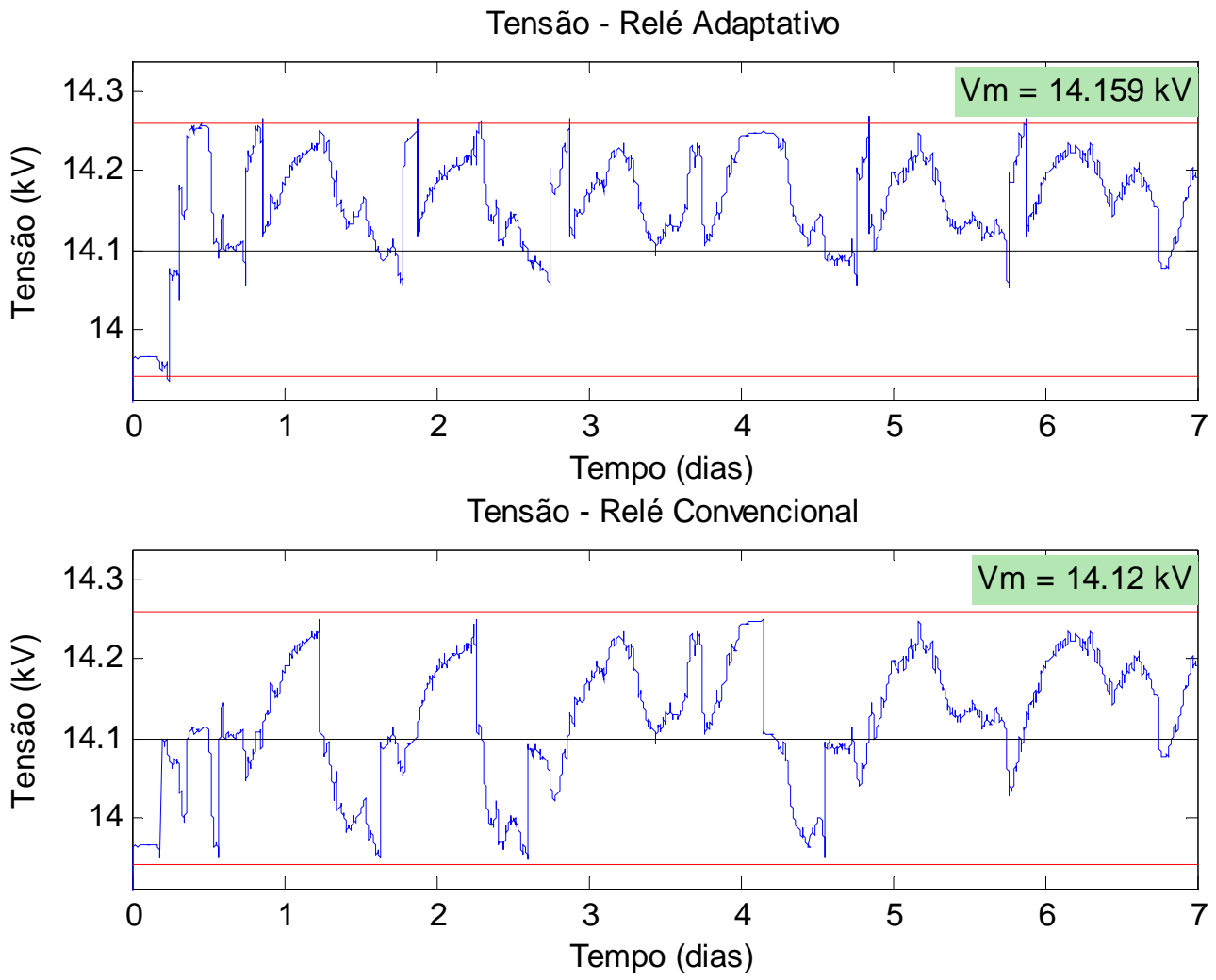

Figura 5.8 - Perfil de tensão na subestação para as simulações de Andradina Trafo 1.

Graficamente, é possível constatar que na maior parte do tempo a estratégia adaptativa manteve a tensão da subestação acima da tensão de referência de $14,1 \mathrm{kV} . \mathrm{Na}$ Figura 5.8 encontra-se também evidenciada a tensão média para o período de simulação, tanto para a estratégia adaptativa quanto para a convencional, ficando registrado que a estratégia fuzzy obteve uma tensão média de simulação $39 \mathrm{~V}$ maior que a tensão média associada à estratégia convencional.

Em alguns períodos, a tensão fica fora da faixa, pois não ultrapassou a temporização mínima para o sistema enviar um comando de mudança de tap do transformador.

Por meio dos gráficos da Figura 5.9, é possível visualizar a regulação de tensão dos relés convencional e Fuzzy para alguns trechos da semana . Escolheu-se alguns deles onde a tensão da subestação controlada pelo relé fuzzy se mostrou mais elevada, se comparada ao relé 
convencional. A Figura 5.9 mostra o objetivo de melhorar o perfil de tensão mais evidente, pois a tensão obtida pelo relé fuzzy permaneceu na maior parte do tempo dentro da faixa superior e respeitando os limites operativos.
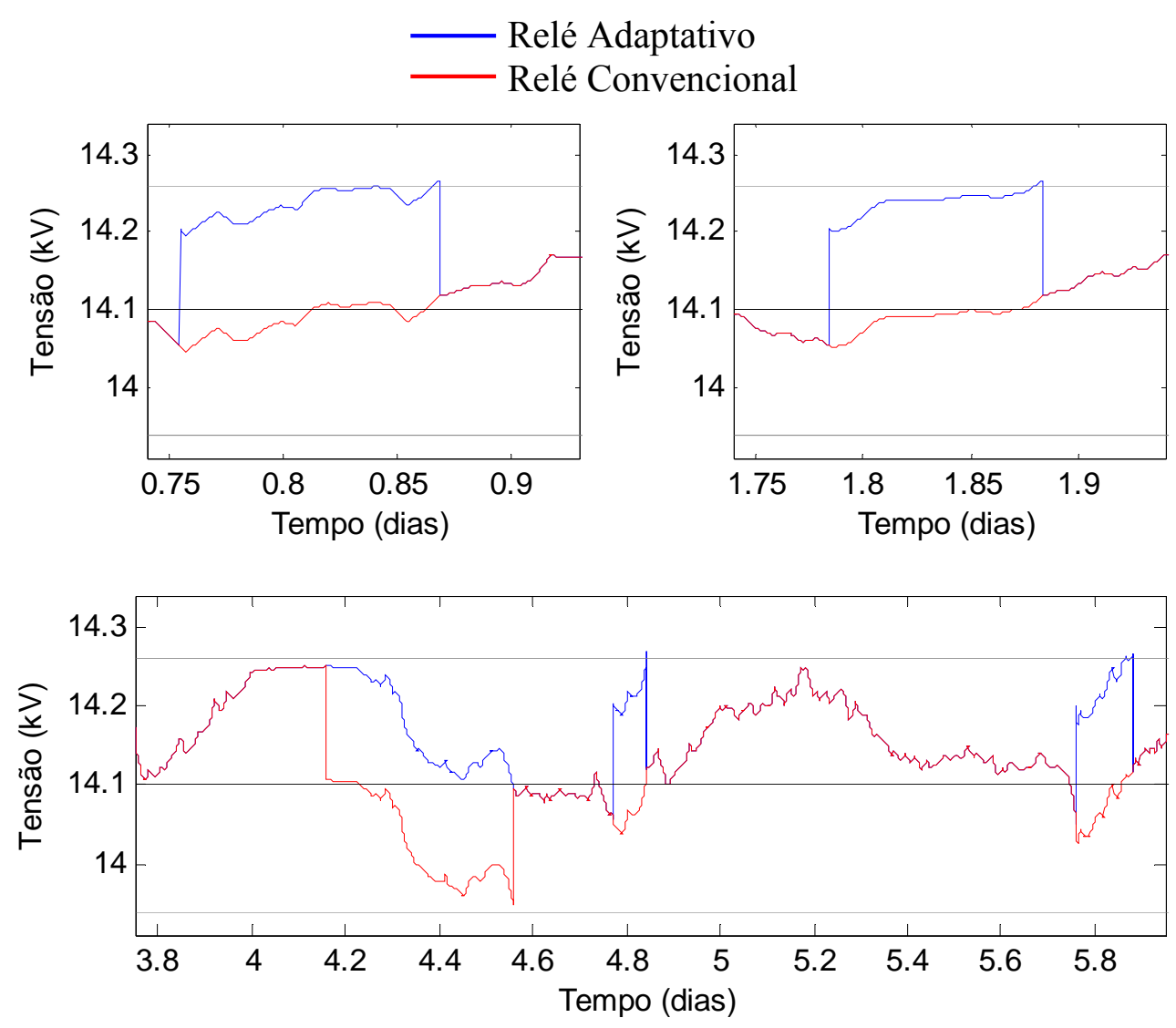

Figura 5.9 - Comparação de tensão para as simulações de Andradina Trafo 1.

O princípio de funcionamento do relé fuzzy pode ser claramente comprovado através da Figura 5.10, ou seja, durante a carga pesada o relé adaptativo realiza comutações para manter a tensão mais elevada possível. Em carga leve racionaliza-se o número de comutações para preservar o comutador de tap. 

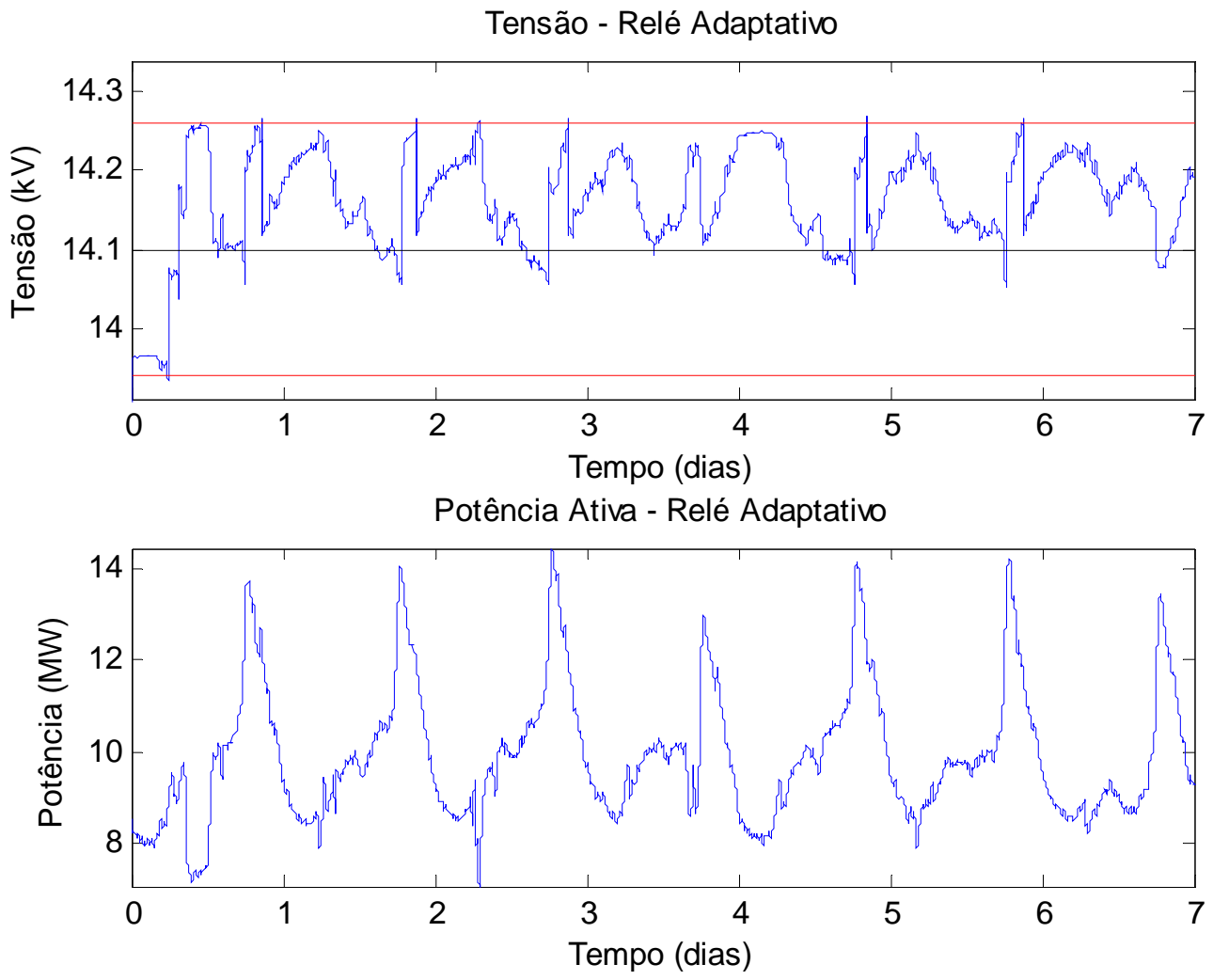

Figura 5.10 - Curvas de potência ativa e tensão para as simulações de Andradina Trafo 1.

Na Figura 5.11, encontra-se um estudo comparativo entre a estratégia adaptativa e a convencional para o tempo de permanência em faixas de tensão. Essas faixas foram criadas com o intuito de avaliar melhor o comportamento da tensão e verificar se a estratégia adaptativa foi capaz de manter a tensão mais elevada para as faixas de interesse. A estratégia adaptativa manteve a tensão na principal faixa de interesse, $14,1 \mathrm{kV}$ a $14,25 \mathrm{kV}$, cerca de $83 \%$ do tempo, contra $64 \%$ da estratégia convencional.

Entre os níveis de tensão $13,95 \mathrm{kV}$ a $14,1 \mathrm{kV}$, ou seja, abaixo da tensão de referência e não atendendo aos objetivos desse trabalho, a estratégia adaptativa manteve a tensão por apenas $11 \%$ do período de simulação estudado (uma semana) nesta faixa contra $35 \%$ da estratégia convencional. 


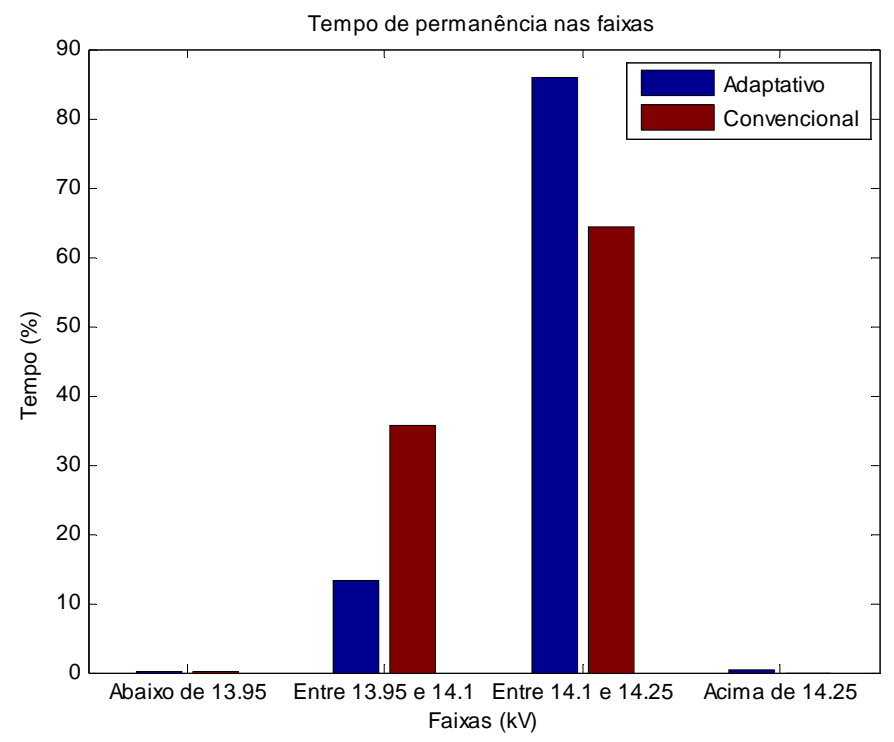

Figura 5.11 - Tempo de permanência nas faixas para as simulações de Andradina Trafo 1.

Na Figura 5.12, comprova-se a eficiência da estratégia adaptativa em manter a tensão média mais elevada em carga pesada. Para todas as faixas de carga pesada atendidas por Andradina (Transformador 1), a começar por níveis de potência ativa maiores ou iguais a 10,9 MW, a tensão média proporcionada pelo relé adaptativo foi mais elevada que o convencional, principalmente para cargas maiores que $13,95 \mathrm{MW}$.

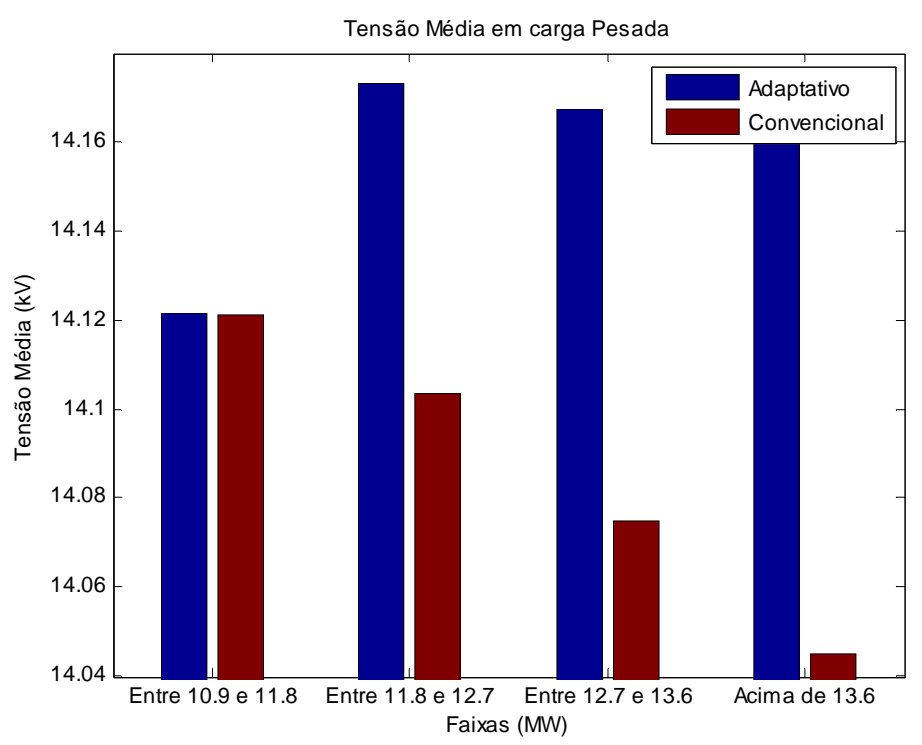

Figura 5.12 - Tensão média em carga pesada para as simulações de Andradina Trafo 1. 


\subsubsection{Subestação Cordeirópolis (Transformador 2)}

Na Figura 5.13, encontra-se registrado o histórico de comutações associado à simulação da relé fuzzy para a subestação Cordeirópolis Trafo 2. Nesta mesma figura, também é possível se comparar o histórico de comutações para a mesma simulação, utilizando-se o relé convencional.
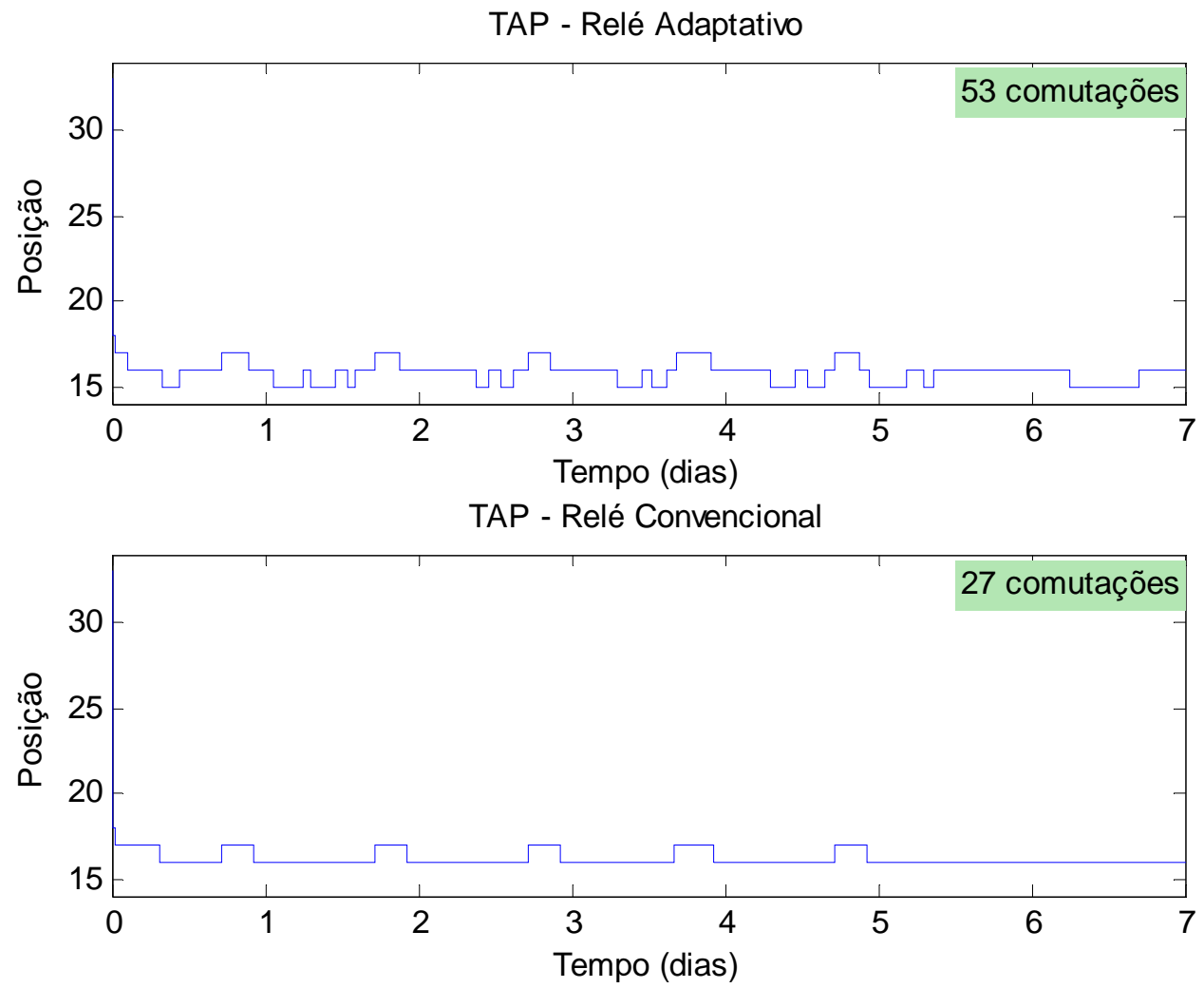

Figura 5.13 - Histórico de comutações para as simulações de Cordeirópolis Trafo 2.

A estratégia adaptativa realizou 26 comutações a mais que a convencional. Isso ocorre devido às características da carga da Subestação de Cordeirópolis, estando a todo momento em níveis mais elevados. Os objetivos de manter a tensão média mais alta para esta subestação podem ser contemplados por meio da Figura 5.14. 


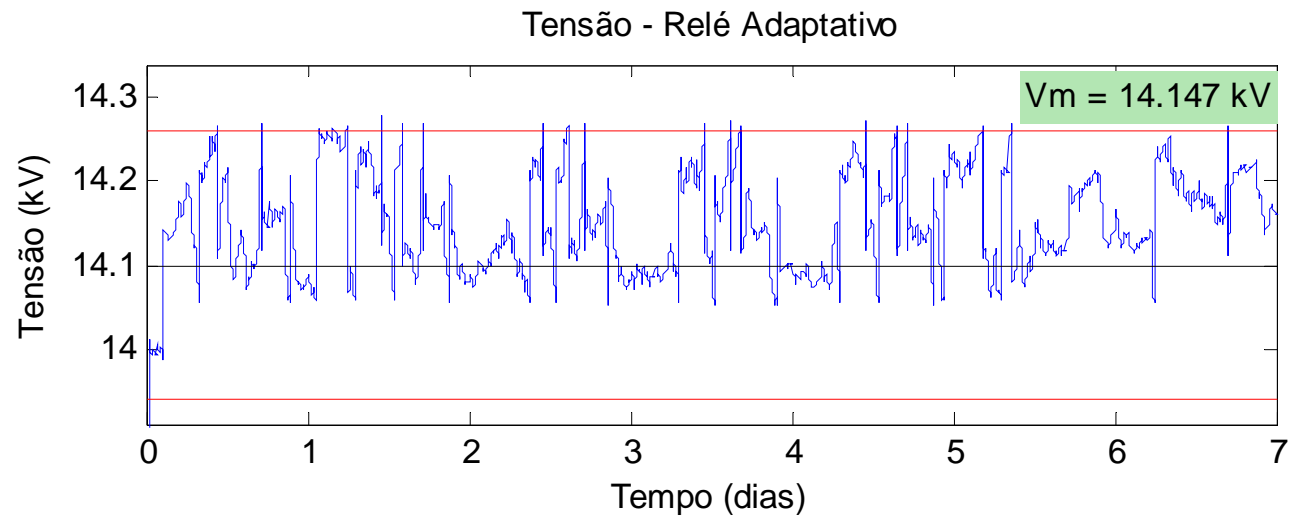

Tensão - Relé Convencional

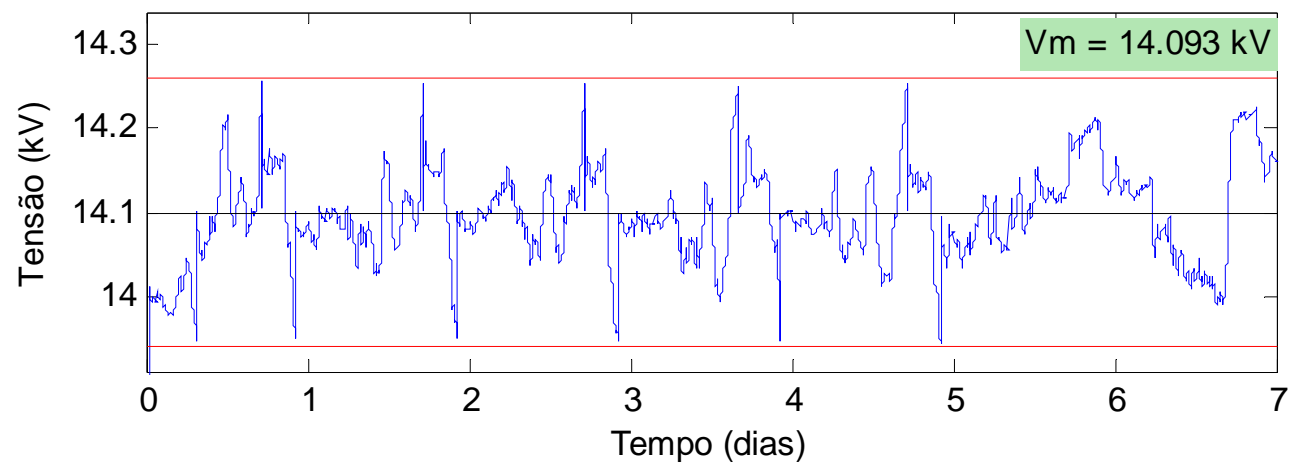

Figura 5.14 - Perfil de tensão na subestação para as simulações de Cordeirópolis Trafo 2.

Graficamente, é possível constatar que na maior parte do tempo a estratégia adaptativa manteve a tensão da subestação acima da tensão de referência de $14,1 \mathrm{kV}$. Na Figura 5.14 encontra-se também evidenciado a tensão média para o período de simulação, tanto para a estratégia adaptativa quanto para a convencional, ficando registrado que a estratégia fuzzy obteve uma tensão média de simulação $54 \mathrm{~V}$ maior que a tensão média associada à estratégia convencional.

Alguns trechos da simulação apresentaram níveis de tensão fora da largura de faixa operativa. Isso ocorre porque a temporização mínima para comutação não foi atingida.

Por meio da Figura 5.15 é possível visualizar a regulação de tensão dos relés convencional e Fuzzy para alguns trechos da semana. Escolheu-se alguns daqueles em que a 
tensão da subestação controlada pelo relé fuzzy se mostrou mais elevada, se comparada ao relé convencional.

Relé Adaptativo

Relé Convencional
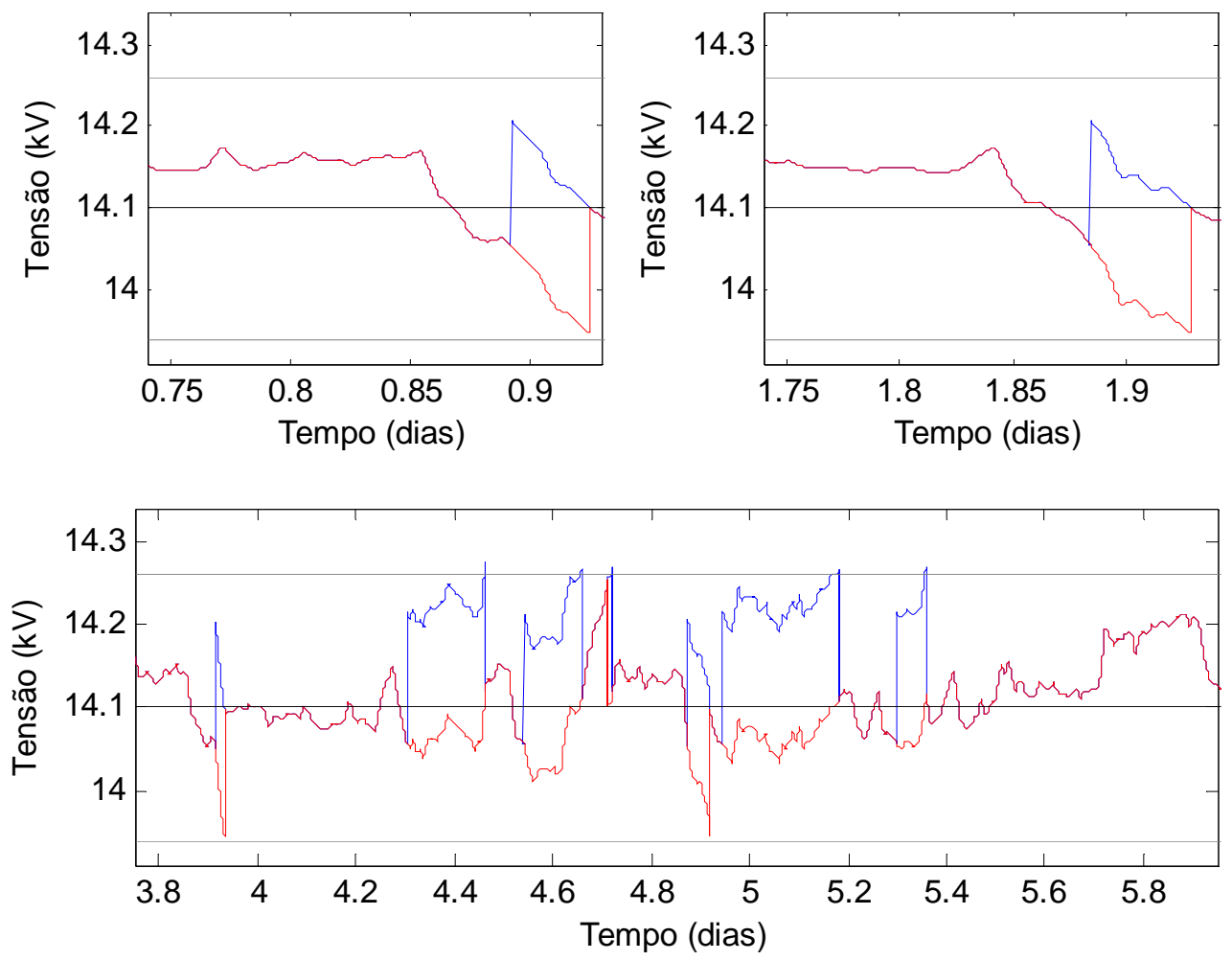

Figura 5.15 - Comparação de tensão para as simulações de Cordeirópolis Trafo 2.

O princípio de funcionamento do relé fuzzy pode ser claramente comprovado através da Figura 5.16, ou seja, durante a carga pesada o relé adaptativo realiza comutações para manter a tensão mais elevada possível. Em carga leve racionaliza-se o número de comutações para preservar o comutador de tap, isto é, economiza-se o número de comutações. 


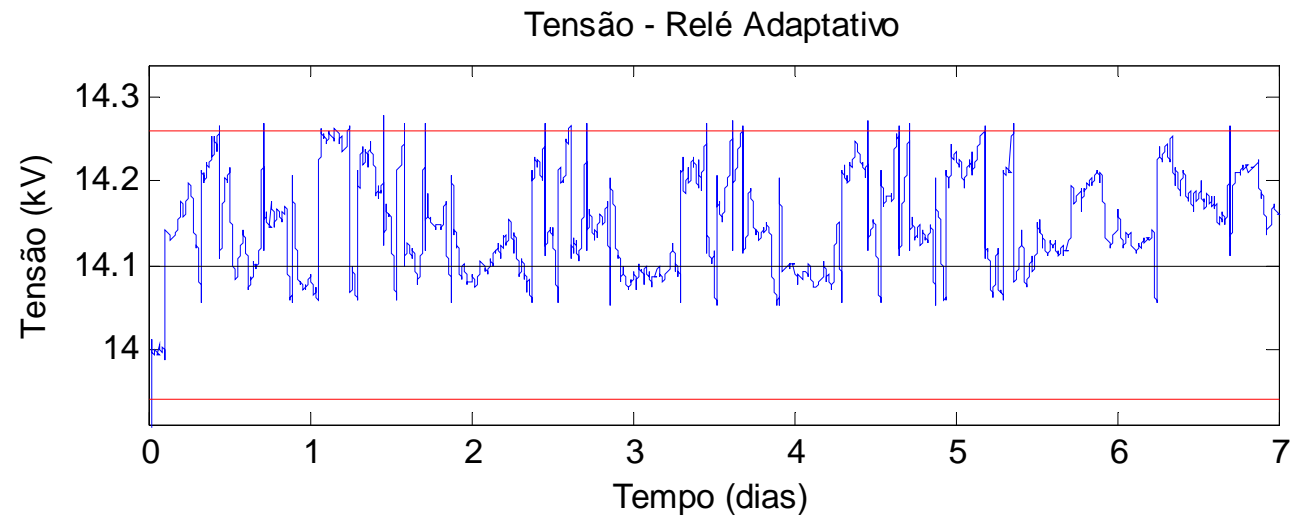

Potência Ativa - Relé Adaptativo

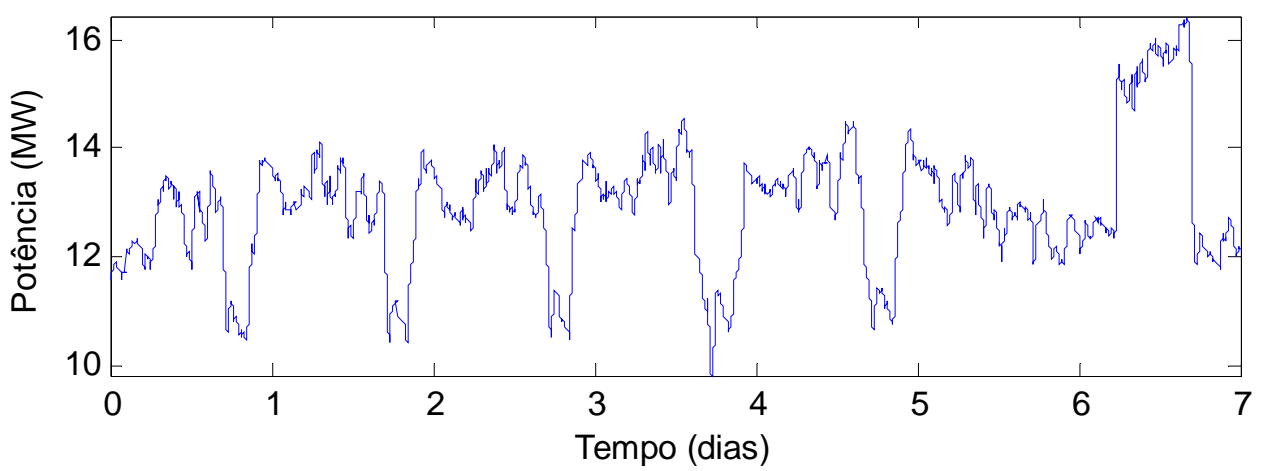

Figura 5.16 - Curvas de potência ativa e tensão para as simulações de Cordeirópolis Trafo 2.

Na Figura 5.17 encontra-se um estudo comparativo entre a estratégia adaptativa e a convencional para o tempo de permanência em faixas de tensão. A estratégia adaptativa manteve a tensão na principal faixa de interesse, $14,1 \mathrm{kV}$ a $14,25 \mathrm{kV}$, cerca de $77 \%$ do tempo, contra $45 \%$ da estratégia convencional.

Entre os níveis de tensão $13,95 \mathrm{kV}$ a $14,1 \mathrm{kV}$, ou seja, abaixo da tensão de referência e sem atender aos interesses deste trabalho, a estratégia adaptativa manteve a tensão apenas $23 \%$ do tempo de simulação analisado (uma semana) nesta faixa contra $55 \%$ da estratégia convencional. 


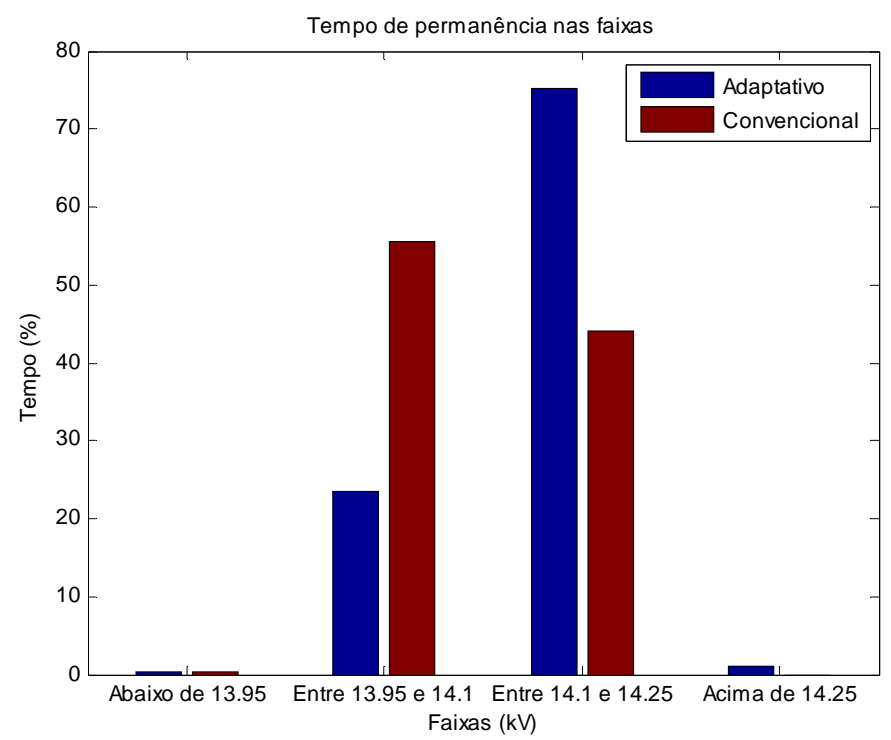

Figura 5.17 - Tempo de permanência nas faixas para as simulações de Cordeirópolis Trafo 2.

Na Figura 5.18, comprova-se a eficiência da estratégia adaptativa em manter a tensão média mais elevada em carga pesada. Para todas as faixas de carga pesada atendidas por Cordeirópolis (Transformador 2), a começar por níveis de potência ativa maiores ou iguais a 14,3 MW, a tensão média proporcionada pelo relé adaptativo foi mais elevada que o convencional, principalmente para cargas maiores que 14,3 MW.

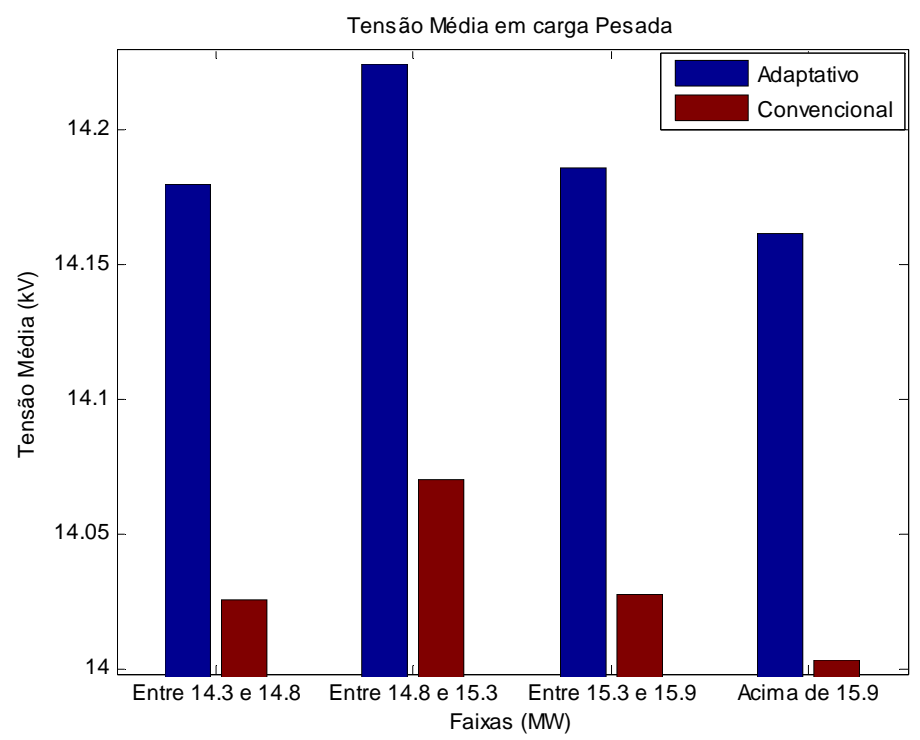

Figura 5.18 - Tensão média em carga pesada para as simulações de Cordeirópolis Trafo 2. 


\subsubsection{Subestação Mogi-Guaçu 2 (Transformador 1)}

Na Figura 5.19 encontra-se registrado o histórico de comutações associado à simulação da estratégia fuzzy para a subestação Mogi-Guaçu 2 Trafo 1. Nesta mesma figura, também é possível se comparar o histórico de comutações para a mesma simulação, utilizando-se a estratégia convencional.
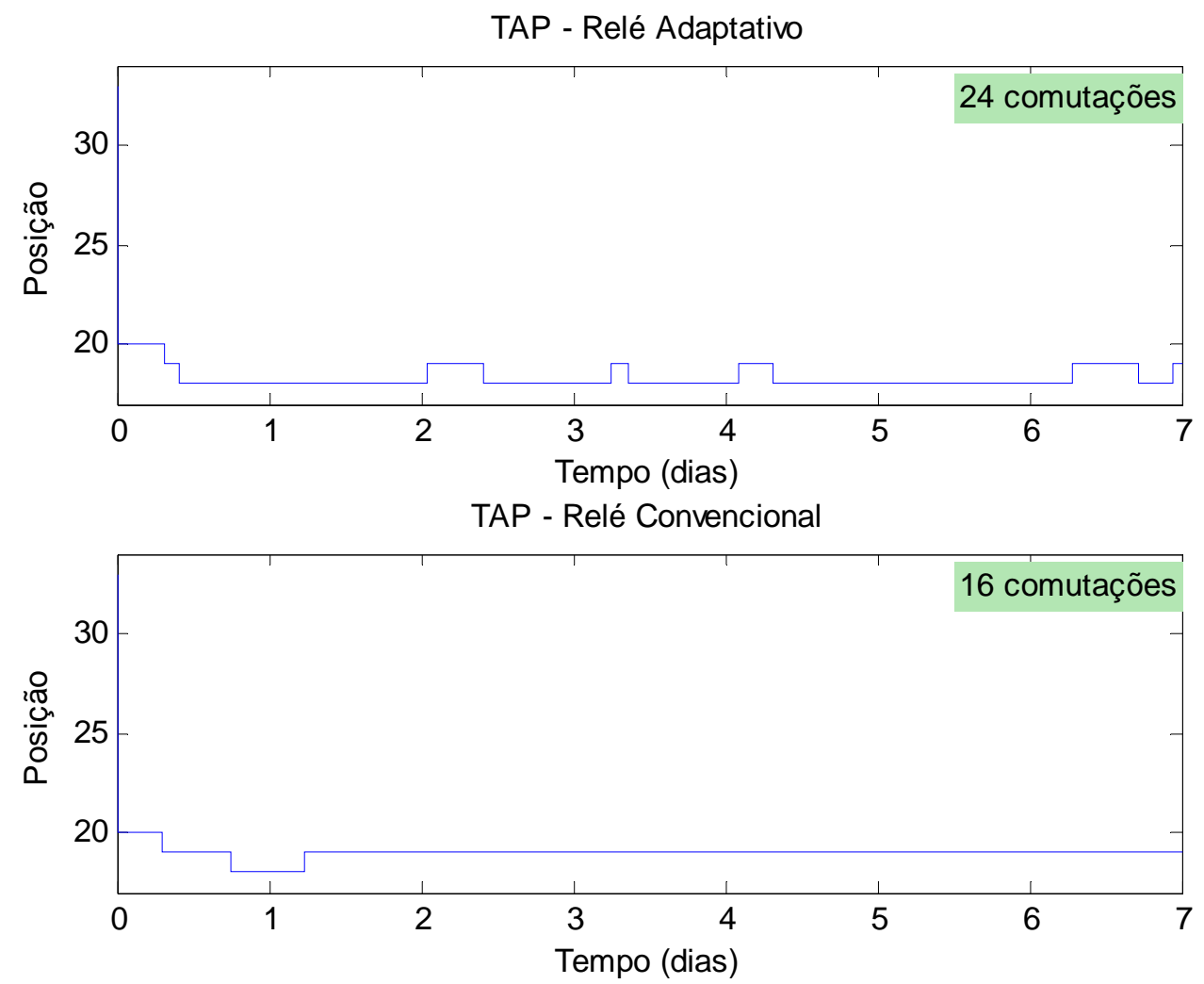

Figura 5.19 - Histórico de comutações para as simulações de Mogi-Guaçu 2 Trafo 1.

A estratégia adaptativa realizou oito comutações a mais que a convencional, porém esse número pode ser considerado pequeno se comparado aos ganhos de tensão obtidos para a aplicação do controle Fuzzy à subestação de Mogi-Guaçu 2 (Transformador 1), como pode ser comprovado pela Figura 5.20. 

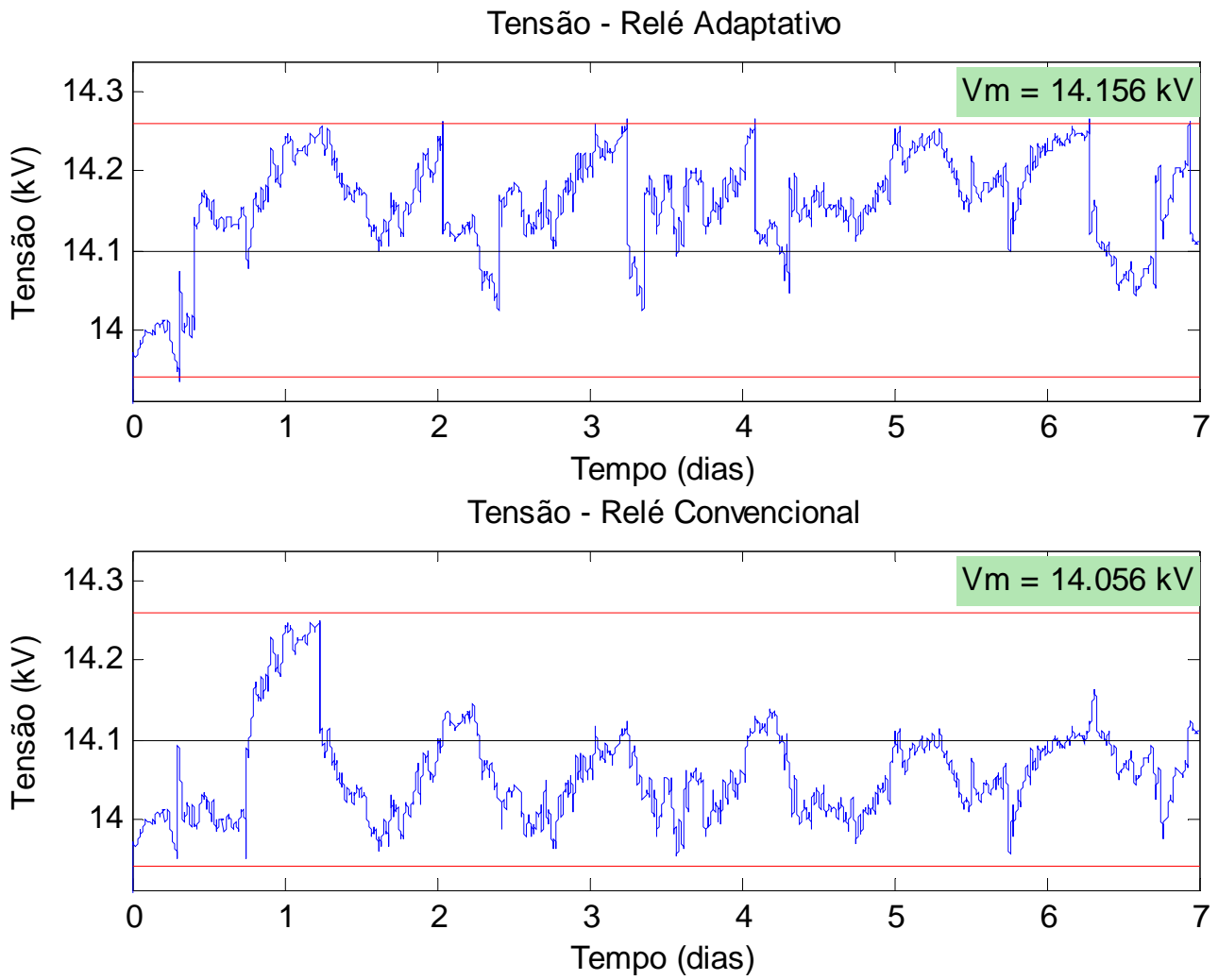

Figura 5.20 - Perfil de tensão na subestação para as simulações de Mogi-Guaçu 2 Trafo 1.

Graficamente, é possível constatar que na maior parte do tempo a estratégia adaptativa manteve a tensão da subestação acima da tensão de referência de $14,1 \mathrm{kV} . \mathrm{Na}$ Figura 5.20, encontra-se também evidenciado a tensão média para o período de simulação, tanto para a estratégia adaptativa quanto para a convencional, ficando registrado que a estratégia fuzzy obteve uma tensão média de simulação $100 \mathrm{~V}$ maior que a tensão média associada à estratégia convencional.

Para esta subestação, pode-se observar através da Figura 5.20 que os períodos em que a tensão ultrapassou a faixa operativa foram menores, se comparados às subestações anteriores.

Na Figura 5.21, encontram-se detalhados alguns trechos da simulação onde a tensão controlada pela estratégia adaptativa se manteve mais elevada, se comparada à convencional. 
Nesta mesma figura, pode-se observar trechos de mais de 24 horas em que a tensão obtida para a simulação adaptativa foi mais elevada.

Relé Adaptativo

Relé Convencional
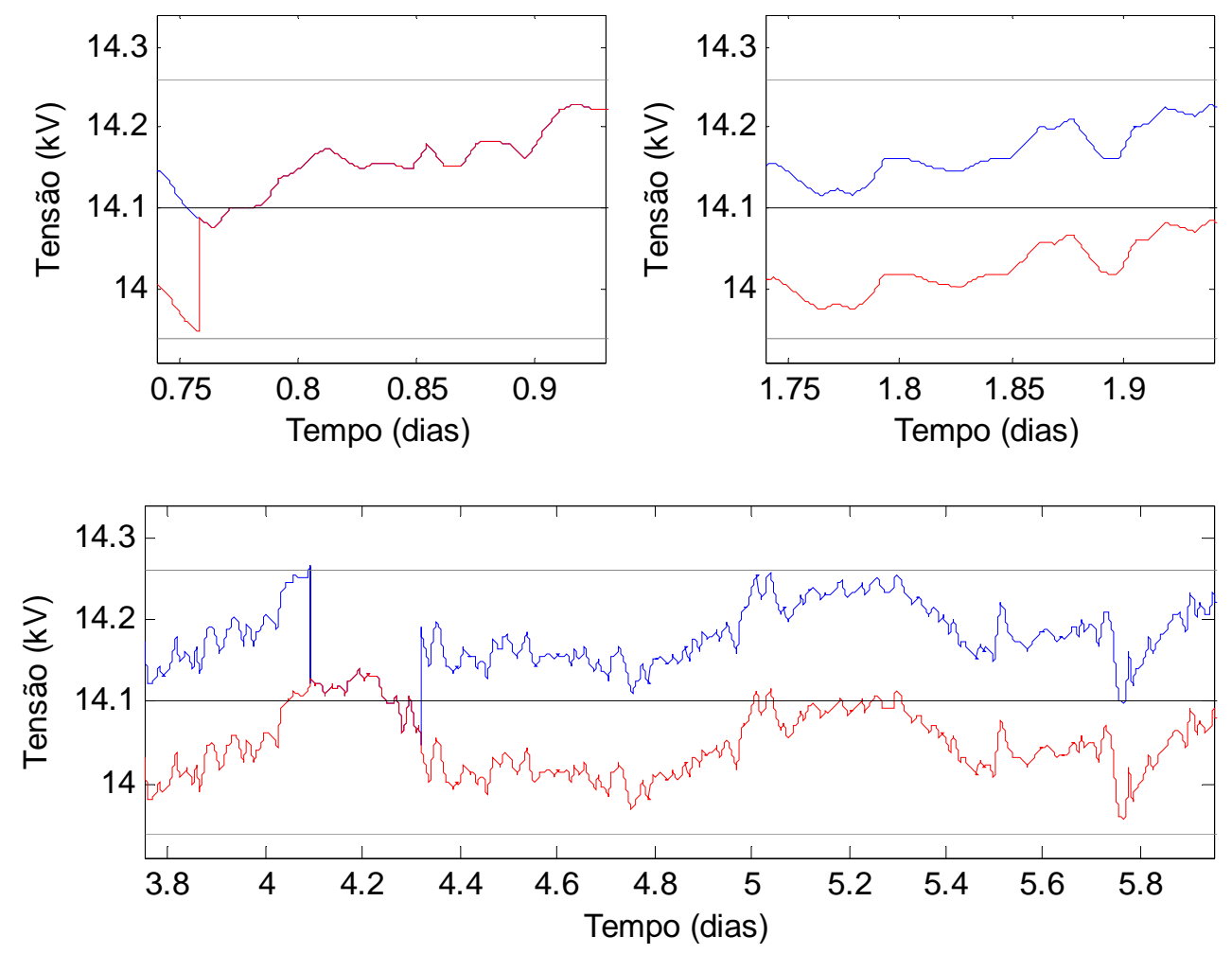

Figura 5.21 - Comparação de tensão para as simulações de Mogi-Guaçu 2 Trafo 1.

O princípio de funcionamento do relé fuzzy pode ser claramente comprovado através da Figura 5.22, ou seja, durante a carga pesada o relé adaptativo realiza comutações para manter a tensão a mais elevada possível. Em carga leve racionaliza-se o número de comutações para preservar o comutador de tap. 

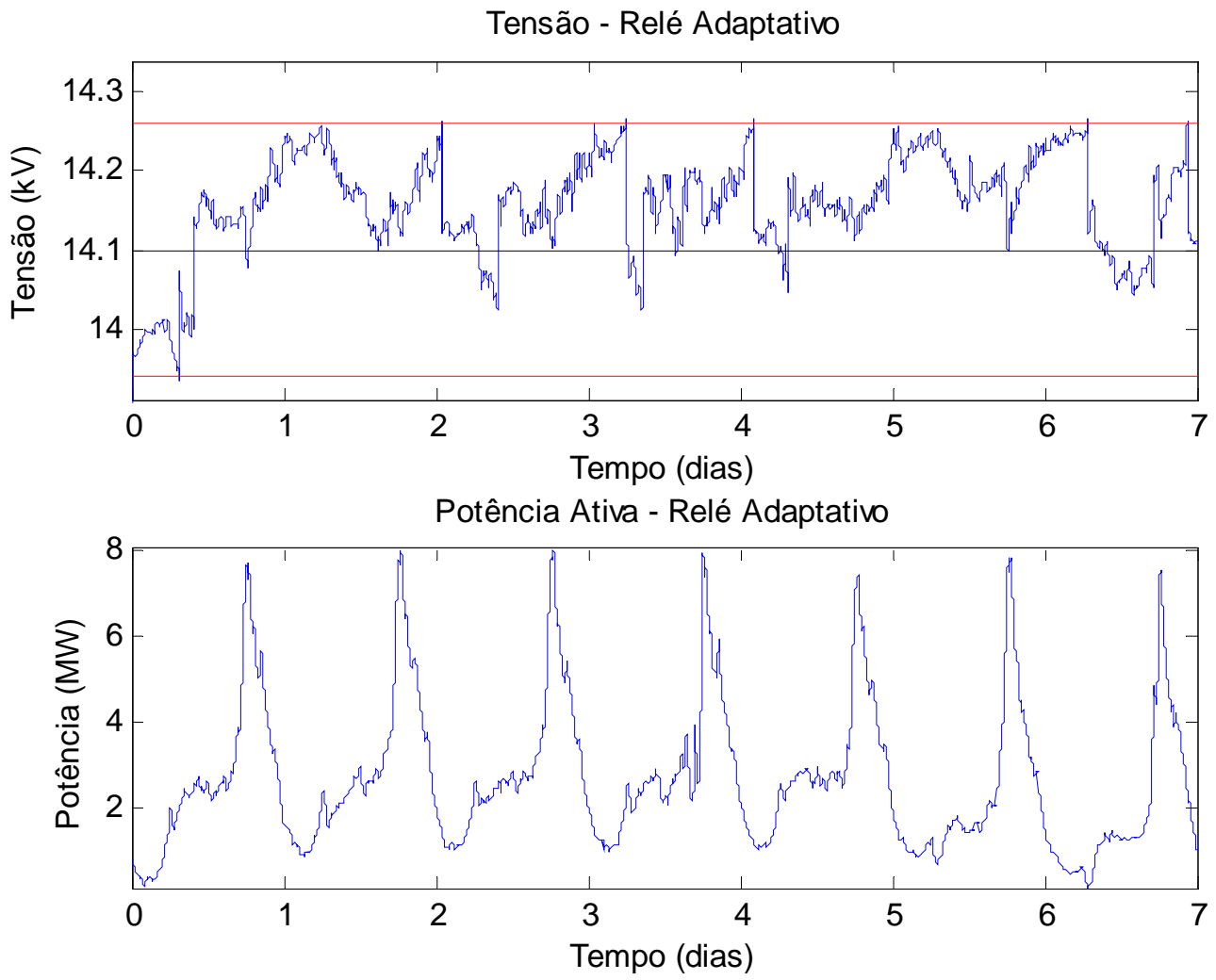

Figura 5.22 - Curvas de potência ativa e tensão para as simulações de Mogi-Guaçu 2 Trafo 1.

$\mathrm{Na}$ Figura 5.23 encontra-se um comparativo entre a estratégia adaptativa e a convencional para o tempo de permanência em faixas de tensão. A estratégia adaptativa manteve a tensão na principal faixa de interesse, $14,1 \mathrm{kV}$ a $14,25 \mathrm{kV}$, cerca de $84 \%$ do tempo, contra $20 \%$ da estratégia convencional.

Entre os níveis de tensão $13,95 \mathrm{kV}$ a $14,1 \mathrm{kV}$, ou seja, abaixo da tensão de referência e não atendendo aos interesses deste trabalho, a estratégia adaptativa manteve a tensão apenas $15 \%$ do tempo de simulação (uma semana) nesta faixa contra $79 \%$ da estratégia convencional. 


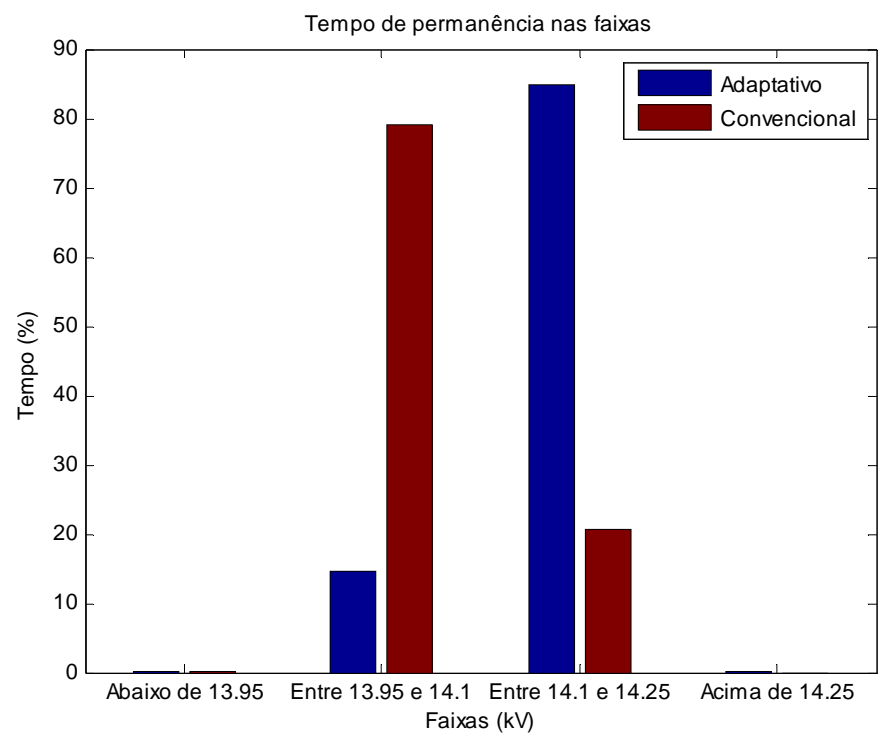

Figura 5.23 - Tempo de permanência nas faixas para as simulações de Mogi-Guaçu 2 Trafo 1.

Na Figura 5.24, comprova-se a eficiência da estratégia adaptativa em manter a tensão média mais elevada em carga pesada. Para todas as faixas de carga pesada atendidas por Mogi-Guaçu 2 (Transformador 1), a começar por níveis de potência ativa maiores ou iguais a 2,93 MW, a tensão média proporcionada pelo relé adaptativo foi mais elevada que o convencional, principalmente para cargas maiores que 6,75 MW.

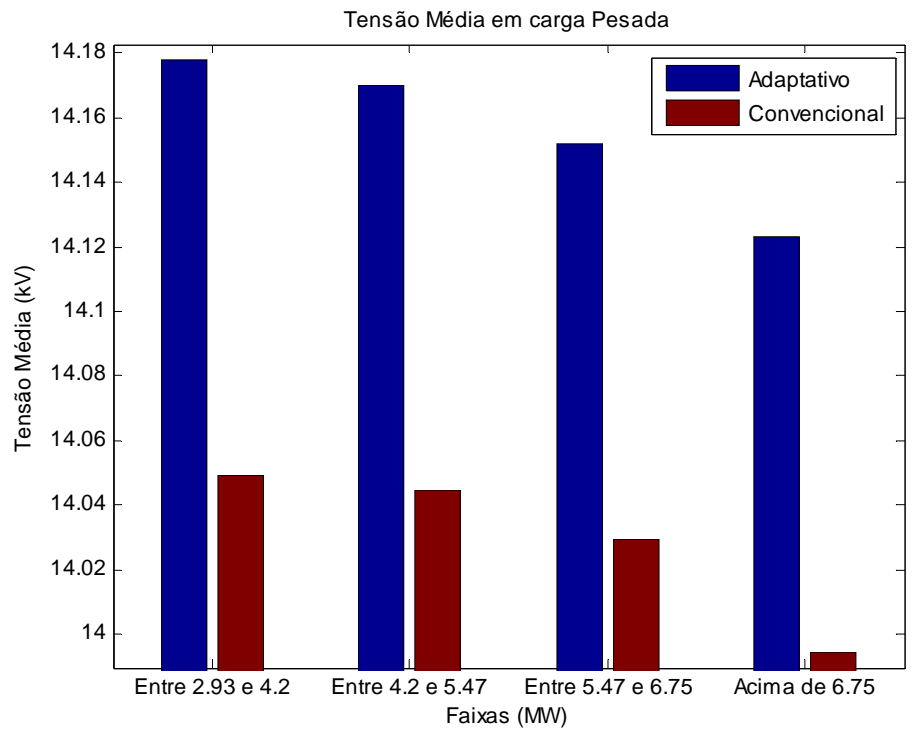

Figura 5.24 - Tensão média em carga pesada para as simulações de Mogi-Guaçu 2 Trafo 1. 


\subsection{Análise comparativa para as subestações de teste}

Nessa seção são apresentados os resultados referentes às subestações de teste para diferentes valores de tensão de referência, desvio de tensão, normalização pela potência média semanal e temporização. Com isso, é possível se fazer uma análise comparativa entre a atuação do sistema proposto nesse trabalho e o sistema convencional de regulação de tensão para diversos grupos de ajuste dos parâmetros do relé regulador de tensão.

A Tabela 5.2 apresenta os resultados para tensão de referência igual a $14,1 \mathrm{kV}$. Encontram-se também registrados os resultados para as três subestações de teste.

Tabela 5.2 - Comparação dos resultados obtidos para as subestações de teste para $\mathrm{V}_{\text {referência }}=$ $14,1 \mathrm{kV}$.

\begin{tabular}{|c|c|c|c|c|}
\hline \multicolumn{5}{|c|}{$V_{\text {referência }}=\mathbf{1 4 , 1} \mathbf{k V}$; Desvio $= \pm \mathbf{1 \%}$} \\
\hline \multirow{2}{*}{$\begin{array}{c}\text { Subestações } \\
\text { de Teste }\end{array}$} & \multicolumn{2}{|c|}{ Relé Convencional } & \multicolumn{2}{c|}{ Relé Fuzzy } \\
\cline { 2 - 5 } & $\begin{array}{c}\text { Número de } \\
\text { comutações }\end{array}$ & $\begin{array}{c}\text { Tensão } \\
\text { Média (kV) }\end{array}$ & $\begin{array}{c}\text { Número de } \\
\text { comutações }\end{array}$ & $\begin{array}{c}\text { Tensão } \\
\text { Média (kV) }\end{array}$ \\
\hline $\begin{array}{c}\text { Andradina } \\
\text { Trafo1 }\end{array}$ & 21 & 14,12 & 25 & 14,159 \\
\hline $\begin{array}{c}\text { Cordeirópolis } \\
\text { Trafo 2 }\end{array}$ & 27 & 14,093 & 53 & 14,147 \\
\hline $\begin{array}{c}\text { Mogi-Guaçu 2 } \\
\text { Trafo 1 }\end{array}$ & 16 & 14,056 & 24 & 14,156 \\
\hline
\end{tabular}

A Tabela 5.3 apresenta os resultados para tensão de referência igual a $14,15 \mathrm{kV}$.

Tabela 5.3 - Comparação dos resultados obtidos para as subestações de teste para $\mathrm{V}_{\text {referência }}=$ $14,15 \mathrm{kV}$.

\begin{tabular}{|c|c|c|c|c|}
\hline \multicolumn{5}{|c|}{$V_{\text {referência }}=\mathbf{1 4 , 1 5} \mathbf{~ k V}$; Desvio $= \pm \mathbf{1 \%}$} \\
\hline \multirow{2}{*}{$\begin{array}{c}\text { Subestações } \\
\text { de Teste }\end{array}$} & \multicolumn{2}{|c|}{ Relé Convencional } & \multicolumn{2}{c|}{ Relé Fuzzy } \\
\cline { 2 - 5 } & $\begin{array}{c}\text { Número de } \\
\text { comutações }\end{array}$ & $\begin{array}{c}\text { Tensão } \\
\text { Média (kV) }\end{array}$ & $\begin{array}{c}\text { Número de } \\
\text { comutações }\end{array}$ & $\begin{array}{c}\text { Tensão } \\
\text { Média (kV) }\end{array}$ \\
\hline $\begin{array}{c}\text { Andradina } \\
\text { Trafo1 }\end{array}$ & 15 & 14,152 & 31 & 14,207 \\
\hline $\begin{array}{c}\text { Cordeirópolis } \\
\text { Trafo 2 }\end{array}$ & 31 & 14,108 & 43 & 14,21 \\
\hline $\begin{array}{c}\text { Mogi-Guaçu 2 } \\
\text { Trafo 1 }\end{array}$ & 17 & 14,178 & 25 & 14,192 \\
\hline
\end{tabular}


A Tabela 5.4 apresenta os resultados para tensão de referência igual a 14,20kV.

Tabela 5.4 - Comparação dos resultados obtidos para as subestações de teste para $\mathrm{V}_{\text {referência }}=$ $14,2 \mathrm{kV}$.

\begin{tabular}{|c|c|c|c|c|}
\hline \multicolumn{5}{|c|}{$V_{\text {referência }}=\mathbf{1 4 , 2 0} \mathbf{~ k V}$; Desvio $= \pm \mathbf{1 \%}$} \\
\hline \multirow{2}{*}{$\begin{array}{c}\text { Subestações } \\
\text { de Teste }\end{array}$} & $\begin{array}{c}\text { Relé Convencional } \\
\text { Número de } \\
\text { comutações }\end{array}$ & $\begin{array}{c}\text { Tensão } \\
\text { Média (kV) }\end{array}$ & $\begin{array}{c}\text { Número de } \\
\text { comutações }\end{array}$ & $\begin{array}{c}\text { Tensão } \\
\text { Média (kV) }\end{array}$ \\
\hline $\begin{array}{c}\text { Andradina } \\
\text { Trafo1 }\end{array}$ & 23 & 14,179 & 32 & 14,257 \\
\hline $\begin{array}{c}\text { Cordeirópolis } \\
\text { Trafo 2 }\end{array}$ & 31 & 14,187 & 38 & 14,252 \\
\hline $\begin{array}{c}\text { Mogi-Guaçu 2 } \\
\text { Trafo 1 }\end{array}$ & 15 & 14,187 & 29 & 14,249 \\
\hline
\end{tabular}

Pelas Tabelas 5.5 a 5.7 é possível verificar a influência da tensão de referência na operação dos relés reguladores de tensão convencional e adaptativo. Em todos os casos, o relé fuzzy manteve a tensão mais alta quando comparado com o relé convencional, mas, por outro lado, observa-se que o relé adaptativo necessitou de um número maior de comutações que o convencional. A utilização de uma tensão de referência maior, em alguns casos como Andradina TR 1, provocou um aumento no número de comutações para o relé fuzzy. Nas outras subestações, o número de comutações reduziu para um ajuste de tensão de referência maior. Isso pode ser explicado pelo fato dos comportamentos de carga dessas subestações serem distintas.

Um outro estudo de caso investigado foi a mudança do desvio de tensão para $1,3 \%$. Os resultados podem ser conferidos na Tabela 5.5. 
Tabela 5.5 - Comparação dos resultados obtidos para as subestações de teste para $\mathrm{V}_{\text {referência }}=$ $14,1 \mathrm{kV}$ e desvios de $1 \%$ e $1,3 \%$.

\begin{tabular}{|c|c|c|c|c|}
\hline \multicolumn{5}{|c|}{$V_{\text {referência }}=14,1 \mathrm{kV}$} \\
\hline & & \multicolumn{3}{|c|}{ Subestações de teste } \\
\hline & & AND TR1 & COR TR2 & MOG2 TR1 \\
\hline \multirow{2}{*}{$\begin{array}{c}\text { Relé } \\
\text { Convencional } \\
\text { Desvio }= \pm 1 \%\end{array}$} & $\begin{array}{l}\text { Número de } \\
\text { comutações }\end{array}$ & 21 & 27 & 16 \\
\hline & $\begin{array}{c}\text { Tensão } \\
\text { Média }(k V)\end{array}$ & 14,12 & 14,093 & 14,056 \\
\hline \multirow{2}{*}{$\begin{array}{c}\text { Relé Fuzzy } \\
\text { Desvio }= \pm 1 \%\end{array}$} & $\begin{array}{l}\text { Número de } \\
\text { comutações }\end{array}$ & 25 & 53 & 24 \\
\hline & $\begin{array}{c}\text { Tensão } \\
\text { Média }(k V)\end{array}$ & 14,159 & 14,147 & 14,156 \\
\hline \multirow{2}{*}{$\begin{array}{c}\text { Relé } \\
\text { Convencional } \\
\text { Desvio }= \pm 1,3 \%\end{array}$} & $\begin{array}{l}\text { Número de } \\
\text { comutações }\end{array}$ & 15 & 27 & 15 \\
\hline & $\begin{array}{c}\text { Tensão } \\
\text { Média }(k V)\end{array}$ & 14,139 & 14,086 & 14,046 \\
\hline \multirow{2}{*}{$\begin{array}{c}\text { Relé Fuzzy } \\
\text { Desvio }= \pm 1,3 \%\end{array}$} & $\begin{array}{l}\text { Número de } \\
\text { comutações }\end{array}$ & 25 & 45 & 17 \\
\hline & $\begin{array}{c}\text { Tensão } \\
\text { Média }(k V)\end{array}$ & 14,167 & 14,165 & 14,171 \\
\hline
\end{tabular}

Da Tabela 5.5 pode ser evidenciado que o aumento no valor do desvio de tensão para 1,3\% reduz ou mantém o número de comutações. Esse fato já era esperado, uma vez que um maior desvio de tensão significa uma maior largura de faixa operativa para o relé.

Foi também estudada a influência da normalização da entrada 1 para o relé fuzzy. Vale ressaltar que a entrada 1 é normalizada pela média histórica semanal de potência ativa. Esta influência foi verificada por meio de três testes. O primeiro é a normalização da potência ativa pela potência média. No segundo, uma insensibilidade de $-20 \%$ foi inserida no valor da potência média, ou seja, a entrada 1 foi normalizada por $80 \%$ do valor da potência média. E no terceiro, uma insensibilidade de $+20 \%$ foi inserida no valor da potência média, ou seja, a entrada 1 foi normalizada por $120 \%$ do valor da potência média. Para os três testes foram utilizados uma tensão de referência de $14,1 \mathrm{kV}$, temporização de 90 segundos e desvio de $1 \%$. Os resultados podem ser conferidos na Tabela 5.6. 
Tabela 5.6 - Comparação dos resultados obtidos para as subestações de teste.

\begin{tabular}{|c|c|c|c|c|c|c|}
\hline \multicolumn{7}{|c|}{$V_{\text {referência }}=14,1 \mathrm{kV} ;$ Temporização $=90 \mathrm{~s}$ e Desvio $= \pm 1 \%$} \\
\hline & \multicolumn{2}{|c|}{$\begin{array}{l}\text { Pnorm }=80 \% \\
\text { da Pot. Média }\end{array}$} & \multicolumn{2}{|c|}{$\begin{array}{c}\text { Pnorm }=100 \% \\
\text { da Pot. Média }\end{array}$} & \multicolumn{2}{|c|}{$\begin{array}{l}\text { Pnorm }=120 \% \\
\text { da Pot. Média }\end{array}$} \\
\hline $\begin{array}{l}\text { Subestações } \\
\text { de Teste }\end{array}$ & $\begin{array}{l}\text { Número de } \\
\text { comutações }\end{array}$ & $\begin{array}{c}\text { Tensão } \\
\text { Média }(k V)\end{array}$ & $\begin{array}{l}\text { Número de } \\
\text { comutações }\end{array}$ & $\begin{array}{c}\text { Tensão } \\
\text { Média (kV) }\end{array}$ & $\begin{array}{l}\text { Número de } \\
\text { comutações }\end{array}$ & $\begin{array}{c}\text { Tensão } \\
\text { Média (kV) }\end{array}$ \\
\hline $\begin{array}{l}\text { Andradina } \\
\text { Trafol }\end{array}$ & 25 & 14,161 & 25 & 14,159 & 25 & 14,151 \\
\hline $\begin{array}{l}\text { Cordeirópolis } \\
\text { Trafo } 2\end{array}$ & 53 & 14,149 & 53 & 14,147 & 31 & 14,104 \\
\hline $\begin{array}{l}\text { Mogi-Guaçu } 2 \\
\text { Trafo } 1\end{array}$ & 24 & 14,159 & 24 & 14,156 & 24 & 14,133 \\
\hline
\end{tabular}

A normalização por meio de $80 \%$ da potência média retorna uma tensão média mais alta, mantendo também o mesmo número de comutações. Já a normalização por $120 \%$ da potência média deixa a tensão média mais baixa, porém ainda superior ao relé convencional. Observa-se também que o número de comutações para o caso de Cordeirópolis TR1 teve uma redução de 22 comutações. Isso mostra que para situações de comportamento de carga industrial, o deslocamento da normalização em $+20 \%$ traz melhores resultados em termos de números de comutação de tap.

Por último, foi estudada a influência da temporização. Na prática, os ajustes de temporização para a atuação do tap variam entre 90 a 110 segundos. Todas as simulações foram testadas utilizando-se valores de temporização de 90, 100 e 110 segundos. Para esse estudo, os resultados não se alteraram. 


\section{CONCLUSÕES}

O objetivo principal deste trabalho foi sistematizar os principais aspectos envolvidos no controle de tensão em sistemas de distribuição de energia elétrica, abordando os métodos mais usuais, bem como os equipamentos mais utilizados para tal propósito. Buscou-se também propor uma estratégia de controle baseado em Sistemas Fuzzy. Outro aspecto importante foi a definição e validação da metodologia proposta.

O trabalho apresentou simulações do comportamento dinâmico de sistemas elétricos de distribuição de energia elétrica e também a comparação de atuação do relé Fuzzy frente ao convencional na regulação da tensão para prover a melhoria do perfil da mesma.

O estudo por meio de simulações foi realizado em duas etapas. A primeira consistiu na implementação computacional do processo de simulação dinâmica no Simulink/Matlab. É importante frisar que essa etapa serviu para realizar aperfeiçoamentos no relé proposto, pois pelo Simulink é possível monitorar todo o processo de simulação por meio de interface gráfica.

$\mathrm{Na}$ segunda etapa, construiu-se um ambiente completo de simulação por meio de rotinas do Matlab. Tal ambiente é composto de dois algoritmos, sendo um o fluxo de carga simplificado por meio de dados históricos de curva de carga e o outro que simula o relé fuzzy (adaptativo).

O relé fuzzy permitiu que o mesmo se adaptasse automaticamente às mudanças que venham a ocorrer na demanda do sistema elétrico, quer fossem elas decorrentes das oscilações 
normais de carga ao longo do tempo, quer advindas das mudanças na configuração do sistema como, por exemplo, manobras ou expansão do sistema elétrico. Com isso, evitou-se que a ocorrência de eventos inesperados na rede causasse o fornecimento de tensão acima ou abaixo dos limites para os consumidores.

Os consumidores finais devem ser contemplados com o aumento da QEE, na medida em que devem ter seus interesses de continuidade dos serviços básicos atendidos ao menor custo e com os maiores níveis de confiabilidade possíveis. Diante desse fato, destaca-se que a aplicação proposta neste trabalho possibilita atender também a esses requisitos.

Outro fator relevante é diz respeito à empresa fornecedora de energia, pois a utilização racional do comutador de tap em transformadores de potência e a manutenção de um nível de tensão mais alto na barra secundária produzem maiores lucros para a empresa.

Com relação aos resultados, foi estudada a regulação de tensão em três subestações reais. Diversas análises comparativas entre as subestações e entre diferentes parâmetros de ajuste dos relés também foram investigadas. Desses estudos ficaram muito bem evidenciadas a racionalização no número de comutações de tap para prover um perfil de tensão mais elevado e dentro de limites operativos.

Para trabalhos futuros, propõe-se o estudo da atuação do relé proposto para outras subestações reais e também a influência de se manter a tensão mais alta nos outros dispositivos reguladores de tensão do sistema de distribuição. Outro estudo relevante do sistema proposto nesse trabalho seria a avaliação de perdas, pois se espera que o sistema de distribuição tenha uma redução das mesmas.

É importante frisar que o sistema proposto nesse trabalho possui baixa complexidade computacional viabilizando a sua implementação em hardware. Portanto, um outro passo 
seria a confecção de protótipo e sua posterior validação em subestações reais de distribuição de energia elétrica. 



\section{REFERÊNCIAS BIBLIOGRÁFICAS}

[1] GANIN, A. Setor Elétrico Brasileiro: Aspectos Regulamentares e Tributários. $1^{\mathrm{a}}$ ed., Rio de Janeiro: Editora Canal Energia, 2003.

[2] CCEE - Câmara de Comercialização de Energia Elétrica - O Setor Elétrico Brasileiro. Disponível em : http://www.ccee.org.br. Acessado em: 11 ago. 2006.

[3] ANEEL - Agência Nacional de Energia Elétrica - Descentralização. Disponível em: http://www.aneel.gov.br/3.htm Acessado em: 01 ago. 2006.

[4] DUGAN, R. C.; McGRANAGHAN, M. F.; SANTOSO, S.; BEATY H. W. Electrical Power Systems Quality. Second Edition, McGraw Hill, 2003. 528p.

[5] ANEEL - Resolução 24 - Continuidade da distribuição de energia elétrica. Disponível em: http://www.aneel.gov.br/biblioteca.cfm Acessado em: 31 jul. 2006.

[6] ANEEL - Resolução 505 Conformidade dos níveis de tensão. Disponível em: http://www.aneel.gov.br/biblioteca.cfm Acessado em: 31 jul. 2006.

[7] ANEEL - Agência Nacional de Energia Elétrica - Procedimentos de Distribuição. Disponível em: http://www.aneel.gov.br/82.htm Acessado em: 31 jul. 2006.

[8] KAGAN, N.; DE OLIVEIRA, C. C. B.; ROBBA, E. J. Introdução a Sistemas de Distribuição de Energia Elétrica. $1^{a}$ ed. São Paulo: Ed. Edgard Blucher, 2005. 328p. ISBN 85-212-0355-1.

[9] SHORT, T. A. Electric Power Distribution Handbook, CRC Press, 2004. ISBN 0-84931791-6. 
[10] EKWUE, A. O.; McQUEEN, J. F. Developments of artificial intelligence techniques for voltage control, In: IEE COLLOQUIUM ON ARTIFICIAL INTELLIGENCE APPLICATIONS IN POWER SYSTEMS, 1995. p. 2/1-2/6.

[11] HU, Z.; WANG, X.; CHEN, H.; TAYLOR, G.A. Volt/VAr control in distribution systems using a time-interval based approach, In: IEE PROCEEDINGS ON GENERATION, TRANSMISSION AND DISTRIBUTION, vol. 150, no. 5, 2003 p. $548-554$.

[12] LIU, Y.; ZHANG, P.; QIU, X. Optimal volt/var control in distribution systems, International Journal of Electrical Power \& Energy Systems, vol. 24, no. 4, 2002. p. 271-276.

[13] HSU, Y. Y.; LU, F. C. A combined artificial neural network-fuzzy dynamic programming approach to reactive power/voltage control in a distribution substation, IEEE Transactions on Power Systems, vol. 13, no. 4, 1998. p. 1265-1271.

[14] ROYTELMAN, I.; GANESAN, V. Modeling of local controllers in distribution network applications, IEEE Transactions on Power Delivery, vol. 15, no. 4, 2000 p. 1232-1237.

[15] LIANG, R. H.; WANG, Y. S. Fuzzy-based reactive power and voltage control in a distribution system, IEEE Transactions on Power Delivery, vol. 18, no. 2, . p. 610618.

[16] Dixon, M. Autodaptive volt/VAr management system In:RURAL ELECTRIC POWER CONFERENCE, 200129 April-1 May 2001.p. D4/1 - D4/8.

[17] Dixon, M. Innovative volt/VAr management provides payback In:TRANSMISSION AND DISTRIBUTION CONFERENCE AND EXPOSITION, 2001 IEEE/PES Volume 1, 28 Oct.-2 Nov. 2001 p. 461 - 468 vol.1. 
[18] CHOI, J. H.; KIM, J. C. The online voltage control of ULTC transformer for distribution voltage regulation, International Journal of Electrical Power \& Energy Systems, vol. 23, no. 2, 2001. p. 91-98.

[19] LIU, X. C.; LI, X. Y.; LEI, X. Z.; POVH, D. Microprocessor-based fuzzy logic controller for improving voltage stability, In: FOURTH INTERNATIONAL CONFERENCE ON ADVANCES IN POWER SYSTEM CONTROL, OPERATION AND MANAGEMENT, 1997.p. 107-112.

[20] ZADEH, L.A.; Soft computing and fuzzy logic SOFTWARE, IEEE Volume 11, Issue 6, Nov. 1994. p. 48-56.

[21] RAJKUMAR, N.; VEKARA T.; ALANDER, J. T., A Review of Applications of Genetic Algorithms to Power Systems. Elsevier Science. Oct. 2003.

[22] REZENDE, S. O.; Sistemas Inteligentes: Fundamentos e Aplicações. RECOPE-IA Ed. Manole, Barueri, SP 2005. 



\section{APÊNDICE A - Sistemas Fuzzy}

Este apêndice tem por objetivo apresentar os principais conceitos associados às técnicas de Sistemas Fuzzy que foram utilizados neste trabalho de mestrado.

O termo fuzzy em inglês tem diversos significados, porém os conceitos mais utilizados passam por vago, difuso, nebuloso, incerto e entre outros. Essa seção tem por finalidade apresentar os conceitos fundamentais de Sistemas Fuzzy com destaque na área de engenharia elétrica.

Os Sistemas Fuzzy são técnicas de inteligência computacional usadas para representação e processamento do conhecimento. Suas características baseiam na lógica fuzzy proposta por Lofti A. Zadeh em 1965. Essa lógica é o ramo da matemática que suporta os modos de raciocínio que são aproximados ao invés de exatos, ou ainda, de forma mais abrangente, pode ser aceita como a melhor maneira de representação do raciocínio humano, que é parcial e aproximado em sua essência (Zadeh, 1965).

A modelagem e o controle fuzzy de sistemas são técnicas para o tratamento de informações qualitativas de uma forma rigorosa. Derivada do conceito de conjuntos fuzzy, a lógica fuzzy constitui a base para o desenvolvimento de métodos e algoritmos de modelagem e controle de processos, permitindo a redução da complexidade de projeto e implementação, tornando-se uma alternativa para a solução de problemas de controle e modelagem de sistemas.

Esta forma de estruturação do raciocínio é capaz de tomar decisões racionais mesmo estando em um ambiente de incertezas e imprecisões, onde os dados desta natureza e até mesmo os conflitantes são tratados (Lee, 1990). A tecnologia advinda da teoria de conjuntos fuzzy e da lógica fuzzy tem permitido a aplicação destas técnicas em diversas áreas do 
conhecimento (Gomide \& Gudwin, 1994; Hirota, 1993), tendo como exemplos os sistemas fuzzy de controle, os quais podem possibilitar um controle mais acurado, além de um desempenho estável e robusto; ou ainda, na modelagem de sistemas, onde através das técnicas de sistemas de inferência fuzzy é possível uma representação mais fiel do mesmo e inclusive a extração de informações qualitativas deste.

Como mencionado anteriormente, a lógica fuzzy procura expressar o raciocínio aproximado, ou seja, através da representação do conhecimento por regras pode-se responder a um determinado estímulo. Na lógica fuzzy existe a opção adicional de se empregar probabilidades lingüísticas, como por exemplo "provável”, "altamente provável” e “improvável”, interpretados como números fuzzy e manipulados pela aritmética fuzzy.

Através da lógica fuzzy, um sistema pode ser representado através de conceitos imprecisos tais como "rápido", "baixo" e "pequeno". Essas propriedades são responsáveis, entre outras, pela facilidade na extração do conhecimento de um sistema a partir de observações realizadas sobre este.

Em um sistema de inferência fuzzy, os valores de entrada são normalizados e convertidos para uma representação fuzzy. Este processo é denominado de fuzzificação das variáveis de entrada. As regras do sistema fuzzy serão executadas em paralelo, conseqüentemente, uma região fuzzy será produzida para cada variável. A criação desta região fuzzy através das regras ativas do sistema é conhecida por agregação. Depois do processamento das regras de inferência, as regiões fuzzy são convertidas em valores não fuzzy, também conhecidas como valores "crisp", determinando assim, o valor de cada variável de saída do sistema. O processo de se converter tal região fuzzy em um valor real é conhecido por defuzzificação. 


\section{Conceitos Sobre Conjuntos e Lógica Fuzzy}

Nesta seção serão apresentados os conceitos básicos relacionados aos conjuntos e a lógica fuzzy tendo como foco a modelagem de sistemas. Apesar de existir uma complexa base formal sustentando seu uso na modelagem e controle de sistemas, serão evidenciados somente os fundamentos necessários para o entendimento da teoria básica de modelagem fuzzy.

Assim, na teoria de conjuntos clássica, um elemento ou pertence a uma classe ou não. Dado um universo de discurso $U$ e um elemento particular $x \in U$, o grau de pertinência $\mu_{A}(x)$ com relação a um conjunto $A \subseteq U$ é dado por:

$$
\mu_{A}(x)= \begin{cases}1, & \text { se } x \in A \\ 0, & \text { se } x \notin A\end{cases}
$$

A função $\mu_{A}(x): U \rightarrow\{0,1\}$ é chamada de função característica na teoria clássica de conjuntos. Pode-se observar através da expressão (A.1) que a função característica, assim definida, pode assumir apenas valores discretos.
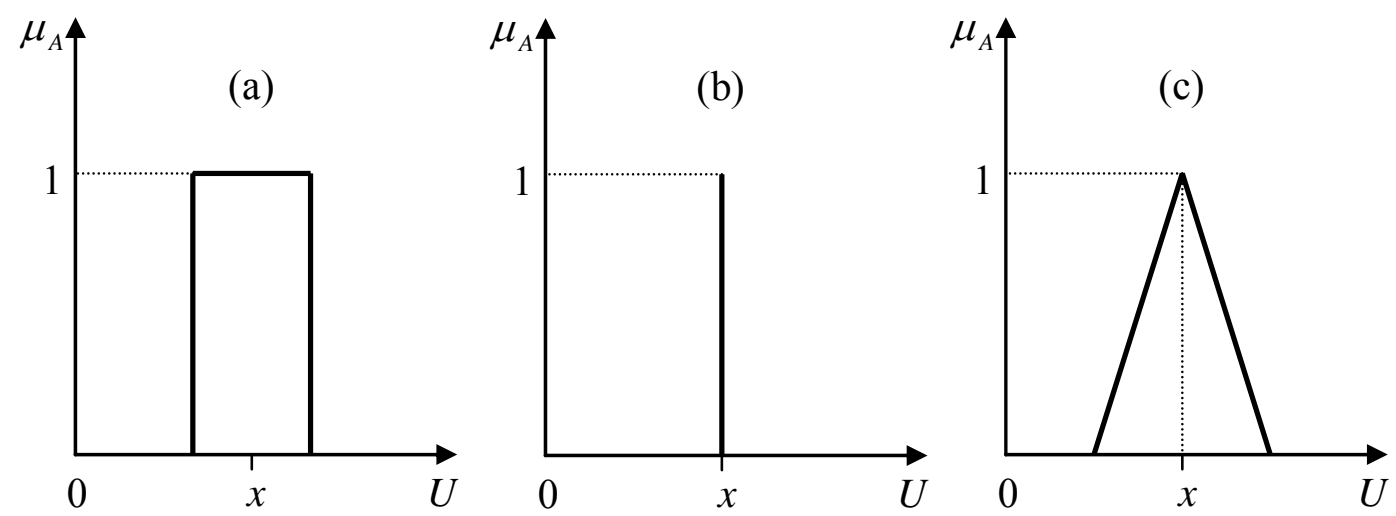

Figura A.1 - Funções de pertinência. 
Freqüentemente, uma generalização desta idéia é utilizada, por exemplo, para manipulação de dados com erros limitados. Todos os números pertencentes a um intervalo pré-definido terão um grau de pertinência 1 , os números que não pertencerem a este intervalo possuirão um grau de pertinência nulo como pode ser observado na Figura A.1 (a). Na Figura A.1 (b) o grau de pertinência é 1 somente em determinado valor, sendo nulo para os demais valores.

Zadeh (1973) propôs uma caracterização mais ampla, na medida em que sugere que alguns elementos são mais pertencentes de um conjunto do que outros. O grau de pertinência pode então assumir qualquer valor entre o intervalo $[0,1]$, sendo que o valor 0 indica uma completa exclusão e um valor 1 representa completa pertinência, ou seja, a função característica passa a ser contínua no seu domínio. Esta generalização aumenta o poder de expressão da função característica. Na Figura A.1 (c), esta abordagem descrita é apresentada na forma de uma função de pertinência triangular com pico em $x$, sugerindo a idéia de que quanto mais próximo de $x$, mais o elemento se identifica com o conceito representado por $x$.

Formalmente, seja $U$ uma coleção de objetos denominados genericamente por $\{u\}$. O domínio $U$ é chamado de universo de discurso, podendo ser contínuo ou discreto.

Um conjunto fuzzy A em um universo de discurso $U$ é definido por uma função de pertinência $\mu_{A}$ que assume valores em um intervalo [0, 1], ou seja:

$$
\mu_{A}: U \rightarrow[0,1]
$$

O conjunto suporte de um conjunto fuzzy A é o sub-conjunto dos pontos $u$ de $U$ tal que $\mu_{A}(u)>0$. Um conjunto fuzzy cujo conjunto suporte é um único ponto de $U$ com $\mu_{A}=1$ é chamado de um conjunto unitário fuzzy. A partir desta definição, os conjuntos clássicos 
passam a ser um caso específico na teoria de conjuntos fuzzy. Na Figura A.1 (c) tem-se uma função de pertinência do tipo triangular, no entanto, pode-se utilizar qualquer função $f$ : $\mathfrak{R} \rightarrow[0,1]$ para a representação de um determinado conjunto fuzzy.

\section{Definição de Operações e Operadores da Lógica Fuzzy}

Sejam $A$ e $B$ dois conjuntos fuzzy definidos em um universo de discurso $U$ com funções de pertinência $\mu_{A}$ e $\mu_{B}$, respectivamente. As operações envolvendo conjuntos fuzzy, tais como a união $(A \cup B)$, a intersecção $(A \cap B)$ e o complemento $(\neg A)$ são definidas respectivamente de maneira formal pelas expressões (A.3), (A.4) e (A.5).

$$
\begin{aligned}
& \mu_{A \cup B}(u)=\mu_{A}(u) \& \mu_{B}(u) \\
& \mu_{A \cap B}(u)=\mu_{A}(u) \Gamma \mu_{B}(u) \\
& \mu_{\neg A}(u)=1-\mu_{A}(u)
\end{aligned}
$$

onde $\Gamma$ é uma norma triangular ( $T$-norma) e \& é uma co-norma triangular ( $S$-norma).

Como exemplo de $S$-norma tem-se a expressão (A.6) e como exemplo da $T$-norma tem-se a expressão (A.7).

$$
\begin{aligned}
& \mu_{A \cup B}=\max \left\{\mu_{A}(u), \mu_{B}(u)\right\} \\
& \mu_{A \cap B}=\min \left\{\mu_{A}(u), \mu_{B}(u)\right\}
\end{aligned}
$$


O emprego do operador "max" representando a s-norma e o emprego do operador “min” representando a T-norma foi proposto inicialmente por Zadeh (1965). No entanto, inúmeras outras $S$-norma e $T$-norma podem ser empregadas na definição dos sistemas fuzzy (Pedrycz \& Gomide, 1998).

\section{Regras Fuzzy}

Para expressar conceitos ou relacionamentos através de elementos da linguagem natural é muito comum o uso de elementos qualitativos ao invés de valores quantitativos. Elementos lingüísticos típicos incluem expressões do tipo "mais ou menos", “alto", "não muitos", "médios", etc. Estas idéias são capturadas pela definição de variáveis lingüísticas. Uma variável lingüística tem por característica assumir valores dentro de um conjunto de termos lingüísticos, ou seja, palavras ou frases. Assim, ao invés de assumir instâncias numéricas, estas variáveis assumem instâncias lingüísticas. Por exemplo, uma variável lingüística "Corrente Elétrica" poderá assumir como valor um dos termos do conjunto \{“muito baixa", "baixa", "média", "alta", "muito alta"\}. Para se atribuir um significado aos termos lingüísticos, associa-se a cada um destes ternos um conjunto fuzzy definido sobre um universo de discurso comum, que neste exemplo será a "Corrente Elétrica". A Figura A.2 ilustra cinco possíveis termos lingüísticos para a variável lingüística representando a corrente elétrica. 


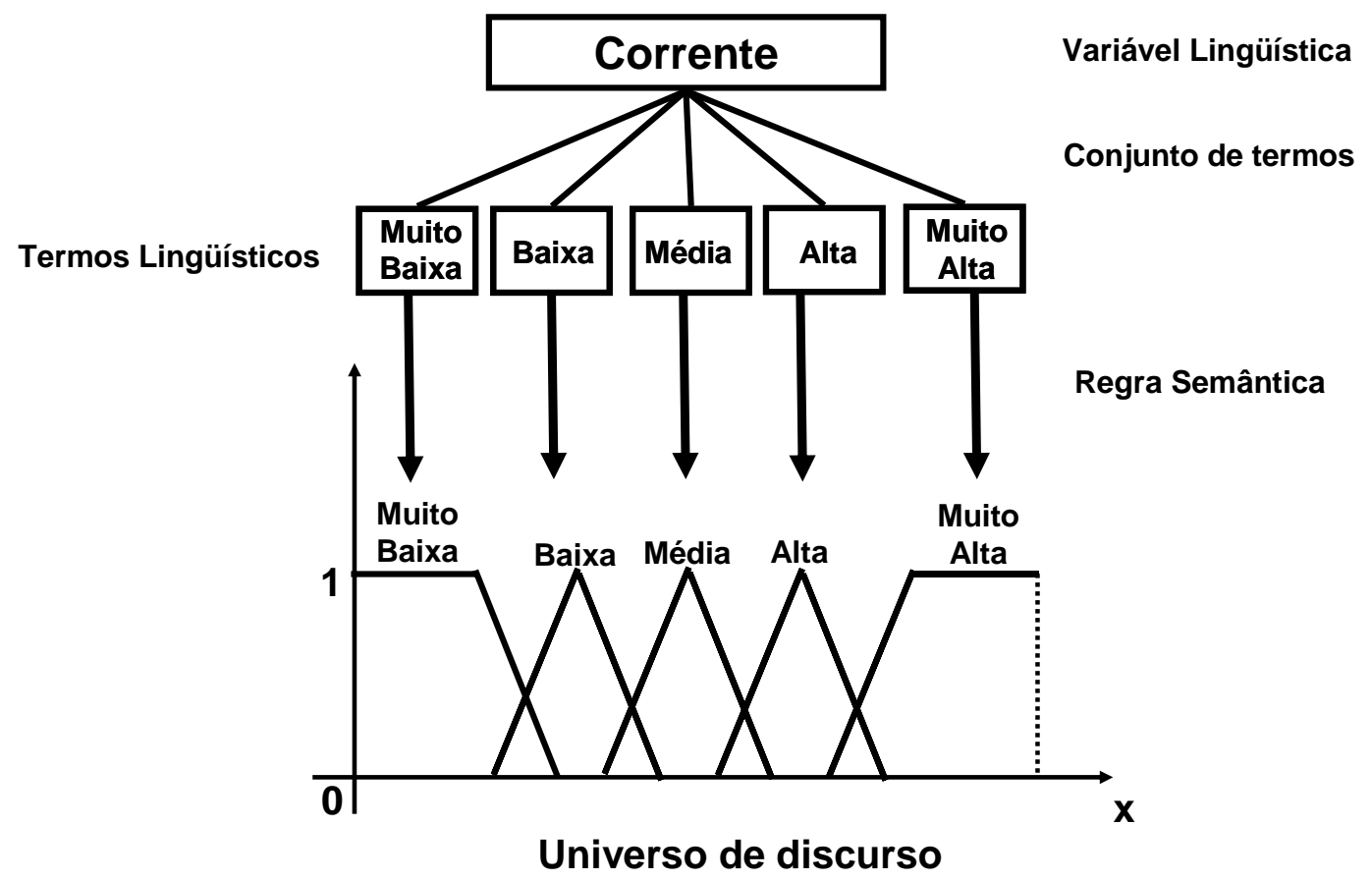

Figura A.2 - Representação da variável lingüística corrente.

A forma mais comum de expressar o conhecimento é por meio de regras do tipo condição-ação. Neste tipo de regra, um conjunto de condições descrevendo uma parcela observável das entradas do processo é associado com uma ação de saída que irá manter ou levar o sistema às condições desejadas, ou ainda, expressar o conhecimento especialista envolvido em um sistema e permitir que a modelagem seja mais flexível e comporte informações qualitativas do processo.

Tipicamente, uma condição é uma proposição lingüística (envolvendo variáveis lingüísticas) sobre o valor de alguma das variáveis de entrada, como por exemplo "o erro é grande e positivo". Da mesma maneira, uma ação típica de controle é uma descrição lingüística, como por exemplo "aumente um pouco a vazão". A idéia embutida junto às regras fuzzy de representar o conhecimento por meio de um conjunto de termos lingüísticos associados às variáveis de saída e entrada do processo é absorvida pelos sistemas de inferência fuzzy. As ações de controle ou as saídas do modelo são expressas de forma similar 
para cada variável de controle (saídas). Regras do tipo se-então são freqüentemente chamadas de declarações condicionais fuzzy ou simplesmente regras fuzzy. Dependendo do propósito, controle ou modelagem, podem ser chamadas ainda de regras de controle fuzzy ou regras de modelagem fuzzy. Uma regra fuzzy típica pode ser dada por:

$$
\begin{aligned}
& \mu_{R_{i}}=\mu_{\left(A_{i} \text { and } B_{i} \rightarrow C_{i}\right)}(u, v, w) \\
& \mu_{R_{i}}=\left[\mu_{A_{i}}(u) \text { and } \mu_{B_{i}}(v)\right] \rightarrow \mu_{C_{i}}(w)
\end{aligned}
$$

onde $A_{i}, B_{i}$ e $C_{i}$ são conjuntos fuzzy pertencentes respectivamente aos universos de discursos $U, V$ e $W$, e o operador $(\rightarrow)$ denota uma função de implicação fuzzy.

Utilizando a regra de inferência composicional de Zadeh (Zadeh, 1973) para uma relação do tipo $R_{A \rightarrow B}$, onde $A \in U$ e $B \in V$, e dado um conjunto fuzzy de $U$ denotado por $A^{\prime}$ e um conjunto fuzzy $B^{\prime}$ de $V$, a inferência de $A^{\prime}$ é dada pela seguinte função de pertinência:

$$
\mu_{B^{\prime}}(v)=\max _{u}\left\{\min \left(\mu_{A^{\prime}}(u), \mu_{R}(u, v)\right)\right\} ; u \in U, v \in V
$$

A ação de controle ou de estimação consistirá da união de todas as funções fuzzy ativadas. O valor final, ou seja, aquele que será apresentado pelas saídas do sistema fuzzy, será determinado pelo processo de defuzzificação. Uma descrição detalhada dos processos envolvidos com a inferência fuzzy pode ser encontrada em Pedrycz \& Gomide (1998).

\section{Agregação de Regras}


Em uma base de regras, quando mais de uma regra é acionada, as contribuições das diversas regras após a inferência são combinadas pelo operador de agregação. Por exemplo, supondo-se que $B_{1}^{\prime}, . ., B_{n}^{\prime}$ são todos os resultados derivados das diversas regras acionadas, todos relacionados a uma mesma variável lingüística, o resultado da implicação de todas as regras $B$ 'será:

$$
B^{\prime}=\bigcup_{i}^{n} B_{i}^{\prime}
$$

onde o símbolo $\bigcup$ representa o operador agregação. Um exemplo de função para o operador agregação é o operador união.
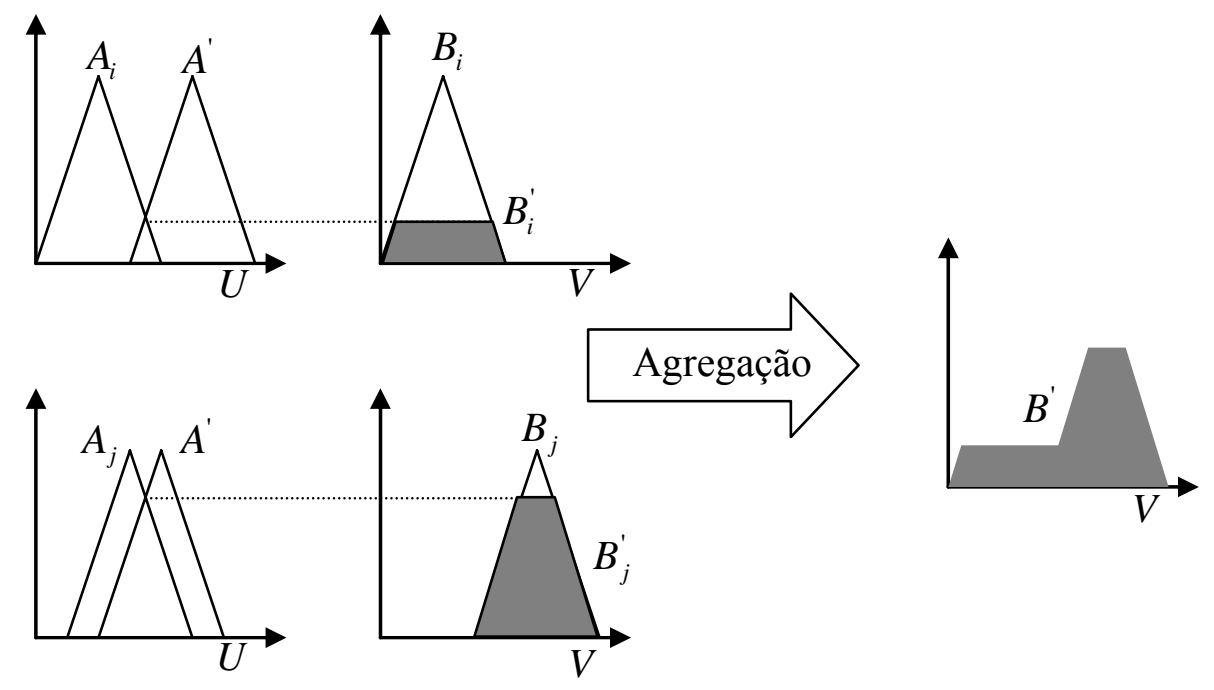

Figura A.3 - Mecanismo de inferência fuzzy.

A Figura A.3 ilustra o processo de inferência max-min quando existem duas regras, $A_{i} \rightarrow B_{i}$ e $A_{j} \rightarrow B_{j}$. $A^{\prime}$ é o fato de entrada, representado como um conjunto fuzzy. 
Todo processo envolvido em um sistema fuzzy é mostrado resumidamente pela Figura A.4. Os valores numéricos provenientes da medição passam pelo processo de fuzzificação, passando então a serem representadas por valores lingüísticos. A base de conhecimento do Sistema Fuzzy encontra-se armazenado nas Regras Fuzzy do tipo "SeEntão". O processo de inferência aplicado aos valores lingüísticos então resulta em uma região de saída, também em valores lingüísticos. Para que estes possam realmente ser utilizados é necessário o processo de defuzzificação, encontra um valor numérico para a região de saída Fuzzy, representada em termos lingüísticos.

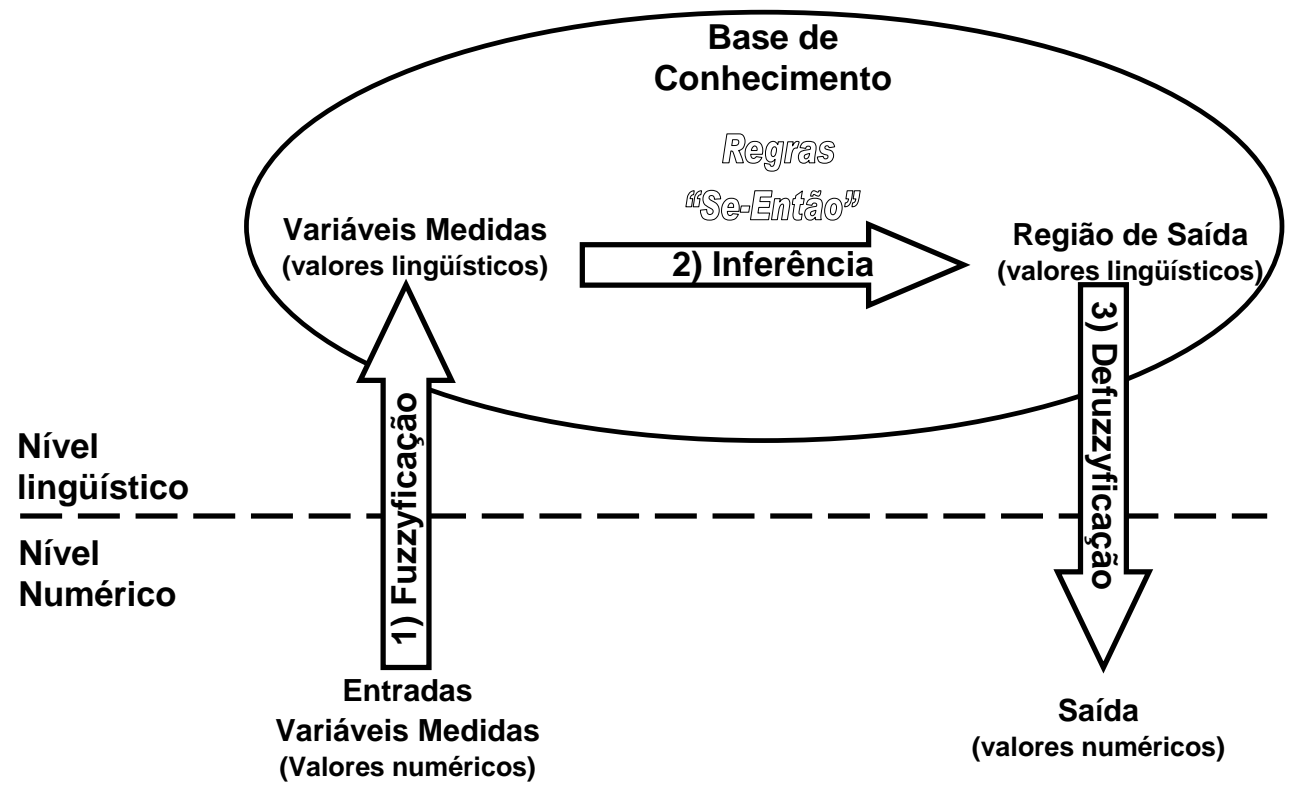

Figura A.4 - Diagrama típico de um modelo de Sistemas Fuzzy.

\section{Referências Bibliográficas}

GOMIDE, F. A. C.; GUDWIN, R. R. "Modelagem, controle, sistemas e lógica fuzzy", Revista Controle e Automação, vol. 4, no. 3, pp. 97-115, 1994.

HIROTA, K. "Industrial Applications of Fuzzy Technology", Springer Verlag, New York, 1993. 
LEE, C. C. "Fuzzy logic in control systems: fuzzy logic controllers - Part I and II", IEEE Transactions on Systems, Man and Cybernetics, vol. 20, pp. 404-435, 1990.

PEDRYCZ, W.; GOMIDE, F. "An Introduction to Fuzzy Sets: Analysis and Design”, Massachusetts Institute of Technology, 1998.

ZADEH, L. A. "Outline of new approach to the analysis of complex systems and decision", IEEE Transactions on Systems, Man and Cybernetics, vol. 3, pp. 28-44, 1973.

ZADEH, L. A. “Fuzzy sets”, Information and Control, vol. 8, pp. 29-44, 1965. 



\section{APÊNDICE B - Curvas históricas de Potência Ativa e Reativa}

As curvas históricas de carga fornecidas pela Elektro referem-se a medições de potência ativa e reativa entre o período de 19/06/2006 a 26/06/2006 tomadas em intervalos de 10 min. As medições foram realizadas no barramento secundário da subestação. Tais curvas são apresentadas no que segue:
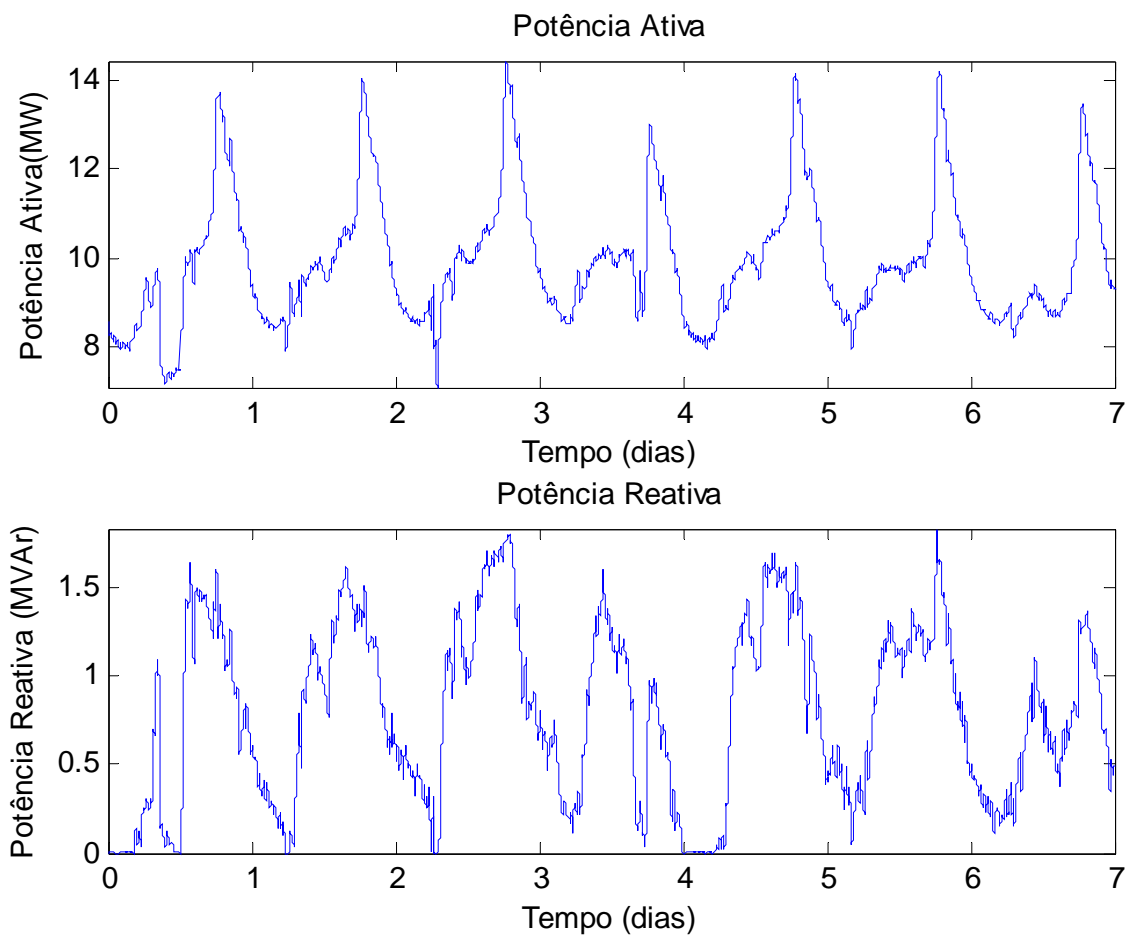

Figura B.1 - Curvas históricas de carga referentes à Andradina Trafo 1. 
Potência Ativa
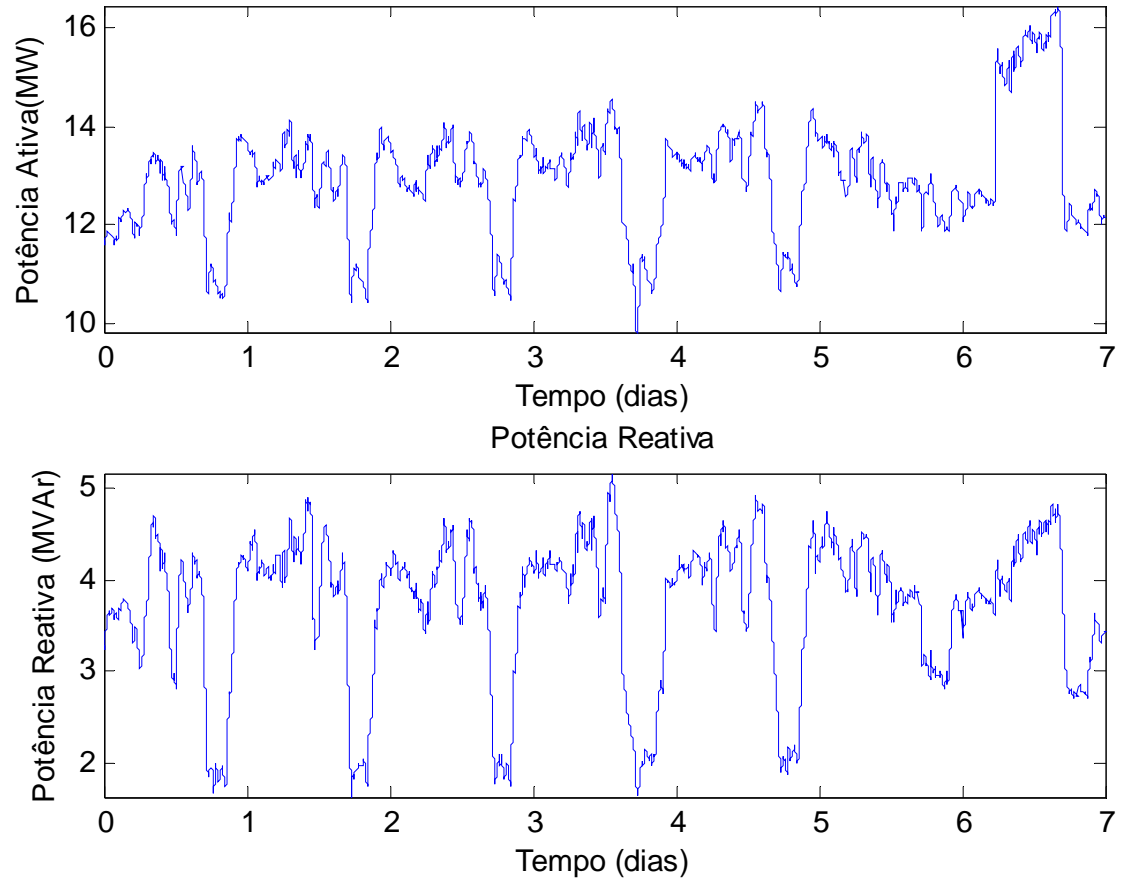

Figura B. 2 - Curvas históricas de carga referentes à Cordeirópolis Trafo 2.
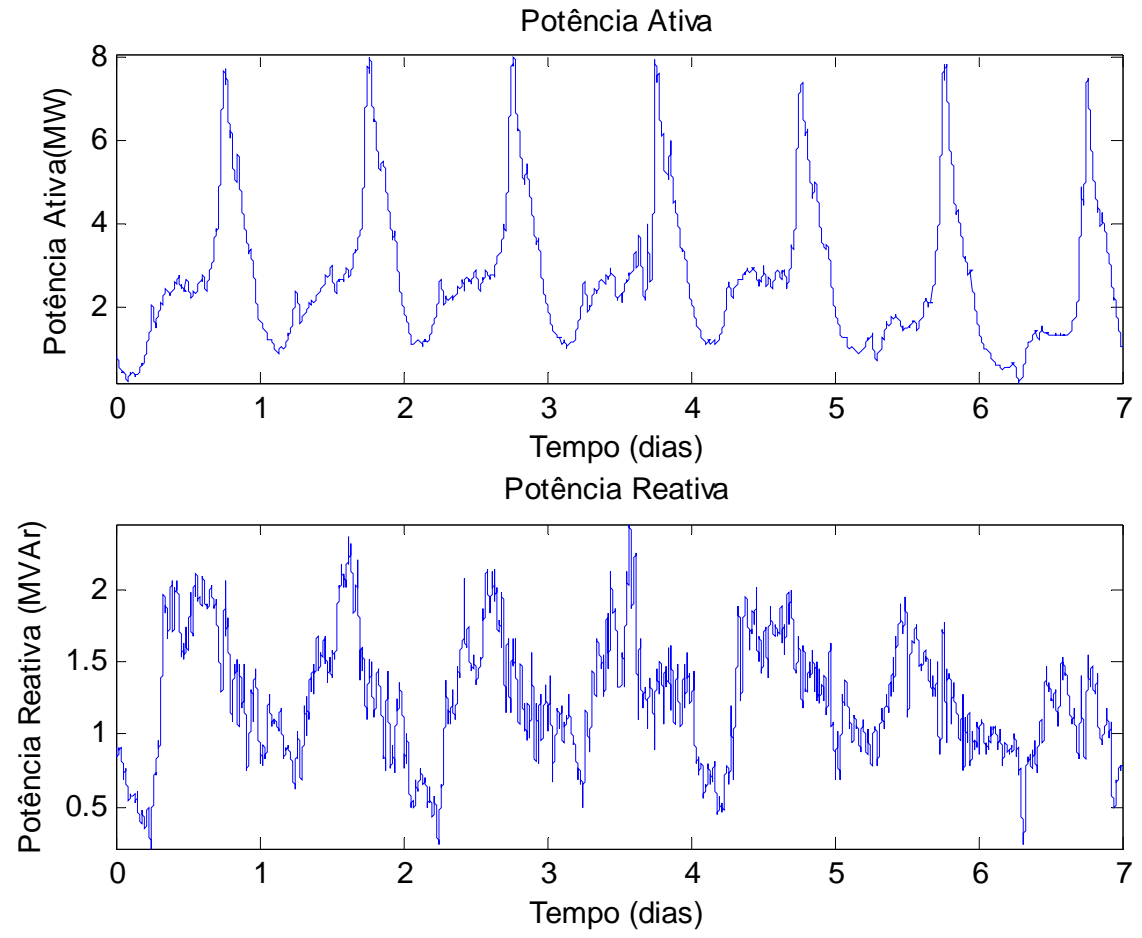

Figura B.3 - Curvas históricas de carga referentes à Mogi-Guaçu 2 Trafo 1. 


\section{APÊNDICE C - Dados dos transformadores}

As tabelas abaixo apresentam os dados referentes aos transformadores das subestações estudadas nesse trabalho.

Tabela C.1 - Transformador 1 da SE Andradina.

$\begin{array}{cccc}\text { Posição do tap } & \begin{array}{c}\text { Relação } \\ \text { de }\end{array} & \text { Resistência (R) } & \text { Reatência (X) } \\ \text { transformação } & 0.1770 & 12.778 \\ -16 & 79.708 & 0.1727 & 12.773 \\ -15 & 80.682 & 0.1685 & 12.768 \\ -14 & 81.656 & 0.1645 & 12.764 \\ -13 & 82.630 & 0.1607 & 12.760 \\ -12 & 83.604 & 0.1570 & 12.756 \\ -11 & 84.577 & 0.1534 & 12.753 \\ -10 & 85.551 & 0.1500 & 12.751 \\ -9 & 86.525 & 0.1467 & 12.749 \\ -8 & 87.499 & 0.1435 & 12.748 \\ -7 & 88.473 & 0.1404 & 12.746 \\ -6 & 89.447 & 0.1375 & 12.746 \\ -5 & 90.421 & 0.1346 & 12.745 \\ -4 & 91.394 & 0.1319 & 12.745 \\ -3 & 92.368 & 0.1292 & 12.746 \\ -2 & 93.342 & 0.1266 & 12.747 \\ -1 & 94.316 & 0.1241 & 12.748 \\ 0 & 95.290 & 0.1233 & 12.748 \\ 1 & 96.264 & 0.1225 & 12.748 \\ 2 & 97.238 & 0.1217 & 12.749 \\ 3 & 98.211 & 0.1209 & 12.750 \\ 4 & 99.185 & 0.1201 & 12.752 \\ 5 & 100.159 & 0.1188 & 12.794 \\ 6 & 101.133 & 0.1176 & 12.837 \\ 7 & 102.107 & 0.1164 & 12.880 \\ 8 & 103.081 & 0.1152 & 12.923 \\ 9 & 104.055 & 0.1141 & 12.967 \\ 10 & 105.028 & 0.1129 & 13.010 \\ 11 & 106.002 & 0.1119 & 13.055 \\ 12 & 106.976 & 0.1108 & 13.099 \\ 13 & 107.950 & 0.1098 & 13.144 \\ 14 & 108.924 & 0.1088 & 13.188 \\ 15 & 109.898 & 0.1078 & 13.234 \\ 16 & 110.872 & & \\ & & & \\ 10 & & & \end{array}$


Tabela C.2 - Transformador 2 da SE Cordeirópolis.

$\begin{array}{cccc}\text { Posição do tap } & \begin{array}{c}\text { Relação } \\ \text { de }\end{array} & \text { Resistência (R) } & \text { Reatência (X) } \\ \text { transformação } & 0.1835 & 14.012 \\ -16 & 79.754 & 0.1816 & 14.048 \\ -15 & 80.725 & 0.1798 & 14.084 \\ -14 & 81.696 & 0.1780 & 14.121 \\ -13 & 82.667 & 0.1762 & 14.159 \\ -12 & 83.638 & 0.1746 & 14.198 \\ -11 & 84.609 & 0.1729 & 14.237 \\ -10 & 85.580 & 0.1713 & 14.277 \\ -9 & 86.551 & 0.1698 & 14.317 \\ -8 & 87.522 & 0.1688 & 14.345 \\ -7 & 88.493 & 0.1678 & 14.373 \\ -6 & 89.464 & 0.1669 & 14.402 \\ -5 & 90.435 & 0.1659 & 14.431 \\ -4 & 91.406 & 0.1650 & 14.461 \\ -3 & 92.377 & 0.1641 & 14.492 \\ -2 & 93.348 & 0.1632 & 14.523 \\ -1 & 94.319 & 0.1623 & 14.554 \\ 0 & 95.290 & 0.1618 & 14.611 \\ 1 & 96.261 & 0.1614 & 14.668 \\ 2 & 97.232 & 0.1609 & 14.725 \\ 3 & 98.203 & 0.1605 & 14.783 \\ 4 & 99.174 & 0.1600 & 14.842 \\ 5 & 100.145 & 0.1584 & 14.923 \\ 6 & 101.116 & 0.1569 & 15.004 \\ 7 & 102.087 & 0.1554 & 15.086 \\ 8 & 103.058 & 0.1540 & 15.168 \\ 9 & 104.029 & 0.1526 & 15.251 \\ 10 & 105.000 & 0.1512 & 15.333 \\ 11 & 105.971 & 0.1499 & 15.416 \\ 12 & 106.942 & 0.1486 & 15.499 \\ 13 & 107.913 & 0.1473 & 15.583 \\ 14 & 108.884 & 0.1461 & 15.666 \\ 15 & 109.855 & 0.1448 & 15.750 \\ 16 & 110.826 & & \end{array}$


Tabela C.3 - Transformador 1 da SE Mogi-Guaçu 2.

\section{Posição do tap}

$-16$

$-15$

$-14$

$-13$

$-12$

$-11$

$-10$

$-9$

$-8$

$-7$

$-6$

$-5$

$-4$

$-3$

$-2$

$-1$

0

1

2

3

4

5

6

7

8

9

10

11

12

13

14

15

16

\section{Relação \\ de transformação}

79.751

80.723

81.695

82.667

83.639

84.611

85.583

86.555

87.528

88.500

89.472

90.444

91.416

92.388

93.360

94.332

95.304

96.276

97.249

98.221

99.193

100.165

101.137

102.109

103.081

104.053

105.025

105.997

106.970

107.942

108.914

109.886

110.858

\section{Resistência (R) Reatência (X)}

0.1882

0.1843

0.1804

0.1767

0.1731

0.1697

0.1664

0.1632

0.1601

0.1571

0.1543

0.1515

0.1488

0.1462

0.1436

0.1412

0.1388

0.1375

0.1362

0.1350

0.1337

0.1326

0.1314

0.1303

0.1292

0.1281

0.1270

0.1260

0.1250

0.1240

0.1230

0.1221

0.1212
19.990

19.550

19.111

18.672

18.235

17.798

17.361

16.925

16.490

16.055

15.621

15.188

14.830

14.473

14.117

13.761

13.405

13.136

12.866

12.598

12.329

12.061

11.839

11.617

11.395

11.174

10.953

10.732

10.511

10.291

10.071

0.9851

0.9631 